\title{
Analysis and evaluation of ecological restoration experiments in the Succulent Karoo (South Africa)
}

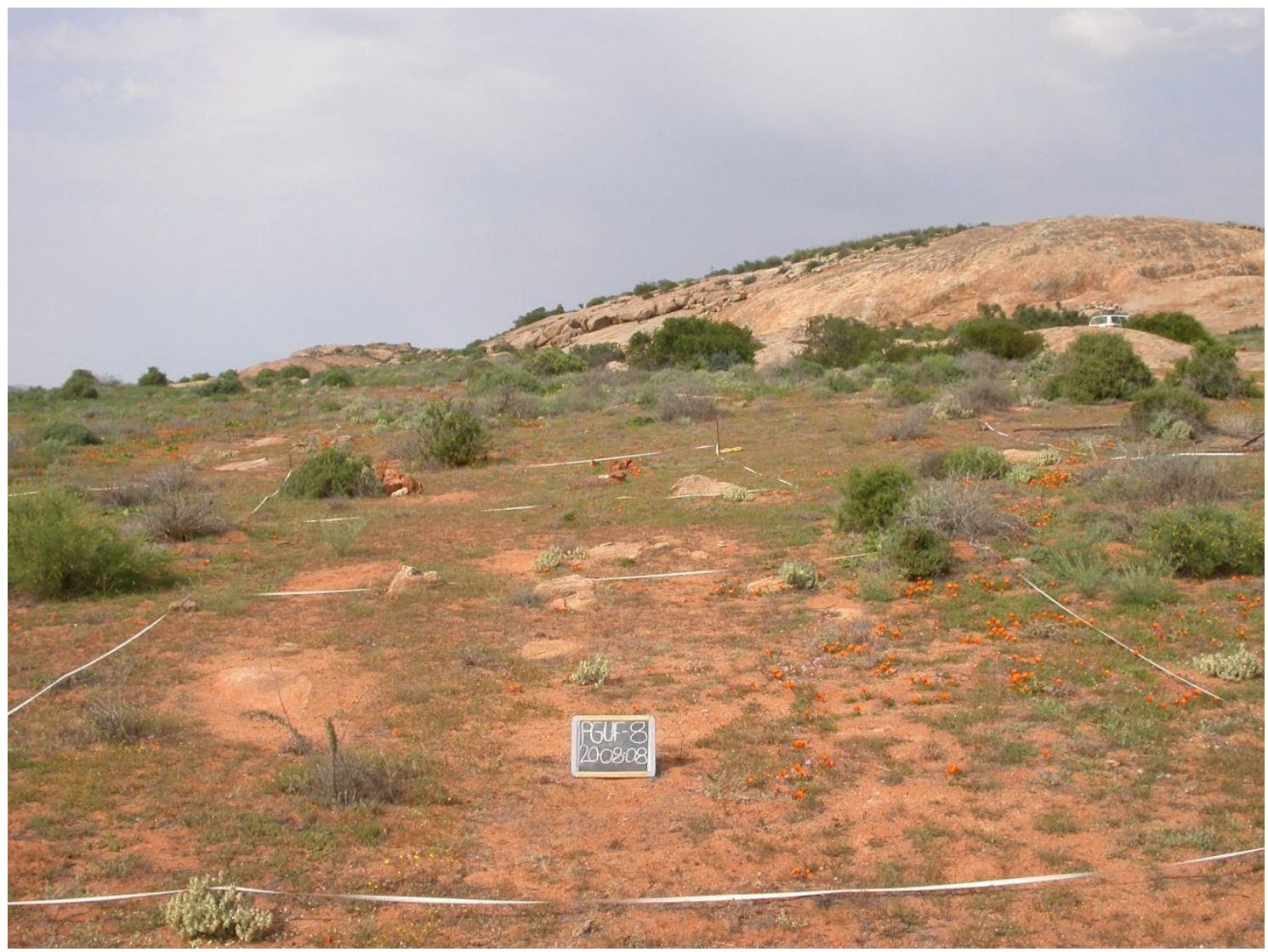

Diploma thesis in Geoecology

submitted by

Sarah Meyer

First Evaluator: Prof. Dr. Dieter Burger

Second Evaluator: Prof. Dr. Norbert Jürgens 


\section{Contents}

CONTENTS.

CONTENT OF FIGURES

CONTENT OF TABLES

ABBREVIATIONS ......................................................................................................................................

1 INTRODUCTION ....................................................................................................................................... 1

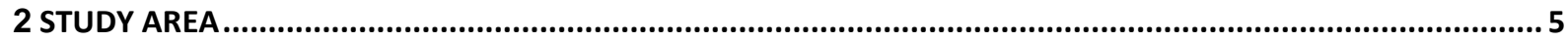

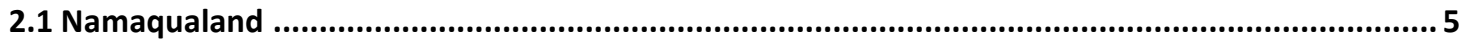

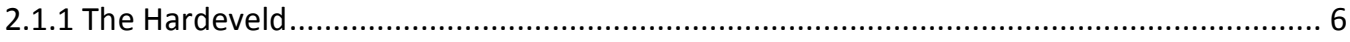

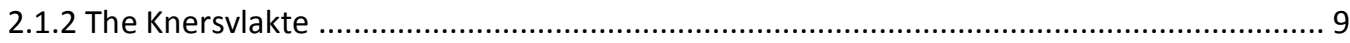

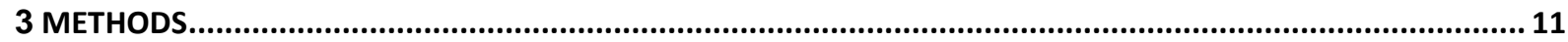

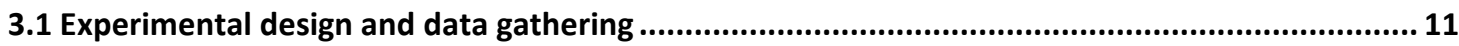

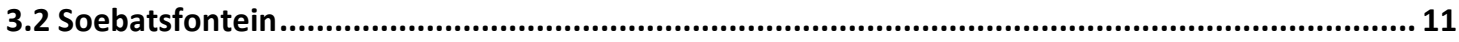

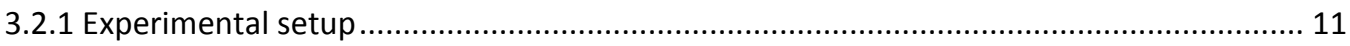

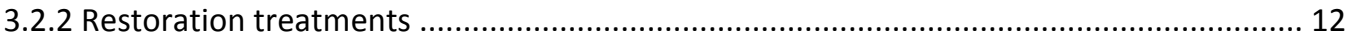

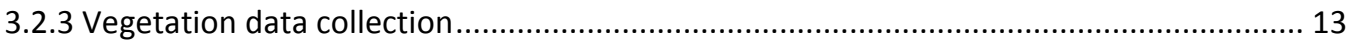

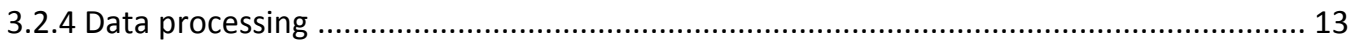

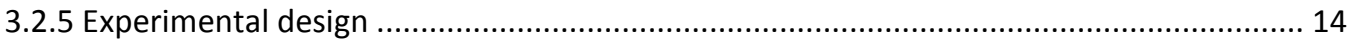

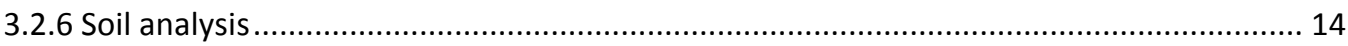

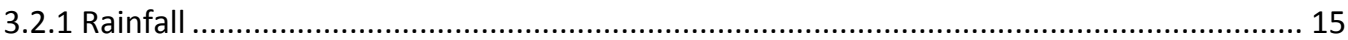

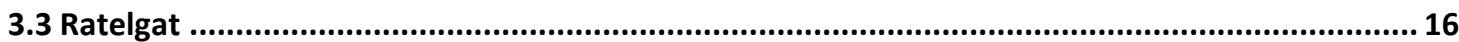

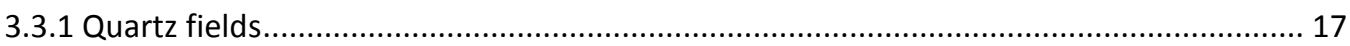

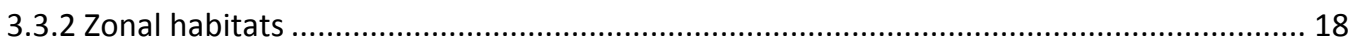

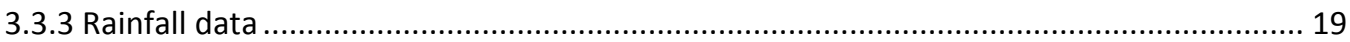




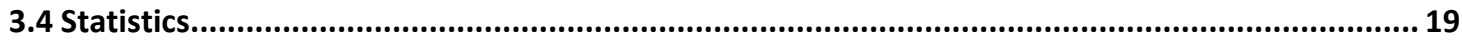

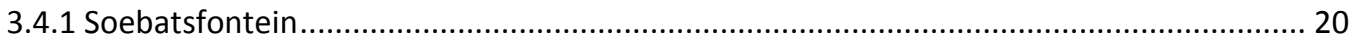

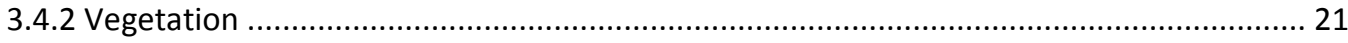

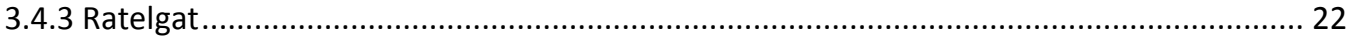

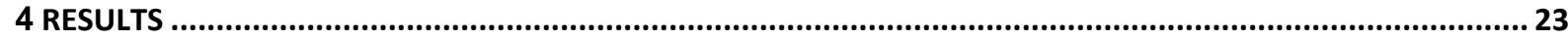

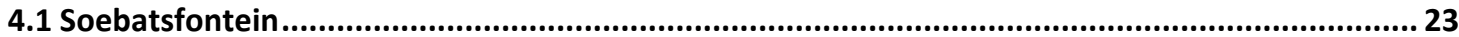

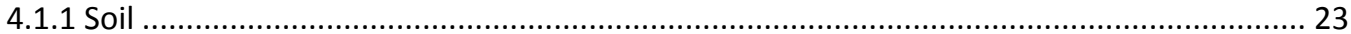

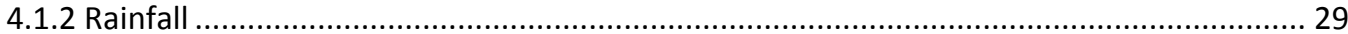

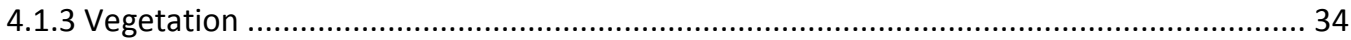

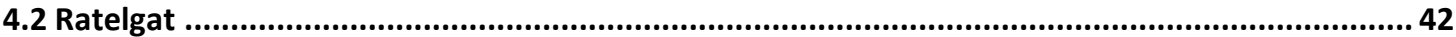

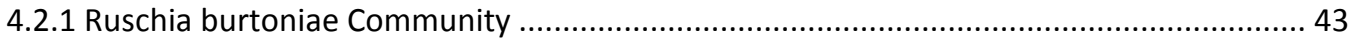

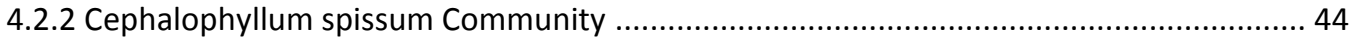

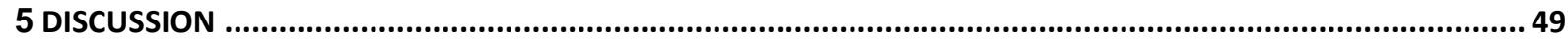

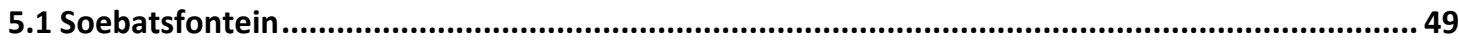

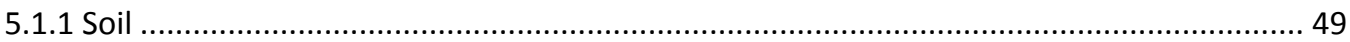

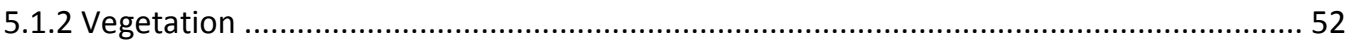

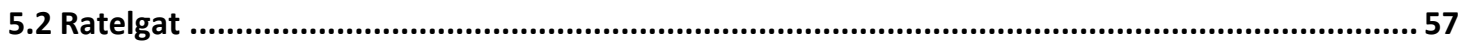

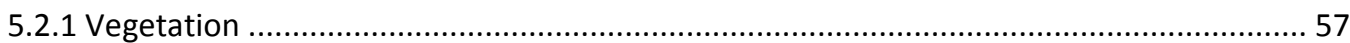

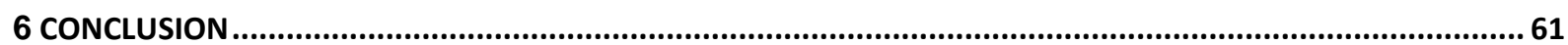

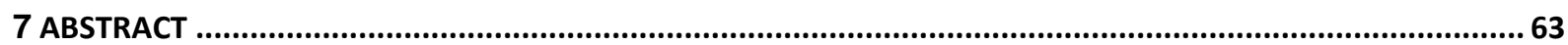

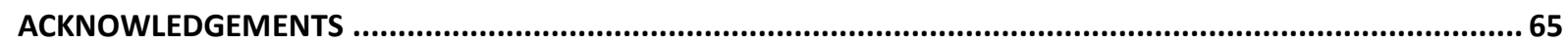

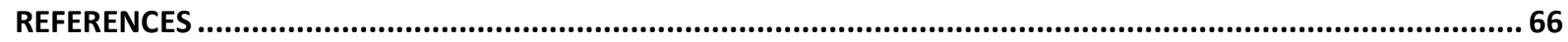

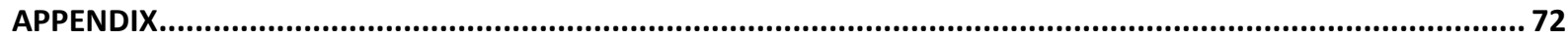

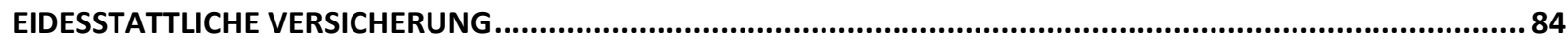




\section{Content of Figures}

Figure 1 Location of Namaqualand and borders of the bioregions.

Figure 2 Climate diagrams of the Namaqualand Bioregions "Namaqualand Heuweltjieveld" (left) and

"Knersvlakte Quartz Vygieveld" (right).

Figure 3 Location of the two study sites (Patrysegat and Quaggasfontein) on the communal farming land of the Soebatsfontein community and within Namaqualand.

Figure 4 Location of the Knersvlakte on the west coast of South-Africa and the camp Ratelgat

Figure 5 Scheme of the two camps divided into two plots (UF= unfenced; F= fenced). Each plot contains 24 subplots of $5 \times 5 \mathrm{~m}$ in size allocated with four different treatments.....

Figure 6 Pipeline on Ratelgat running through quartz field patches and zonal habitats. Loss of vegetation and erosion are apparent

Figure 7 Restoration treatments inside quartz fields.....

Figure 8 Plot of the canonical discriminant function and group centroids.

Figure 9 Amount of total annual rainfall for the climate station Soebatsfontein - Quaggafontein.

Figure 10 Amount of rainfall within the four seasons autumn (MAM), winter (JJA), spring (SON) and summer (DJF).

Figure 11 Monthly precipitation for the climate station Ratelgat from October 2004 when the treatments were installed until August 2008.

Figure 12 Number of species and individuals per plot before and after installation of the brushpack + levelling treatment at Ratelgat. 48 


\section{Content of Tables}

Table 1: Overview of the replication rate for each active treatment at Patrysegat and Quaggasfontein within fenced and unfenced plots

Table 2 Overview of the soil parameters $\mathrm{pH}, \mathrm{EC}, \mathrm{C} / \mathrm{N}, \mathrm{N}_{-} \mathrm{T}$ and $\mathrm{C}_{-} \mathrm{T}$ for the two camps at Soebatsfontein. Presented are means \pm SD for fenced (F) / unfenced (UF) plots of each camp separately and for both camps together.

Table 3 Results of the multivariate test statistic for differences in site, grazing, active treatments and the interaction grazing*active treatments on group centroids for the restoration subplots at Soebatsfontein.

Table 4 Summary of the univariate ANOVAs for the parameters site, grazing and active treatments on $\mathrm{pH}, \mathrm{C} \_\mathrm{N}$ and $\log E C$ for the restoration subplots at Soebatsfontein

Table 6 Differences between treatment groups for EC $[\mu \mathrm{S} / \mathrm{cm}], C_{-} N$ ratio, C_T and $N_{-} T$ at Patrysegat and Quaggasfontein.

Table 7 Standardized canoncial discriminant function coefficients and canonical variate correlation coefficients for the first and second function of the canonical discriminant analysis for $\mathrm{pH}, \operatorname{logEC}$ and $\mathrm{C} / \mathrm{N}$ for the Soebatsfontein subplots.

Table 8 Results of the MLR's for relative abundance of the different life form groups against total annual rainfall.

Table 9 Influence of seasonal rainfall on the relative abundance of different life form groups.

Table 10 Differences between fenced and unfenced plots at Patrysegat for total cover, total cover annuals and total cover perennials.

Table 11 Differences between fenced and unfenced plots at Quaggasfontein regarding total cover, total cover annuals and total cover perennials.

Table 12 Results for differences between active treatments on mean total cover of annuals and perennials at fenced and unfenced subplots at Quaggasfontein

Table 13 Results for differences between fenced and unfenced plots for mean number of all individuals, annuals and perennials at Patrysegat. 
Table 14 Differences between active treatments on total number of annuals and perennials at fenced and unfenced subplots at Patrysegat.

Table 15 Results for differences between fenced and unfenced plots for mean number of all individuals, annuals and perennials at Quaggasfontein

Table 17 Difference in species richness of annuals, perennials and all species between fenced and unfenced subplots at Patrysegat.

Table 18 Difference in species richness of annuals and perennials between fenced and unfenced plots at Quaggasfontein. .40

Table 19 Differences between active treatments for mean species richness of annuals and perennials at fenced and unfenced subplots at Quaggasfontein.

Table 20 Differences between treatments for number of individuals and species richness of the Ruschia burtoniae community plots at Ratelgat

Table 21 Summary of the one-way ANOVA results for total cover (2005) for differences between treatments..43

Table 22 Differences for number of individuals of Ruschia burtonia under the three different treatments for 2005 and 2008.

Table 23 Differences between years for number of individuals, species richness and total cover for the Ruschia burtoniae community plots at Ratelgat.

Table 24 Summary of the results for species richness, number of individuals and total cover for the Chepalophyllum spissum community plots at Ratelgat

Table 25 Differences between the treatments for number of Cephalophyllum spissum individuals at Ratelgat..45

Table 26 Differences between years for species richness, number of individuals and total cover. for the Chepalophyllum spissum community plots at Ratelgat

Table 27 Differences between "control" and "brushpack" treatment plots for number of individuals in the different life form groups for the zonal habitet plots at Ratelgat

Table 28 Differences between "brushpack" and "control" plots for species richness within different life form groups for the zonal habitet plots at Ratelgat..... 
Table 29 Differences between years for species richness and number of individuals in the different life form groups for the zonal habitet plots at Ratelgat

Appendix I Results of the discriminant analysis for treatment as grouping variable and logEC, $\mathrm{pH}$ and $\mathrm{C} / \mathrm{N}$ as independent variables for the Soebatsfontein dataset.

Appendix II Values for the group centroids along the first and second axis found by the canonical discriminant analysis for the four treatment groups of the Soebatsfontein restoration subplots....

Appendix $V$ Relationship between annual rainfall and mean relative abundance of different life form groups for all 96 restoration subplots at Soebatsfontein for 2004-2008.

Appendix VII Differences between active treatments on mean total cover of annuals and perennials at fenced and unfenced subplots at Patrysegat.......

Appendix VIII Comparison of the mean number of individuals at Patrysegat and Quaggasfontein for 2004-2008..

Appendix IX Selected pictures of the restoration subplots at Patrysegat (Soebatsfontein) top left fenced subplot with "stones" treatment; top right fenced subplot with" brushpacks"; down left fenced subplot "control" and down right unfenced subplot with treatment "manure \& palm fronds from 26.09.05.

Appendix X Differences between active treatments on number of annuals and perennials at fenced and unfenced subplots at Quaggasfontein.

Appendix XI Differences in species richness of annuals and perennials between active treatments at fenced and unfenced subplots at Patrysegat.

Appendix XII Total annual rainfall for the climate station Luiperskop (Ratelgat) montly rain data for 2001 to 2008. 


\section{Abbreviations}

EC

ANOVA

MANOVA

MLR

N_T

C_T

LSH

MFD

$S G D_{\text {pot }}$

SSU electrical conductivity

analysis of variance

multivariate analysis of variance

multiple linear regression

total amount of nitrogen

total amount of carbon

least significant difference

mean frost days

potential sheep grazind days

small stock unit 


\section{Introduction}

Rangelands occupy over $70 \%$ of South Africa's land area and are the major land use type in Namaqualand where in 1994 approximately $89 \%$ of the 5.3 million ha were used for some kind of livestock farming (Snyman 2003, May \& Lahiff 2007).

In arid and thus fragile rangelands, degradation is a common problem (Hoffman \& Ashwell 2001, Snyman 1999) and has been ascribed mainly to overgrazing (Kraaij \& Milton 2006, Hoffman \& Ashwell 2001), mining activities (Botha et al. 2008) and changes in the rainfall regime and is seen as a severe threat to Namaqualand's exceptionally high biodiversity and endemism (Desmet 2007, Cowling et al. 1999, Anderson et al. 2004). With the arrival of European settlers the former pastoralists' (i.e., Khoekhoen of Namaqualand) practices to move with their stocks around to take advantage of summer and winter rainfall areas changed and they were forced to move into smaller communal areas and had to stop their transhumant strategies (Boonzair et al $1996 \mathrm{In}$ : Samuels et al. 2007).

The answers on the question whether livestock has a negative impact on the vegetation of the Karoo vary. While some authors attributed the severe degradation which became apparent within the last centuries, primarily to overgrazing (Todd 2006, Dean et al. 1995, Anderson et al. 2004, Yeaton \& Esler 1990) others state that the observed patterns are natural, caused by short-term fluctuations of rainfall and that the influence of grazing might only become apparent in the long term (O'Connor \& Roux 1995, Wiegand et al. 1998, Wiegand \& Milton 1996). Wiegand et al. (1998) simulated the vegetation dynamic of five typical dominant Karoo shrubs and showed slow turn-over rates of the vegetation which can be explained by the persistence of long-living species which occupy sites that would otherwise be free for the establishment of new species (Rahlao et al. 2008). According to this model, recovery of rangeland conditions even after 60 years of resting from grazing was not likely to occur. On the other hand, in the model rangeland remained in a good condition even after 20 years of heavy grazing pressure (Wiegand et al. 1998). These results indicate that restoration of overgrazed areas in semi-arid environments is a slow process and that a response of the vegetation either to intensification of grazing pressure or to resting takes a considerable amount of time.

The observed shifts in vegetation composition of the Karoo in response to heavy grazing by sheep and goats are on the one hand changes from communities dominated by palatable leaf-succulent shrubs to a community formed by unpalatable and woody shrubs like Galenia africana (Simons \& Allsopp 2007, Milton 1994). Selective grazing of preferred forage plants, suppressing their successful seed and flower production is seen as being responsible for this shift (Milton 1994). On the other hand, heavy grazing also resulted in a replacement of perennials by shorter living species such as geophytes and annuals for communal, heavily grazed farmland at Paulshoek in Namaqualand (Todd \& Hoffmann 1999). Also soils are influenced by livestock grazing and trampling with reported increase of soil compaction (Betteridge et al. 1999), lower stability of soil aggregates (Warren et al. 1986), reduced soil fertility and water holding capacity (Dormaar \& Willims 1998). Increase of 
surface water run-off and direct impact of raindrops on the bare soil surface which lost its vegetation cover due to overgrazing are cause of topsoil erosion (du Toit et al. 2009, Snyman 1998.)

It is known that without active intervention degraded rangelands are unlikely to revert to their pre-disturbance stage (van den Berg \& Kellner 2005, Friedel 1991) and the exclusion of livestock alone is not sufficient to restore those (Mucina et al. 2006). The need for more active interventions is generally recognized (Milton et al. 1994, Milton \& Dean 1994, Snyman 2003, Visser et al. 2004) and also particular for the overgrazed rangeland on sheep farms in the Karoo (Wiegand \& Milton 1996).

Restoration in the sense of "ecological restoration" can be defined as a process by which degraded land is returned to a state as close as possible to the one existent before the disturbance started. It aims to restore the natural conditions of the ecosystem with its original structure, ecosystem functions and species diversity (Visser et al. 2004, Allen 1995). It also aims to form a system that is sustainable in the long-term and needs little maintenance (Hobbs \& Norton 2006). Restoration normally involves costly and complex active human intervention which intends to accelerate the rate of succession. Commonly applied interventions are: removal of non-native species, reintroduction of plant, animal and microorganisms, techniques to improve water infiltration into the soil, increase nutrient and organic matter content, creation of a suitable microclimate and microtopography and the control of soil erosion (Allen 1995, Snyman 2003). Passive restoration in contrast aims to remove the original causes for degradation, such as overgrazing and let natural succession proceed with no further human intervention.

There has been an enormous increase of interest in restoration techniques to reverse degradation world-wide (Hobbs \& Norton 1996, Anderson et al. 2004) and in the Succulent Karoo Biome (Burke 2008, Snyman 1999), where the restoration of former mining areas of the Namaqualand is statutory since 1992 (Carrick \& Krüger 2007, Hälbich 2003). Thus, the development of appropriate and effective restoration methods is of great importance. The value of incorporating land-user's knowledge in the development of restoration practices is frequently recognized for Namaqualand (Botha et al. 2008) and elsewhere in the world (Higgs 2005, Huntington 2000). The experience of locals, which often conduct their own informal trials was tried to capture and incorporate in the treatments applied in this study.

Although active intervention has often economic objectives, such as to improve the availability of forage plants and therefore the grazing capacity, the true value of a restored ecosystem has to be seen in combination with the protection of rare species, increased biodiversity and the indirect return of their ecosystem services (Westmann 1977). In Namaqualand the high biodiversity of flowering plants brings already a direct financial return due to its attractiveness for tourism (van Rooyen 2002).

This is the main aim of the restoration trials conducted in the Knersvlakte, a centre of diversity and endemism and the core area of the quartz fields. Due to the unique quartz fields, its species richness and endemic flora, the conservation authority of the Western Cape Province, CapeNature, is on the way to establish the extensive "Knersvlakte Conservation Area". The farm Ratelgat, which belongs to the Griqua Development Trust, shall 
form part of this reserve and belong to a buffer zone where some management actions such as mining and moderate grazing will be allowed (Etzold 2006). The use of land as a conservation area with its associated possibility for ecotourism is seen as a great economical potential for the region (Desmet 2007). This can be an additional motivation for the farmer community in the Knersvlakte to protect the quartz fields on their farms.

Despite the increasing interest in conservation of quartz fields little research exists about the impacts of mechanical disturbance on them and their restorability. One pioneer work is the precursor study from Etzold (2006), who installed the restoration treatments at Ratelgat and conducted the field surveys and analysis for 2004 and 2005. One study is known which examined the factors influencing the diversity of quartz field vegetation (van Tonder 2007) and another project from the CapeNature reserve in the Western Little Karoo investigated the impact of herbivores (trampling and grazing) on endemic plant species of quartz fields (Farmer 2005). No evidence was found there that current low stocking rates caused damage to plants on quartz patches. A slight negative impact on species richness and abundance of endemic quartz field species in the Knersvlakte due to grazing was found by Haarmeyer (2009) though. The relatively small ecological niche in which quartz field specialists exist, makes disturbance of their habitat, such as occurring by construction work, fatal. Little is known about suitable methods on how to restore these specific systems and research, like this study, is needed to fill this gap and to identify restoration methods for degraded quartz fields like those at Ratelgat.

This study examines the effect of different (active and passive) restoration techniques at two sites in the Namaqualand of the Succulent Karoo. One study is located in the Knersvlakte and aims to reverse the negative effects created through the construction of an underground water pipeline running through quartz fields and zonal vegetation on communal rangeland of the farm Ratelgat. The other study site is located in the Soebatsfontein commonage within the Hardeveld bioregion and intends to restore communal farm land, which is degraded due to overgrazing by sheep in the past before the farmland had been handed over to the community. Both trials have been implemented during 2004 and monitored regularly until 2008. The following research questions are addressed for the sites at Soebatsfontein $(A)$ and for the site at Ratelgat $(B)$ :

A):

- Doesexclusion of grazing, brushpacking, application of manure, or re-creation of natural heterogeneity (stone heaps), have a strong effect on the re-establishment of vegetation on sites degraded by overgrazing?

- What is the effect of rainfall and its seasonal distribution on abundance of species within different life form groups?

- Is there an effect of the treatments on soil properties visible $(\mathrm{pH}, \mathrm{EC}, \mathrm{C} / \mathrm{N})$ four years after the treatments were set in place? 
B:

- Are levelling, planting, or scattering of quartz stones more successful in restore vegetation of degraded quartz fields?

- Does brushpacking have a positive effect on species abundance, species richness and foliage cover?

- How severe is the negative installation effect of a treatment consisting of levelling and brushpacking?

The results obtained from this study shall assist the farmers in their decision how to best restore degraded or disturbed sites on their farm land. 


\section{Study area}

\subsection{Namaqualand}

Namaqualand is a biogeographical province situated within the larger Succulent Karoo Biome. This Biome is home to the world's richest succulent flora, with dwarf leaf-succulent shrubs consisting mainly of members of the Aizoaceae and Crassulaceae dominating the vegetation (Lombard et al. 1999, Jürgens et al. 1999). In comparison to other winter-rainfall semi-deserts it has a seasonal but quite reliable rainfall regime with an average of about $170 \mathrm{~mm}$ per year (Mucina et al. 2006). The high rainfall predictability is thought to facilitate the species diversity of the Biome (Cowling et al. 1999). Since the cold upwelling waters of the Benguela Current temper and buffer climatic extremes the climate is relatively mild with a mean annual temperature of $16.8^{\circ}$ (Mucina et al. 2006) and rare frost events. Strong prevailing southerly winds during summer months (Anderson et al. 2004) and strong easterly berg winds during winter and spring are prominent features of the climate (Carrick \& Krüger 2007). Because of its outstanding insect, vertebrates and plant species diversity with more than 1940 endemic plant species (Myers et al. 2000), the Biome is rated to be the only arid of 25 global biodiversity hotspots identified by Myers et al. (2000).

Namaqualand stretches from the Orange River, which represents the frontier to Namibia down to the Olifants River in the south (Figure 1). To the east the Atlantic Ocean and to the west the highlands (Bushmanland plains) bound the province, which shows a general pattern of coastal plains, followed by the escarpment and highlands. The flora of Namaqualand is classified today after a new phytogeographical subdivision as part of the Greater Cape Floral Kingdom (Jürgens 1991) and is dominated by shallow-rooting dwarf leaf succulent shrubs. On disturbed sites ephemeral communities consisting of geophytes and annuals replace the perennial shrubland and create a colorful mass display of wild flowers during springtime for which Namaqualand is famous (Desmet 2007, Van Rooyen 2002).

Smaller bioregions within the province can be distinguished by climate, flora and the structure of the physical environment. Two of them, the Knersvlakte and the Hardeveld (Figure 1) house the camps were the restoration experiments of this study were conducted and will be further described. 


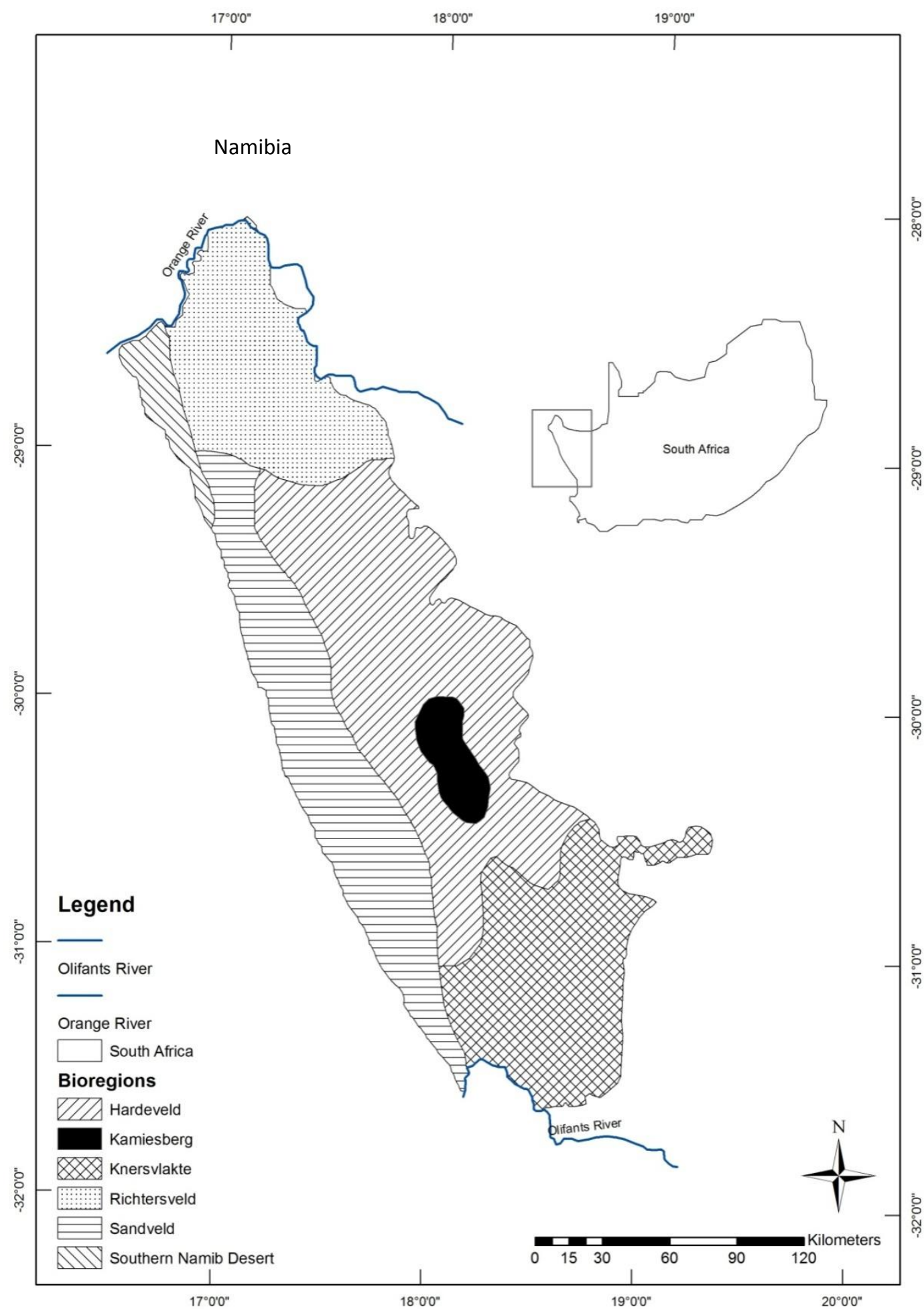

Figure 1 Location of Namaqualand and borders of the bioregions described by Hilton-Taylor (1996). Redrawn from Cowling et al. (1999).

\subsubsection{The Hardeveld}

Situated between the Knersvlakte to the south and the Richtersveld to the north this bioregion forms the transition from the lower lying Sandveld with its deep, marine derived sands of fairly recent origin to the higher lying central portion of Namaqualand, the Kamiesberg. Granite foothills of the Kamiesberg alternate with lowlying sandy plains (Desmet 2007, Hilton-Taylor 1996). The base-rich, loamy, red soils of the area derive from 
igneous gneisses and granites and are rich in clay (Desmet 2007, Petersen 2008). Omnipresent in Namaqualand are the impenetrable hardpan layers underlying most valleys. In the Hardeveld region they are formed by silica (dorbank) (Desmet, 2007). A distinctive feature of this landscape is the round, slightly elevated termite mounds called heuweltjies with up to $35 \mathrm{~m}$ diameter and $1.5 \mathrm{~m}$ in height which are associated with higher nutrient content and a distinct vegetation cover (Petersen 2008). They have attracted much interest of research in this area (Röwer 2009, Labitzky 2009, Petersen 2008, Herpel 2008) but are not further described because the restoration plots of this study are not located on them.

The vegetation unit of the study site is called Namaqualand Heuweltjieveld Skn4 (Mucina et al. 2006) and consists of a mosaic of heuweltjievelds and patches in between. The vegetation is dominated by leaf-succulent shrubs, forming a low shrubland with a canopy cover of 20-45\% (Mucina et al. 2006). Rain occurs mainly in the cold months from May to August (Figure 2, left) when temperatures are often below $10^{\circ} \mathrm{C}$. The mean annual precipitation is only $115 \mathrm{~mm}$, but dew and sea fog occur frequently and are a considerable source of additional moisture for the shallow rooting perennials (Botha et al. 2008). Frost events are rare (mean frost days $=1 \mathrm{~d}$ ). The mean annual temperature is $17.8^{\circ} \mathrm{C}$, with highest temperatures recorded for December and January with over $30^{\circ} \mathrm{C}$ (Mucina et al. 2006).
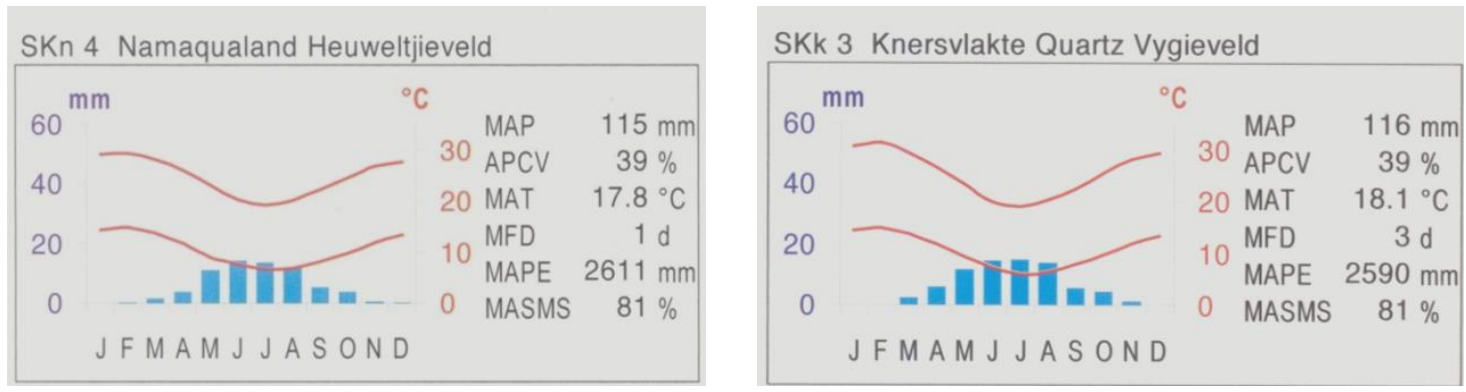

Figure 2 Climate diagrams of the Namaqualand Bioregions "Namaqualand Heuweltjieveld" (left) and "Knersvlakte Quartz Vygieveld" (right). Blue bars show the median monthly precipitation. Upper and lower red lines are mean daily maximum and minimum temperatures. MAP = mean annual precipitation; APCV = annual precipitation coefficient of variation; MAT = mean annual temperature; MFD = mean frost days (screen temp. $<0^{\circ} \mathrm{C}$ ); MAPE = mean annual potential evaporation; MASMS = mean annual soil moisture stress (\% of days when evaporative demand was more than double the soil moisture supply) (Mucina et al. 2006, p. 252).

The two camps, Patrysegat and Quaggasfontein where the restoration experiments were conducted lie close to the village Soebatsfontein (Figure 3) with around 270 inhabitants (www.biota-africa.org). The settlement is located approximately $50 \mathrm{~km}$ southwest of Springbok and within a coastal distance of $30 \mathrm{~km}$. While Patrysegat is situated on the upper slope of a flat anticline, Quaggasfontein is located on the lower slope of a quite smooth hill making the inclination of both camps rather similar. 


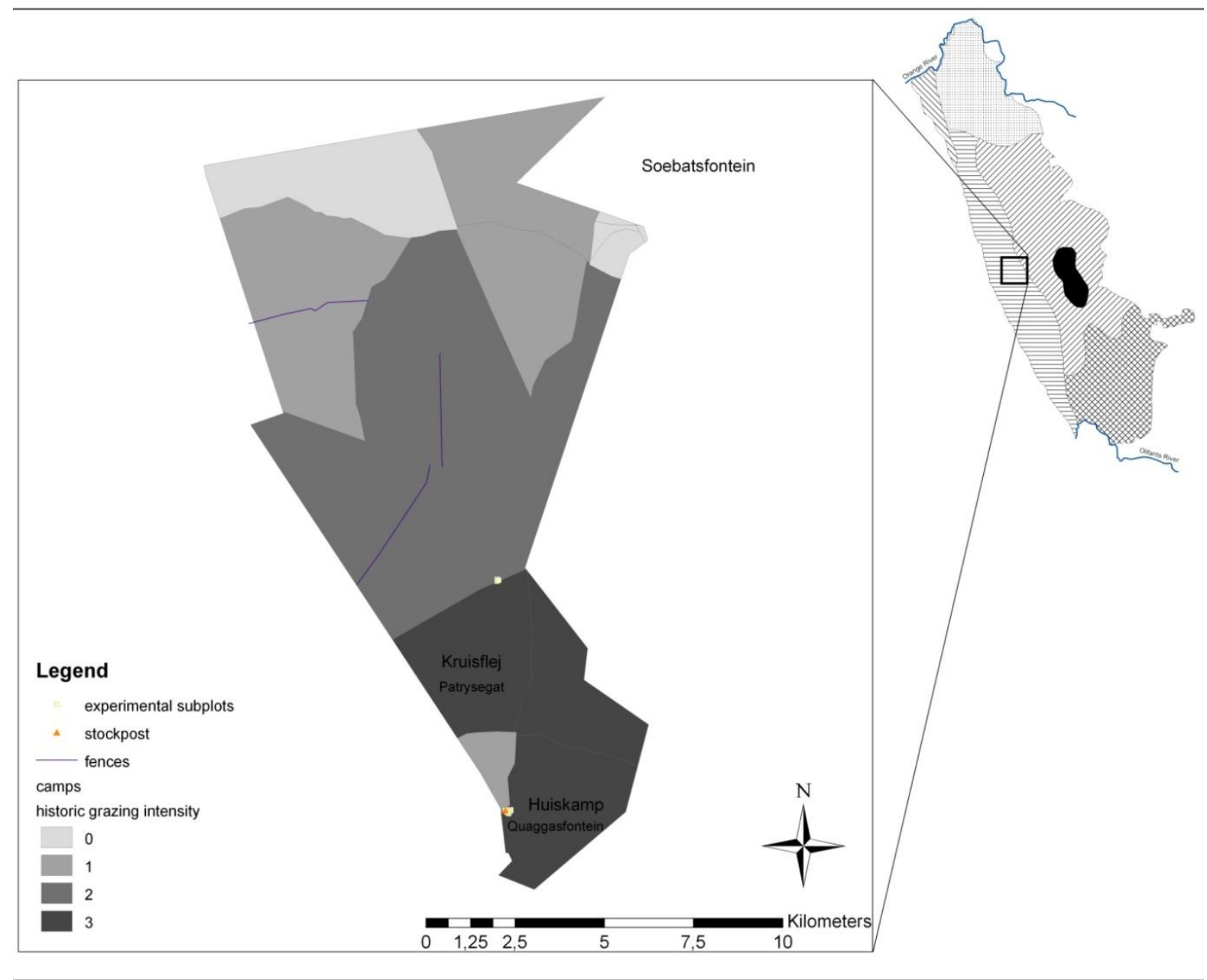

Figure 3 Location of the two study sites (Patrysegat and Quaggasfontein) on the communal farming land of the Soebatsfontein community and within Namaqualand. Shown are borders of the camps, fences and the stockpost at Quaggasfontein. Grazing intensity classes were overtaken from (Labitzky 2009). Shape files are kindly provided by Inga Roewer.

In the past the grazing system of the area was pastoral but displaced by a period of fenced commercial sheep farming use by the De Beers mining company from 1986 to 1999 (Petersen 2008, Labitzky 2009). In 1999 (Anderson et al. 2004) the community got the utilization right for 15,000 ha land back and uses it today for small stock farming with goats and sheep plus some rain-fed crop production. The current stocking rates are below the recommended ones and access to the land is strongly controlled (Petersen 2008), but due to the history of overgrazing by the former land use practices Anderson et al. (2004) state that more than a third of the Soebatsfontein community area are degraded with evidence of soil erosion. The community is keen to improve the ecological status and the productivity of their land and has even been awarded a Landcare grant of the South African Landcare program for their efforts (Anderson et al. 2004).

The main soil units identified by Peterson (2008) for the area of Soebatsfontein are Cambisols, Durisols, Leptosols and Regosols. Durisols are exclusively associated with heuweltjies and therefore not relevant for this study. Leptosols and Regsols occur mainly on the higher parts, whereas Cambisols dominate the lower lying areas (Peterson 2008). Additional soil units reported by Labitzky (2009) to occur on the two camps are Calcisols and Gypsisols. 
Labitzky (2009) assessed the two camps in terms of their grazing history until 1999 and grouped the camps in three classes of increasing grazing intensity. An assumed carrying capacity of 9 ha /SSU (= Small Stock Unit, one sheep or goat) was used to calculate "potential sheep grazing days" ((area/carrying capacity)× 365 days). The actual sheep grazing days were expressed as percentage of the assumed potential sheep grazing days $\left(S_{G D} D_{\text {pot }}\right)$ and averaged over the recorded years. Camps that were used by $>120 \%$ of the $S G D_{\text {pot }}$ were classified into the grazing intensity class high, between $80-120 \%$ grazing intensity was rated intermediate and below $80 \%$ as low (Labitzky 2009). Both camps Patrysegat and Quaggasfontein fall into the highest historic grazing intensity class (Figure 3), the actual grazing pressure is thought to be lower but no reliable data are available. The closer location of Quaggasfontein to the stockpost which is around $150 \mathrm{~m}$ far away (Figure 3), compared to Patrysegat which is approximately $6.5 \mathrm{~km}$ further away from it, is thought to create higher grazing pressure for Quaggasfontein.

\subsubsection{The Knersvlakte}

Located in southern Namaqualand the Knersvlakte $\left(30^{\circ} 45^{\prime}-31^{\circ} 40^{\prime} \mathrm{S}, 18^{\circ} 15^{\prime}-19^{\circ} 00^{\prime} \mathrm{E}\right.$ ) (Schmiedel \& Jürgens 1999, p. 59) is a slightly undulating coastal plain confined by the Olifants River to the south and the bioregions (following the classification by Cowling et al. 1999) Hardeveld and Sandveld to the north (Figure 1). To the east the Knersvlakte is bordered by the great escarpment and forms the transition to the summer-rainfall region of the Nama-Karoo Biome (Cowling et al. 1999, Jürgens 1986).

The Knersvlakte lies in between the igneous Namaqualand Metamorphic Complex to the north and the sandstone and shale sediments of the Cape Fold Mountains to the south and is underlain by shales, phyllites, limestone and imbedded quartz veins (Petersen 2008, Schmiedel \& Jürgens 1999). These quartz veins are the origin of the white quartz gravels and stones $(0.2-6 \mathrm{~cm}$ in diameter) which occur in patches and house a unique flora which is edaphically and floristically distinct from the surrounding zonal vegetation (Schmiedel 2002, Schmiedel \& Jürgens 1999). The vegetation of these quartz fields is characterized by leaf-succulents mainly Aizoaceae with a minute growth form. Most of the occurring species are nanochamaephytes $(<5 \mathrm{~cm})$, microchamaephytes $(5-15 \mathrm{~cm})$ or geophytes (Schmiedel \& Jürgens 1999, Schmiedel \& Jürgens 2004). In contrast to adjacent zonal habitats, quartz fields possess a markedly lower canopy cover and extreme edaphic conditions such as a high soil salinity which intensifies aridity, or very shallow soils with a low pore volume (Schmiedel 2002). For the Knersvlakte 39 endemic species specialized on these azonal habitats are reported by Schmiedel \& Jürgens (1999).

The study was carried out on the camp Ratelgat previously named Luiperskop around $20 \mathrm{~km}$ northwest from Vanrhynsdorp (Figure 4). Since 2000 the camp belongs to the Griqua Development Trust and is used by the Griqua people for extensive small stock grazing (around 150 sheep, a few donkeys and goats) and cultural purposes. The establishment of some ecotourism facilities is planned (Etzold 2006, Petersen 2008). The camp covers an area of 7,000 ha and has been moderately grazed since 2000 with a grazing intensity of 17 ha per SSU, = small stock units (Haarmeyer 2009). This means that 17 ha of land are necessary per animal (sheep or goat) for sustainable stock farming. 


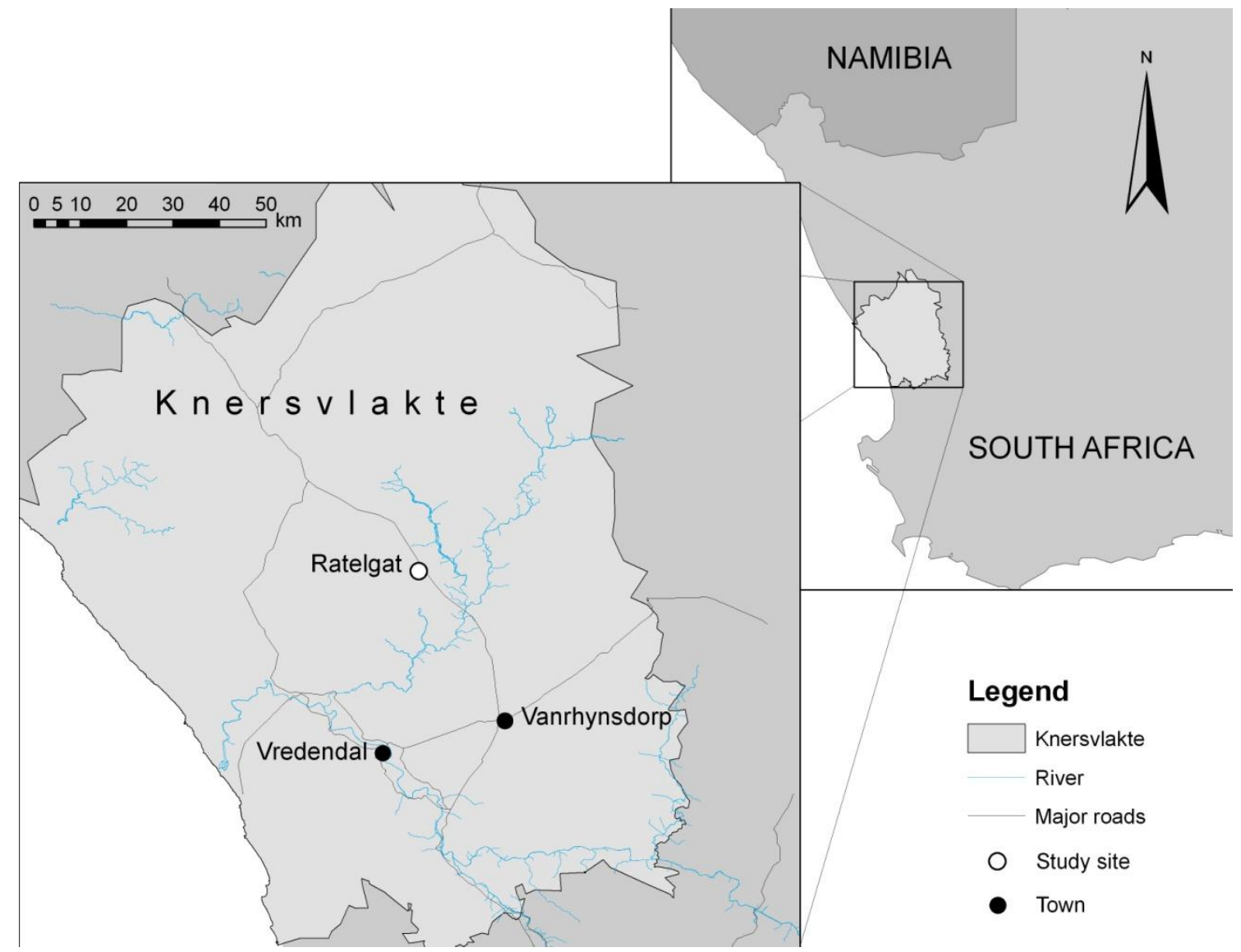

Figure 4 Location of the Knersvlakte on the west coast of South-Africa and the camp Ratelgat located on the N7 northwest of Vanrhynsdorp (shape files provided by Cape Nature)

The vegetation unit of the study site is called Knersvlakte Quartz Vygieveld SKk3 (Mucina et al. 2006) and dominated by leaf succulent dwarf shrubs of the Aizoaceae and Asteraceae. Small patches with quartz vygies (Aizoacea species) are embedded in a low succulent shrubland with Ruschia and Drosanthemum as prominent genera (Mucina et al. 2006). Increased occurrence of species like: Drosanthemum hispidum, Malephora purpureo-croccea, Mesembryanthemum guerichianum, the disturbance-adapted Galenia africana (Petersen 2008) and the alien Atriplex lindleyi are, among others, a sign of local disturbance (Mucina et al. 2006).

The summers in this bioregion are hot and dry with temperatures between $30-35^{\circ} \mathrm{C}$. In winter winters temperatures are comparably mild and range between $5-10^{\circ} \mathrm{C}$ (Figure 2, right). On average 3 frost days per year occur and the mean annual precipitation is $116 \mathrm{~mm}$ (Mucina et al. 2006). Main soil units found are Cambisols, Leptosols and Solonchaks. The Hypersal-Yermic Solonchak is typical for the saline quartz fields, whereas the red, loamy Cambisols are found mainly on the less saline substrates (Petersen 2008). 


\section{Methods}

\subsection{Experimental design and data gathering}

Vegetation data and soil samples for Soebatsfontein were collected by Ute Schmiedel and para-ecologist Reginald Christiaan. The vegetation survey at Ratelgat was conducted by Sophia Etzold (2004-2005), Ute Schmiedel (2006-2007) and para-ecologist Wynand Pieters (2008).

In order to keep things simple and avoid confusion all following chapters will be split in two parts. The first part deals with the restoration experiments conducted in Soebatsfontein (Hardeveld) and the second part covers the experiments at Ratelgat (Knersvlakte).

\subsection{Soebatsfontein}

\subsubsection{Experimental setup}

The restoration subplots were established on the camp Patrysegat $\left(30^{\circ} 26^{\prime} 39^{\prime \prime} \mathrm{S} ; 1^{\circ} 55^{\prime} 36^{\prime \prime}\right)$ and Quaggasfontein ( $\left.30^{\circ} 26^{\prime} 33^{\prime \prime} \mathrm{S}, 17^{\circ} 55^{\prime} 41^{\prime \prime}\right)$ in November 2004.

At each camp a block was chosen and divided in two plots (Figure 5). One part of the plot was fenced to exclude grazing, the other part was left unprotected and open to herbivores. At each plot four treatments: "stones", "brushpacking", "manure \& palm fronds" and "controls" were applied in a randomized design to avoid confounding factors such as inhomogeneity in soil or climatic conditions. A distance of at least $0.5 \mathrm{~m}$ between two adjacent subplots was maintained throughout and thought to ensure independency among replicates. The dimension of each subplot was $5 \times 5 \mathrm{~m}$. In general five replications for each manipulative treatment and 9 for the control were conducted (Table 1). However, for the fenced part at Quaggasfontein unintentionally a different treatment replication rate was arranged, creating an unequal sample size inbetween the two plots.

The subplots were first surveyed in November 2004, before the establishment of the treatments took place. In the following years the sites were revisited in September 2005, September/October 2006, July/September 2007 and August to October 2008, to record abundance and cover of species. In order not to overlook potential short term effects of the active restoration treatments they were analyzed for every year following the installation. The effect of grazing exclusion on the vegetation is thought to be a long term one and it was therefore only evaluated for 2008.

Although the focus of this work is on the effects of manipulations on vegetation, the examination of soil parameters is known to have the advantage that they are less strongly affected by short-term rainfall fluctuations or droughts (Smet \& Ward 2006). Topsoil samples from 2008 were therefore used to investigate changes on the parameters $\mathrm{pH}$, electrical conductivity $(\mathrm{EC})$, total carbon and total nitrogen content four years after the restoration treatments were set in place. 


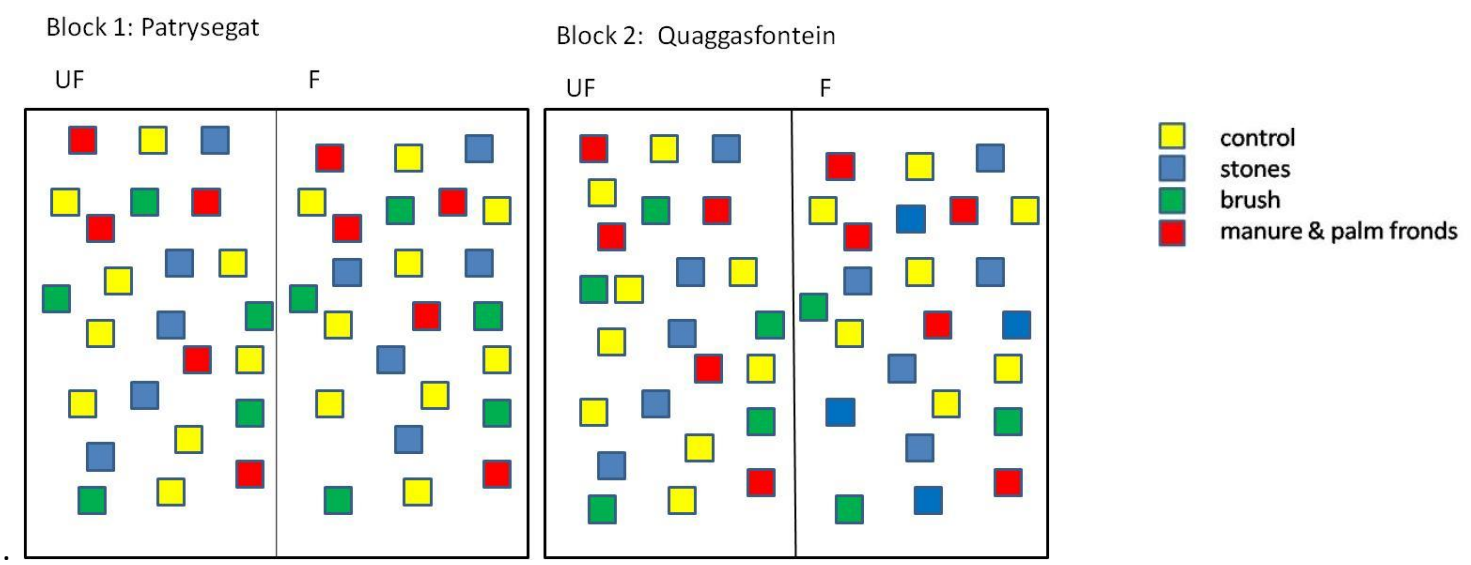

Figure 5 Scheme of the two camps divided into two plots (UF= unfenced; $F=$ fenced). Each plot contains 24 subplots of $5 \times 5 \mathrm{~m}$ in size allocated with four different treatments

Table 1: Overview of the replication rate for each active treatment at Patrysegat and Quaggasfontein within fenced and unfenced plots.

\begin{tabular}{lllll}
\hline $\mathbf{N}$ & Patrysegat & \multicolumn{3}{l}{ Quaggasfontein } \\
\hline treatment & unfenced plot & fenced plot & unfenced plot & fenced plot \\
control & 9 & 9 & 9 & 7 \\
stones & 5 & 5 & 5 & 9 \\
brushpack & 5 & 5 & 5 & 3 \\
manure \& palm fronds & 5 & 5 & 5 & 5 \\
$\mathbf{N}$ & $\mathbf{2 4}$ & $\mathbf{2 4}$ & $\mathbf{2 4}$ & $\mathbf{2 4}$ \\
\hline
\end{tabular}

\subsubsection{Restoration treatments}

The treatments were applied once in 2004 forming a typical pulse experiment (Gotelli \& Ellison, 2004), where the resilience of the plots to a single perturbation (=treatment) is measured. The following treatments were carried out:

"manure \& palm fronds": Manure from sheep and goats was applied onto each designated plot covering approximately $70 \%$ of the soil surface, rocks and stones were omitted (see photo Appendix IX). The expectation is that the organic material will improve the nutrient status of the soil with particular higher rates of exchangeable $\mathrm{Ca}$ and $\mathrm{Mg}$ (Mokolobate \& Haynes 2002), but also will favour the retention of water and will improve microbial activity (Zink \& Allen 1998).Palm fronds were spread over the manure afterwards to avoid relocation by wind.

"brushpacking": Approximately 90\% of designated plots were covered with woody branches of Salsola sp. up to a height of approximately $0.5 \mathrm{~m}$ (see photo Appendix IX). Native rock surface was excluded, used plants were harvested from the surrounding area. Brushpacks simulate the protective effect of the natural plant cover (Coetzee 2005) and act as safe sites which catch fine soil particles, water and wind-blown seeds (Beukes \& Cowling 2003, Tongway \& Ludwig 1996, Milton 1995). They protect the soil against rain splash and wind erosion, decrease soil temperature and improve soil moisture. The Salsola packs form a mechanical protection for germinating plants against grazing animals, eventual decay and contribute to the organic content of the topsoil (Coetzee 2005). In contrast to living vegetation brushpacks do not compete for resources but act as 
fertile islands that capture resources and improve biotic activity (Simons \& Allsopp 2007).

"stones": Six stone heaps per subplot were formed (see photo Appendix IX). Three out of them were made up of siliceous rocks, the rest of more calcareous rocks to provide microsites for both calciphile and acidophile species. The stones were taken along the street where enough suitable material was available and where their removal did not perturb other vegetation. The expectation is that the small stone hills are able to catch windblown seeds and soil material.

"control": On each camp and in each plot nine, respectively seven, subplots were left without any treatment.

\subsubsection{Vegetation data collection}

The foliage cover of the vegetation was estimated as close as possible to the precise value. Covers under $1 \%$ were estimated in most instances after following classes: $0.01,0.02,0.03,0.05,0.1,0.2,0.25,0.5,0.75,1.5,2.0$, 2.5 etc. In general the abundance of all vascular plant taxa was counted. However for perennial species only those individuals which had survived one dry season were considered. Species were identified using following field key:

le Roux, A 2005, Namaqualand South African Wild Flower Guide 1, [3 ${ }^{\text {rd }}$ edn $]$ Botanical Society of South Africa, Cape Town.

\subsubsection{Data processing}

Because a lot of species were not recorded with their abundance or cover values, the dataset was subject to some data imputations. Out of the 6257 individual species records, recorded over the 5 years, in total 1487 $(23.77 \%)$ abundance and 51 cover data $(0.008 \%)$ were missing for the Soebatsfontein dataset. Although the gaps in the dataset are extensive, I decided to impute the missing values by gaining as much information as possible out of the remaining data sharing the position of Harrell $(2001$, p. 47$)$ that:" Imputing missing values and then doing an ordinary analysis as if the imputed values were real measurements is usually better than excluding subjects with incomplete data."

In total 700 missing values (mainly abundance) were subsequently estimated by Ute Schmiedel using expert knowledge after the following principles: For perennial species with missing abundance data the abundance values of the previous and following year of the subplot were examined. If they were identical, the missing abundance value of the year in between was imputed. For the annual taxa, the missing abundance values were only added if the cover was small $(<0.25)$ and the experience from the field allowed to derive the abundance from the cover of the species. The missing abundance values for annuals with higher cover values $(n=17)$ were only estimated when the years around had abundance data and a clear trend through the cover data was visible. In total 664 missing abundance values were added like this. 
The missing cover data were estimated by looking at the surrounding cover values for the species and the recorded number of individuals for the same year.

The remaining gaps for abundance values were imputed following suggestions from Harrell (2001) for completely missing at random data, using a method developed for missing abundance vegetation data by Schmiedel et al. (in prep.). The method uses the information available in the remaining subplots and years to impute the missing value after following procedure: The mean abundance of a species per subplot without the year $x x x x$ of which the missing value comes from is calculated $(=x)$. This value includes the information about the situation in the single subplot. The relative difference in abundance in year xxxx relative to all other years is calculated for every subplot and the mean for every year over all plots which contains the species is calculated $(=y)$. The so obtained value incorporates the overall trend for the commonness of the species in the regarded year into the formula. Then to gain the missing value $(=z)$ following formula is applied: $z=x^{*}(1+y)$. For species which occurred only in a few plots or not in all years, the formula has problems and delivers abundance values of zero. This is wrong, because the values were only defined and detected as "missing values" if there was clear evidence, through an existing cover value that the species occurred in this subplot in the regarded year. Therefore these output values of zero were replaced by 1 for all subsequent analysis. For species where too less matrix information existed to give the formula sufficient power simpler methods (mean of previous and following year) were used to impute the values $(n=5)$.

\subsubsection{Experimental design}

The manipulative experiment comprised the two fixed predictor variables, grazing and active restoration treatments ("stones", "brushpacking", "manure \& palm fronds"), plus two sites as random factor. The response variables were total cover, number of individuals, species richness, and the soil parameters $\left(\mathrm{pH}, \mathrm{C} / \mathrm{N}, \mathrm{EC}, \mathrm{C}_{-} \mathrm{T}\right.$ and $\left.N_{-} \mathrm{T}\right)$.

The experiment was repeated in time 2004-2008 (trajectory experiment) and space resulting in a combination of trajectory and snapshot experiment. The treatments were applied to all designated plots only once forming a pulse experiment. To avoid confounding factors the subplots were randomly located within the plots and the treatments assigned randomly to each subplot, thus separating potential confounding factors (inhomogeneity of soil and microclimate conditions) from the treatment effects.

\subsubsection{Soil analysis}

For the laboratory analysis one mixed soil sample from the first $1-10 \mathrm{~cm}$ depth was collected in 2008 by Ute Schmiedel and Reginald Christiaan. Altogether nine subsamples, from the corners, the centre and points in between were taken and mixed. The so obtained topsoil samples were taken for further analysis to Germany, where I analyzed them in the soil laboratories of the University of Hamburg and Karlsruhe. 
The samples were first sieved to $2 \mathrm{~mm}$ (suggestion in ISO 11464: 2006) and subsequently the chemical characteristics $\mathrm{pH}_{\mathrm{CaC} 12}$, electrical conductivity (EC), total amount of nitrogen (N_T) and total amount of carbon (C_T) were determined. Since the $\mathrm{C} / \mathrm{N}$ analysis is using small sample quantities it is advised (ISO 11464 2006) to ground the samples to achieve better homogeneity. A subsample of $10 \mathrm{~g}$ was therefore grounded for 5 minutes time using a centrifugal ball mill (Retsch, S100) with a grinding jar of zirconia and a refiner filling of six grinding balls.

The $\mathrm{pH}$ value was determined with a Schott BlueLine $13 \mathrm{pH}$ meter following the standard procedure (ISO 10390: 2005). Calcium dichloride as extraction reagent was used because it is thought to possess a similar ionic strength (Houba et al. 2000) as most natural soil solutions and gives a better idea of bioavailable elements, in contrast to measurements in water extracts. To account for the expected low organic carbon content of the soils a different soil suspension ratio of 1:2.5 (10g dry soil $\left.+25 \mathrm{ml} 0.01 \mathrm{M} \mathrm{CaCl}_{2}\right)$ instead of 1:5 was used.

To get an estimation of salinity the electrical conductivity was measured. Deviating from the ISO standard (ISO 11265: 1994$)$ a soil suspension of 1:2.5 (20g fine material $+50 \mathrm{ml}$ aqua bidest) was prepared and allowed to sediment for at least one hour - to reduce filtration time. The measurement was carried out with a conductivity electrode TetraCon ${ }^{\circledR} 325$ from WTW.

Total amount of nitrogen (N) and carbon (TC) were analyzed simultaneously using the fine grounded subsamples. A quantity of $1-1.2 \mathrm{~g}$ of the samples was weighted in and combusted with oxygen at $900^{\circ} \mathrm{C}$. The developed gases $\left(\mathrm{CO}, \mathrm{CO}_{2}, \mathrm{~N}_{2}, \mathrm{NO}_{x}\right)$ are reduced to $\mathrm{N}_{2}$ and $\mathrm{CO}_{2}$ and measured separately by a thermal conductivity detector. The utilised device was a vario Max elemental analyser.

\subsubsection{Rainfall}

In arid regions water and the competition of plants for soil moisture is definitely one of if not the most important factor influencing the vegetation (Cowling et al 1994, Milton 1995). For plants in the Succulent Karoo rainfall in autumn or early winter determines the emergence of seedlings, plant establishment is decided by the occurrence of follow up rains in winter and spring (Milton 1995). In order to investigate the effect of rainfall and its seasonal distribution on plant abundance multi linear regressions were conducted. Because different life form types might react differently to rainfall (Kraaij \& Milton 2006, O`Connor \& Roux 1995) the analysis was conducted separately for different life form types.

Rain data were obtained from the climate station Soebatsfontein- Quaggafontein 478, which is run by the BIOTA Southern Africa project. Monthly rain data were available for April 2001 until December 2008 and can be downloaded from: http://www.biota-africa.org/obs_select.php. 


\subsection{Ratelgat}

The experiments were triggered by "the request of the Griqua people" on how to restore a $10 \mathrm{~km}$ long and about $1 \mathrm{~m}$ broad strip of land, located on the camp Ratelgat. Due to the construction of a subterranean water pipeline to supply the livestock with water in 2000 , the soil surface and vegetation were severely disturbed (Figure 6). The pipeline, running through quartz fields and areas without quartz cover, shows poor vegetation cover and intensified soil erosion (Etzold 2006).

The part of this study dealing the Knersvlakte experiments is a continuation of the diploma thesis by Sophia Etzold (Etzold 2006), which established the experimental plots and carried out the analysis for 2004 and 2005.

To assess the restoration possibilities for mechanical disturbed quartz fields experiments were set up in October 2004 on disturbed sites (pipeline) of the quartz fields itself as well as on zonal vegetation outside the quartz plots (see section zonal habitats). The plots were revisited in 2005 (August and October) and 2008 (November-December) to pursuit their development. For the quartz field communities' cover and abundance values for 2004 and 2005 are analyzed as well as abundance data for 2008 . For the brushpack experiments only abundance of species was recorded throughout the experiment. To get an estimate of the assumed negative installation effect of the "brushpack" treatment like destruction of plants due to trampling, breaking off of plant material and as a major element the levelling impact, the brushpack plots were recorded before and immediately after treatment installation.
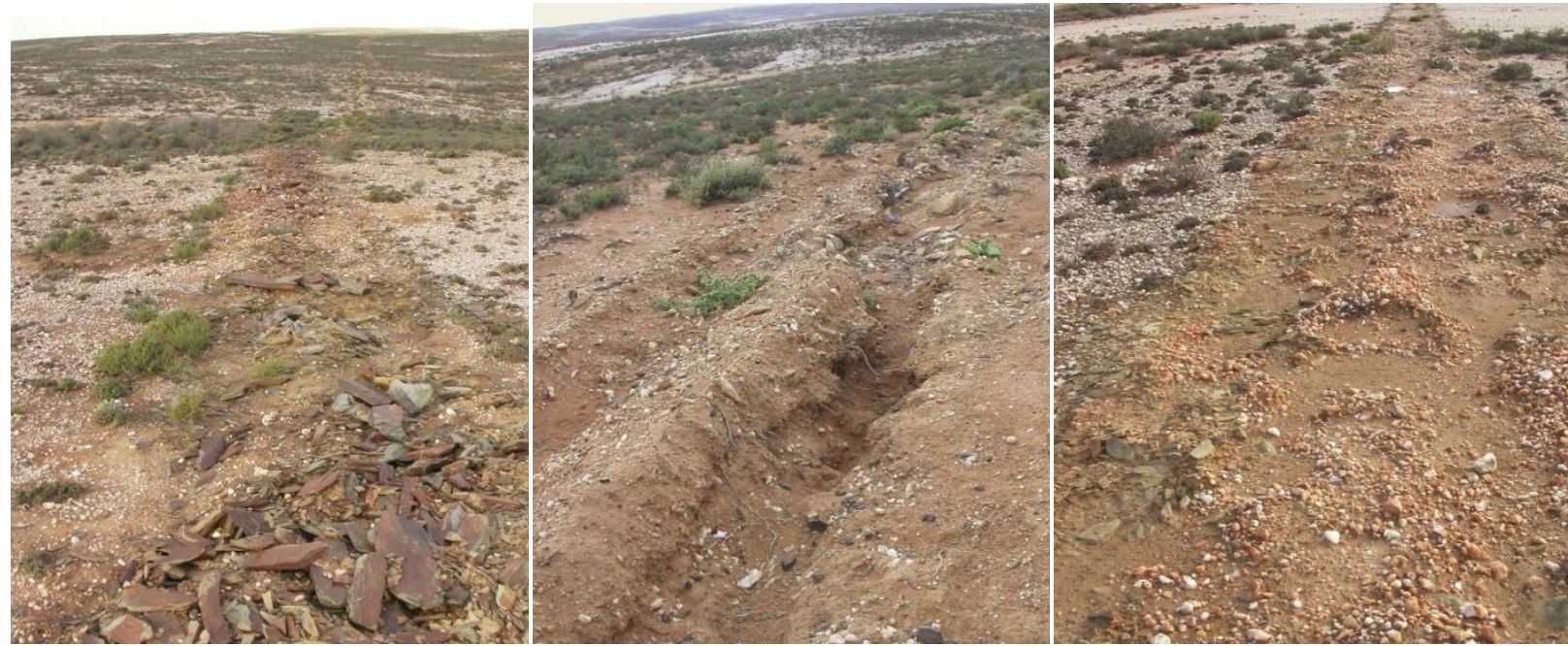

Figure 6 Pipeline on Ratelgat running through quartz field patches and zonal habitats. Loss of vegetation and erosion are apparent (Sophia Etzold).

Together with people from the Griqua community the applied treatments were excogitated during three workshops in 2004. The first workshop in August had the aim of informing about the ecology and importance of the quartz fields, pointing up their uniqueness and the problem of disturbance. In addition the Griquas were encouraged to present their ideas and visions about the future of their farmland. During these workshops the applied treatments, teaming up scientific and indigenous knowledge were developed (Etzold 2006). 
For quartz field areas and non quartz field patches different restoration techniques were applied and are described separately below.

\subsubsection{Quartz fields}

Two quartz field communities, the Cephalophyllum spissum and the Ruschia burtoniae-community were chosen and stand for typical saline and non-saline compositions. Ruschia burtoniae is a widespread community in the Knersvlakte which typically inhabits acid, shallow, non-saline quartz fields and is strongly dominated by the meso-chamaephyte Ruschia burtoniae (Schmiedel 2002). The Cephalophyllum spissum community comprises many endemic species and is characterized by the compact nano-chamaephyte C.spissum which is endemic to the central Knersvlakte (Schmiedel 2002). It occurs on saline soils with a moderate stone content in the central part of the Knersvlakte and is thought to be endangered due to its small geographical and ecological restrictions (Schmiedel 2002).

The experimental plots were arranged in series to provide as equal conditions as possible. If plots had to be located in slope position, the control plot was situated above them to avoid influence. Each plot was $1 \times 3 \mathrm{~m}$ in size with $0.5 \mathrm{~m}$ distance in between (Etzold 2006). The following treatments were carried out (Figure 7):

Levelling of the soil surface ("levelling") to restore the surface area of the quartz fields. Additionally big shale plates dislocated by the construction work were removed and individuals of the invasive species Atriplex lindleyi ssp. inflata pulled out. Atriplex lindleyi ssp. inflata is an alien chenopod saltbush native to Australia and occurs often in areas which experienced overstocking (Mills et al. 2005).

Levelling of the soil surface and planting ("planting") of Cephalophyllum spissum. 20 Individuals from the surrounding were transplanted into dedicated plots. This treatment was applied only to plots belonging to the Cephalophyllum spissum community.

Levelling of the soil surface and scattering of quartz stones ("stones") with a size of $6-20 \mathrm{~cm}$, covering about $10 \%$ of each plot. The stones shall act as seed catcher, reduce wind speed, shade upcoming seedlings and reconstitute the situation on the quartz fields before their disturbance.

Control ("control”) plots without any manipulation.

Each treatment was replicated 10 times meeting the "Rule of 10" from Gotelli and Ellison (2004) for experimental setups with a reasonable statistical power to detect revealing patterns. 


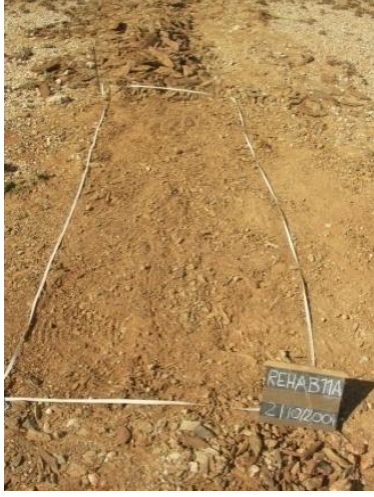

a) levelling

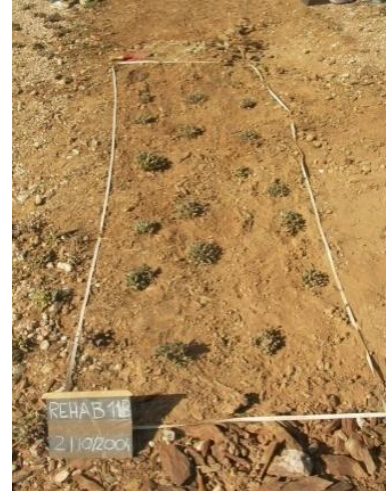

b) planting of C.spissum individuals

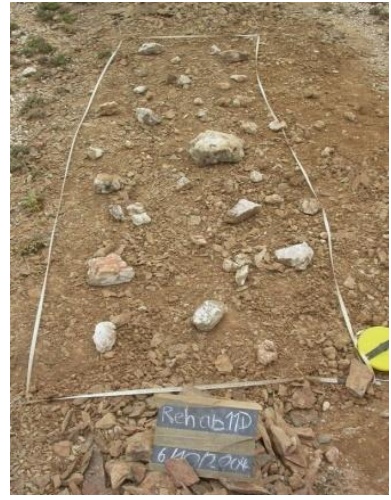

c) scattering of quartz stones

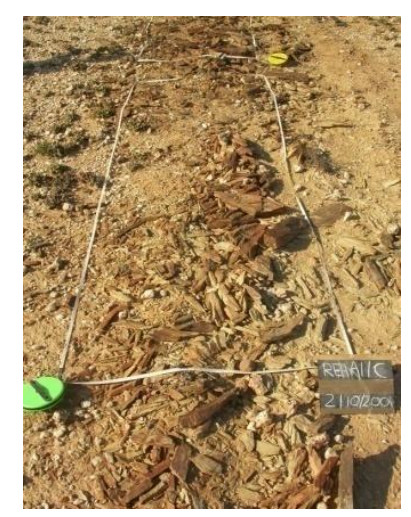

d) control plot

Figure 7 Restoration treatments inside quartz fields (Sophia Etzold)

For the Ruschia burtoniae community vegetation data from 30 permanent plots ( 10 levelling, 10 stones and 10 controls) were examined regarding the parameters species richness, number of individuals and total cover per plot.

For the Cephalophyllum spissum community vegetation data from 43 permanent plots were analyzed using the same three vegetation parameters as for the Ruschia burtoniae community. Four of the plots (one leveling, two control and one planting treatment plot) have not been re-visited in 2008. Since an imputing of the data was not possible, I decided to exclude these plots from the analysis for 2008. The resulting plot numbers per treatment for 2008 were therefore 9 plots for leveling, 10 for planting, 10 plots for stones treatment and 10 controls.

\subsubsection{Zonal habitats}

Quartz fields occur typically in islands and form patches stretching 1 to over 100m (Schmiedel \& Jürgens 1999). Parts of the pipeline which were not covered with quartz debris house zonal vegetation and possess deeper, loamy soil (Etzold 2006). For these areas with a higher cover of meso- und macrochamaephytes unlike quartz fields the treatment "brushpack" was applied.

In total 19 plots $(1 \times 20 \mathrm{~m})$ were set up. One control plot served as control for two plots which means that 9 control and 10 brushpack plots were existent. Plots were placed in shrubby areas outside quartz fields alternating brushpack and control treatment. If one plot covered the whole shrub island, the following plot was placed in the next available shrubby community. Attention was paid to choose sites with comparable inclination, exposition, species composition, cover values and level of disturbance (Etzold 2006).

The brushpacks were made up of Galenia africana shrubs, which occur frequently on Ratelgat. This species is out-of-favour by South African herders and considered to be unpalatable or even toxic (Simons \& Allsopp 2007, Riginos \& Hoffman 2003, Richardson et al. 2007). Each dedicated plot was first levelled and afterwards covered with $G$. africana shrubs up to a height of $20-50 \mathrm{~cm}$. Standing plants on the plots were tried to be saved except Atripley lindleyi ssp. inflata which was removed. The brushpacks shall rebuilt the patchiness of this landscape by capturing and storing water, litter and soil particles and slowly release these resources again helping plants 
to survive and become established (Ludwig \& Tongway 1996a). Vegetation data were recorded before and after the installation in August/September 2004, in August 2005 and December 2008.

\subsubsection{Rainfall data}

Rain data were obtained from the climate station Ratelgat- Luiperskop which is run by the BIOTA Southern Africa project. Monthly rain data were available for April 2001 until August 2008 and data can be downloaded from: http://www.biota-africa.org/obs_select.php. Five monthly precipitation values in this record were missing and imputed following suggestion by Harrell (2001) as follows: missing monthly values were replaced by the means of the preceding and subsequent month of the same year and the same month of the two adjacent years. If consecutive values had to be imputed the value for the missing month was imputed as the mean of the preceding and following year.

\subsection{Statistics}

Applied value of significance throughout all analysis was $p<0.05$. The decision for parametric or nonparametric tests was taken after visual inspection of distributions via box-plots, histograms and standardized residual plots as advised by Quinn \& Keough (2002). If frequency distributions were skewed or variances were inhomogeneous, data were first log or square root transformed and inspected again. If the assumptions of parametric tests were still doubtful, non-parametric tests were applied. However, even for rank or otherwise transformed data means of the untransformed data are presented to allow an easier interpretation. A rejection of $\mathrm{H}_{0}$ with transformed data is assumed to be also valid for the untransformed dataset. All statistical analyses were conducted with the statistic software SPSS 17.0.

The employed parameters used for the vegetation analyses are:

1. Number of individuals: number of individuals per subplot and year.

2. Number of annuals: number of annual individuals per subplot and year.

3. Number of perennials: number of perennial individuals per subplot and year.

4. Species richness: number of species per plot/subplot and year

5. Annual species richness: number of annual species per subplot and year.

6. Perennial species richness: number of perennial species per subplot and year.

7. Total cover: sum of all individual cover values per subplot and year.

8. Total cover annuals: sum of all cover values of annual species per subplot and year. 
9. Total cover perennials: sum of all cover values of perennial species per subplot and year.

10. Relative abundance of life form group $\mathbf{x}$ : abundance of all species within the subplot and year belonging to life form group $x$ divided by the mean for the subplot and life form group over all years studied.

\subsubsection{Soebatsfontein}

\subsubsection{Soil}

Testing several response variables measured on the same experimental unit (subplot) bears the risk of correlation. Conducted ANOVAS on each response variable separately might therefore not be independent of each other. It is recommended therefore to adjust the significance levels of each ANOVA with a Bonferroni correction (Quinn \& Keough 2002) or to protect the single ANOVAs with a previous MANOVA (Field 2009).

I decided for the MANOVA with a subsequent discriminant analysis for treatment as grouping variable. The assumption of multivariate normality was not tested separately, but assumed if univariate normality within each group for all dependent variables was given. Homogeneity of variances was checked preliminary using Levene's test to test for equality of variances and Box's test of equality of covariance matrices to check the assumption of homogeneity of covariances (Field 2009). To avoid multicollinearity between soil parameters highly correlated predictor variables with a Spearman's rank coefficient higher than $r>0.8$ were excluded from the analysis. As suggested by Field (2009) and Quinn \& Keough (2002), Pillai's Trace was used as multivariate test statistic to identify differences between group centroids. This statistic is thought to be most robust for unequal sample sizes, if homogeneity of covariance matrices and the assumption of multivariate normality are supportable.

\subsubsection{Rainfall}

To examine the effect of seasonal rainfall on the relative abundance of species a multiple linear model containing the total rainfall of the same, previous and the pre-previous year was fitted. Because findings of other ecological research (Cowling et al. 1994, Milton 1995, Kraaij \& Milton 2006) indicate that not only the total rainfall but also the seasonal distribution of rain is important, each year was split into four parts in accordance to a division by MacKellar et al. (2007) and added as separate predictor variables into the model. The division is as follows: spring (September to November =SON), summer (December to February = DJF), autumn (March to May = MAM) and winter (June until August = JJA). The analysis was conducted separately for the life forms "geophytes", "chamaephytes \& phanerophytes", "therophytes" and "hemicryptophytes" as well as all life forms together.

For each model presented the following assumptions of multiple linear regression (Field 2009, Backhaus et al. 1996) apply: 
1. Normal distribution of residuals and homoscedasticity ${ }^{1}$ were checked visually with a plot of the standardized predicted values against the standardized residuals.

2. No excessive multicollinearity, this requirement of not perfect linear relationship between two or more predictor variables is checked by inspecting the correlation matrix and the tolerance values. The latter one should be over 0.1 and the variance inflation factor (VIF) should be $<10$ (Quinn \& Keough 2002).

3. Only moderate autocorrelation: this independency of residuals is especially important when time series are analyzed. It is inspected and quantified by the Durbin/Watson test, which tests for serial correlation between the residuals. Values below 1 or over 3 are cause for concern (Field 2009). .

4. Non-zero variance: the predictors should have some variation in their values.

5. Linearity: assumption that the relationship of the model is linear; this can be checked visually with scatter plots.

The effect of seasonal rainfall on relative abundance of the different life form groups was examined with multiple linear regressions for each of the four life form groups and the four seasonal rainfall variables as potential predictors. To avoid collinearity, I identified collinear predictor variables with a correlation matrix at $r>0.8$ with Pearsons correlation coefficients and used only one of the correlating variables. The variables were added in an automated stepwise backward method as suggested by (Field 2009) in contrast to forward methods, which can show a suppressor effect. $F$ to enter was set at 3.84 and a variable was removed if its $F$ value was less than 2.71 . From the so gained models the one with the highest $F$ value was chosen and is presented.

\subsubsection{Vegetation}

Differences between sites and fenced/unfenced plots were checked using independent t-tests or MannWhitney- U- tests. Differences between years (=within subject factor), active treatments (= between-subject factor) and grazing were examined using the General Linear Model repeated measurement design (=mixed ANOVA) or Mann-Whitney $U$ and Kruskal-Wallis tests. Significant results for years were further examined using LSH (LSH = least significant difference) t-tests with Bonferroni-Holm corrections, which are less conservative than the Bonferroni adjustments and still hold good control over the inflated Type I error rate risk in multiple testing situations (Bärlocher 2000, Köhler et al. 1996). The correction is obtained by sorting the p-values in ascending order and compare the smallest one against $\alpha / k$ ( $k=$ number of individual comparisons). It is significant if $p<\alpha / k$, the next smaller $p$-value is compared against $\alpha /(k-1)$ and so forth, this procedure is continued until $p_{n}>\alpha /(k-n)$ (c). Significant results for treatments were further broken down with LSH or Kruskal-Wallis tests and subsequent Bonferroni-Holm corrections.

\footnotetext{
${ }^{1}$ Homoscedasticity:fact that the residuals at each level of the predictor variables are constant
} 
Because it is inspected that the dataset is strongly dominated by annual species (=therophytes) and their high frequency might hide effects on perennial species (chamaephytes, phanerophytes, geophytes and hemicryptophytes), the investigation of the effects "exclusion of grazing" and "active restoration treatments" on the occurrence, cover and abundance of species was done for annuals and perennials separately.

\subsubsection{Ratelgat}

\subsubsection{Vegetation}

\subsection{Quartz fields}

To test for differences between treatments I performed Kruskal-Wallis tests, the non-parametric analogue of a one-way ANOVA, or ANOVAs if normality and homogeneity of variances allowed this on the parameters species richness, number of individuals and total cover. The effect of time was investigated by using the Kruskal-Wallis test with years as grouping variable and species richness and individuals as response. If for total cover only two groups (year 2004 and 2005) had to be compared, the Mann-Whitney U test was applied. Parameters with significant test results were further analyzed using LSH tests with a Bonferroni-Holm correction of the resultant p-values.

\subsection{Zonal habitats}

\section{Brushpacking treatment}

The considered vegetation parameters for the analysis were number of individuals and species richness. The analysis was conducted separately for the life form types "chamaephytes \& phanerophytes", "geophytes", "hemicryptophytes" and "therophytes".

The $\mathrm{H}_{0}$ is that the two variables species richness and number of individuals were the same before and after treatment installation. The comparison was done using a dependent t-test or a non-parametric variate if variances were not equal or the distribution was unsymmetrical. Although the non-parametric analogue to the paired t-test would be the Wilcoxon signed rank test, the independent Mann-Withney $-U$ test was chosen instead. The Wilcoxon rank test is more sensitive to the direction of differences than to the magnitude and since I wanted to get an estimate of the magnitude of the installation effect this test would have been unfavorable 


\section{Results}

For the raw vegetation, rain and soil data please refer to the electronic appendices (attached as CD-ROM). The contents of the electronic appendices are listed in Appendix XIII.

\subsection{Soebatsfontein}

\subsubsection{Soil}

In this section the results for the soil parameters $\mathrm{pH}, \mathrm{EC}, \mathrm{C} / \mathrm{N}, \mathrm{C}_{-} \mathrm{T}$ and $\mathrm{N}_{-} \mathrm{T}$ are presented regarding differences between the two camps, grazed and ungrazed plots and the active restoration treatments. The accuracy of measurement for N_T and C_T was three decimal places but this level of exactness was not seen as relevant for this study and only two decimal places are presented.

Overall the two camps were similar in the range of the measured soil parameters (Table 2). Differences between the sites were found for the $\mathrm{C} / \mathrm{N}$ ratio and grazing proved to be influencing electrical conductivity. $A$ significant influence on $\mathrm{pH}, \mathrm{EC}, \mathrm{N}_{-} \mathrm{T}, \mathrm{C}_{-} \mathrm{T}$ and $\mathrm{C} / \mathrm{N}$ (only Quaggasfontein) was found for the active restoration treatments.

\section{MANOVA}

To test the effects of the exclusion of herbivores (grazing treatment $=F / U F$ ) and the active treatments on soil properties, a MANOVA with $\mathrm{pH}, \log E C, C / N_{1} N_{-} T$ and $C_{-} T$ as dependent variables, the different active treatments and fenced/unfenced groups as fixed factors and site as covariate was conducted.

Total amount of nitrogen ( $N_{-} T$ ) and total amount of carbon ( $\left.C_{-} T\right)$ were highly correlated with each other, Spearmans $r=0.988$ as well as with $C_{-} N\left(r_{C_{-} T}=.783\right.$ and $\left.r_{N_{-} T}=.694\right)$. Since neither $C_{-} T$ nor $N_{-} T$ met the assumptions of MANOVA only $\mathrm{pH}, \operatorname{logEC}$ and $\mathrm{C}_{-} \mathrm{N}$ remained within the analysis.

Box's test was not significant $F(42,8198)=55.415 ; p=.229$ and Levenes' test showed no violation of the homogeneity of variance assumption $\left[F_{C_{-} N}(7,88)=.994 ; p=.441, F_{p H}(7,88)=.494 ; p=.837, F_{\operatorname{logEC}}(7,88)=.730\right.$, $p=.647]$. 
Table 2 Overview of the soil parameters pH, EC, C/N, N_T and C_T for the two camps at Soebatsfontein. Presented are means \pm SD for fenced (F) / unfenced (UF) plots of each camp separately and for both camps together.

\begin{tabular}{|c|c|c|c|c|c|c|c|c|c|c|c|c|c|c|}
\hline \multirow[b]{3}{*}{ parameter } & \multicolumn{6}{|l|}{ Patrysegat } & \multicolumn{8}{|c|}{ Quaggasfontein } \\
\hline & \multicolumn{2}{|c|}{$\mathrm{F}$} & \multicolumn{2}{|c|}{ UF } & \multicolumn{2}{|c|}{ Total } & \multicolumn{2}{|c|}{$\mathrm{F}$} & \multicolumn{2}{|c|}{ UF } & \multicolumn{2}{|c|}{ Total } & \multicolumn{2}{|c|}{ Total both camps } \\
\hline & mean & SD & mean & SD & mean & SD & mean & SD & mean & SD & mean & SD & mean & SD \\
\hline $\mathrm{pHCaCl} 2$ & 6.96 & 0.51 & 6.93 & 0.40 & 6.94 & 0.45 & 6.75 & 0.37 & 6.87 & 0.31 & 6.81 & 0.34 & 6.88 & 0.40 \\
\hline $\mathrm{EC}(\mu \mathrm{S} / \mathrm{cm})$ & 162.04 & 110.35 & 118.38 & 57.55 & 139.30 & 88.75 & 110.55 & 137.57 & 89.14 & 60.25 & 99.40 & 104.06 & 119.35 & 98.27 \\
\hline $\mathrm{C} / \mathrm{N}$ ratio & 10.50 & 0.65 & 9.93 & 0.56 & 10.21 & 0.66 & 8.91 & 0.90 & 9.11 & 0.72 & 9.01 & 0.81 & 9.61 & 0.95 \\
\hline N_T [\%] & 0.06 & 0.02 & 0.05 & 0.02 & 0.05 & 0.02 & 0.07 & 0.08 & 0.04 & 0.02 & 0.05 & 0.06 & 0.05 & 0.05 \\
\hline C_T [\%] & 0.62 & 0.22 & 0.51 & 0.25 & 0.57 & 0.24 & 0.66 & 0.34 & 0.18 & .08 & .50 & .65 & .53 & .49 \\
\hline
\end{tabular}


The multivariate test resulted in the rejection of $\mathrm{H}_{0}$ that there is no difference in group centroids for the factors "site" and "active treatments" (Table 3). The interaction "grazingxactive treatments" was not significant. It can be concluded that "active treatments" and "site" have an effect on soil properties but no overall effect of grazing on all soil parameters together was apparent.

Table 3 Results of the multivariate test statistic for differences in site, grazing, active treatments and the interaction grazing*active treatments on group centroids for the restoration subplots at Soebatsfontein. Presented are the results for Pillai's Trace; $\mathrm{N}=96$.

\begin{tabular}{lllllll}
\hline factor & & Value & $\mathrm{F}$ & hypothesis df & error df & $\mathrm{p}$ \\
site & Pillai's Trace & .192 & 23.257 & 3.000 & 85.000 & .000 \\
grazing & Pillai's Trace & .071 & 2.178 & 3.000 & 85.000 & .097 \\
active treatments & Pillai's Trace & .515 & 6.010 & 9.000 & 261.000 & .000 \\
grazing*active treatments & Pillai's Trace & .075 & .744 & 9.000 & 261.000 & .668 \\
\hline
\end{tabular}

To investigate the contribution and nature of the individual effects of $\mathrm{pH}, \operatorname{logEC}$ and $\mathrm{C} / \mathrm{N}$ to the group differences univariate ANOVAs` were examined.

Table 4 Summary of the univariate ANOVAs for the parameters site, grazing and active treatments on pH, C_N and logEC for the restoration subplots at Soebatsfontein. Significant $p$-values (with applied Bonferroni-Holm correction) are presented in bold.

\begin{tabular}{llclll}
\hline factor & soil & df & MS & F & p. \\
site & pH & 1 & .349 & 3.372 & .070 \\
& C_N & 1 & 32.140 & 66.344 & .000 \\
& logEC & 1 & .939 & 20.339 & .000 \\
grazing & pH & 1 & .004 & .042 & .839 \\
& C_N & 1 & 1.001 & 2.066 & .154 \\
active treatments & logEC & 1 & .224 & 4.853 & .030 \\
& pH & 3 & .909 & 19.676 & .000 \\
& C_N & 3 & 2.903 & 5.993 & .001 \\
treatment*grazing & logEC & 3 & .909 & 19.676 & .000 \\
& pH & 3 & .153 & 1.480 & .226 \\
& C_N & 3 & .037 & .076 & .973 \\
& logEC & 3 & .068 & 1.465 & .230 \\
\hline
\end{tabular}

\section{site}

The ANOVA's showed (Table 4), that C_N ratios were significantly higher for Patrysegat (mean=10.21 \pm 0.66 ) than for Quaggasfontein (mean $=9.01 \pm 0.81$ ) and the same is true for electrical conductivity with $139.30 \pm$ $88.75 \mu \mathrm{S} / \mathrm{cm}$ compared to $99.40 \pm 104.06 \mu \mathrm{S} / \mathrm{cm}$ for Quaggasfontein. 
grazing

Since significant differences were found between the two sites for $\mathrm{C} / \mathrm{N}$ and logEC (Table 4) the examination of grazing effects was conducted separately for each camp. It revealed that $\mathrm{C} / \mathrm{N}$ at Patrysegat was significantly higher in the fenced than unfenced part with $U=152.500$ and $p=.004$. Both, $C_{-} T(U=137.500, p=.001)$ and $N_{-} T(U=160.000, p=.006)$ contribute significantly to this difference with higher mean values for the fenced part. No significant differences for the grazing treatment on any of these three parameters were found for Quaggasfontein. Grazing showed an effect on logEC with higher values for the fenced plots at both camps but the effect was not significant [Patrysegat: $F(1,48)=2.284, p=.138$; Quaggasfontein: $F(1,48)=.208, p=.650]$.

\section{active treatments}

The ANOVAs showed (Table 4) that all three parameters were significantly influenced by the active treatments. For $\mathrm{pH}$ the effect of active treatments was investigated on all 96 subplots together because neither site nor grazing had proofed to have a significant influence. A posteriori t-tests (Table 5) revealed that soil $\mathrm{pH}$ was highest under the "manure \& palm fronds" treatment followed by the "brushpack" one.

Table 5 Soil pH in the different treatment groups for Quaggasfontein and Patrysegat together. $\mathbf{N}=\mathbf{9 6}$ Small letters in bold behind the means indicate homogenous groups according to LSH with applied Bonferroni-Holm correction.

\begin{tabular}{llll}
\hline treatment & mean & SD & $\mathrm{N}$ \\
control & $6.70 \mathrm{a}$ & .355 & 34 \\
stones & $6.70 \mathrm{a}$ & .320 & 24 \\
brushpack & $6.98 \mathrm{~b}$ & .356 & 18 \\
manure \& palm fronds & $7.30 \mathrm{c}$ & .246 & 20 \\
total & 6.88 & .403 & 96 \\
\hline
\end{tabular}

Because the ANOVAs' revealed that the EC and C_N values for Patrysegat and Quaggasfontein were significantly different I examined the active treatment effect separately for each camp. The effect of the treatments on EC was overall significant for both camps (Table 6), but post-hoc tests were only able to differentiate the "manure \& palm fronds" treatment from the remaining three groups for Quaggasfontein. For the C_N ratio a separation of the same treatment compared to the "control" and "stones" ones could be achieved for Quaggasfontein. For Patrysegat no effect for the two soil parameters was stated. 
Table 6 Differences between treatment groups for EC $[\mu \mathrm{S} / \mathrm{cm}], \mathrm{C} \_\mathrm{N}$ ratio, C_T and N_T at Patrysegat and Quaggasfontein. p-values were obtained by Kruskal-Wallis tests with applied Bonferroni-Holm correction. Small letters in bold behind the means indicate homogenous groups according to LSH with Bonferroni-Holm correction. $0=$ control, $1=$ stones, $2=$ brushpack, 3= manure \& palm fronds treatment.

\begin{tabular}{|c|c|c|c|c|c|c|}
\hline \multirow{2}{*}{$\begin{array}{l}\text { EC } \\
\text { treatment }\end{array}$} & \multicolumn{2}{|c|}{ Patrysegat } & \multicolumn{4}{|c|}{ Quaggasfontein } \\
\hline & mean & SD & $\mathrm{N}$ & mean & SD & $\mathrm{N}$ \\
\hline 0 & 112.87 & 51.58 & 18 & $52.49 a$ & 20.26 & 16 \\
\hline 1 & 103.53 & 58.98 & 10 & $60.64 a$ & 48.30 & 14 \\
\hline 2 & 175.52 & 141.05 & 10 & $88.54 a$ & 32.77 & 8 \\
\hline 3 & 186.42 & 77.40 & 10 & $237.40 \mathrm{~b}$ & 155.39 & 10 \\
\hline Total & 139.30 & 88.75 & 48 & 99.40 & 104.06 & 48 \\
\hline \multirow[t]{2}{*}{ test statistic } & $\mathrm{Chi}^{2}$ & $\mathrm{dF}$ & $\mathrm{p}$ & Chi2 & $\mathrm{dF}$ & $\mathrm{p}$ \\
\hline & 9.172 & 3 & .023 & 26.683 & 3 & .000 \\
\hline \multicolumn{7}{|l|}{ C_N } \\
\hline treatment & & & $\mathrm{N}$ & & & $\mathrm{N}$ \\
\hline 0 & 10.04 & 0.58 & 18 & $8.69 a b$ & 0.65 & 16 \\
\hline 1 & 10.30 & 0.64 & 10 & $8.54 a$ & 0.50 & 14 \\
\hline 2 & 10.54 & 0.83 & 10 & $9.44 b$ & 0.83 & 8 \\
\hline 3 & 10.11 & 0.60 & 10 & $9.84 \mathrm{bc}$ & 0.62 & 10 \\
\hline Total & 10.21 & 0.67 & 48 & 9.01 & 0.81 & 48 \\
\hline \multirow[t]{2}{*}{ test statistic } & $\mathrm{Chi}^{2}$ & $\mathrm{dF}$ & $\mathrm{p}$ & Chi2 & $\mathrm{dF}$ & $p$ \\
\hline & 2.809 & 3 & .435 & 19.058 & 3 & .000 \\
\hline \multicolumn{7}{|l|}{ N_T } \\
\hline treatment & & & $\mathrm{N}$ & & & N \\
\hline 0 & $0.05 a$ & 0.01 & 18 & $0.03 a$ & 0.01 & 16 \\
\hline 1 & $0.05 a$ & 0.01 & 10 & $0.03 a$ & 0.01 & 14 \\
\hline 2 & $0.05 a$ & 0.02 & 10 & $0.04 a$ & 0.00 & 8 \\
\hline 3 & $0.08 b$ & 0.03 & 10 & $0.13 b$ & 0.10 & 10 \\
\hline Total & 0.05 & 0.02 & 48 & 0.05 & 0.06 & 48 \\
\hline \multirow[t]{2}{*}{ test statistic } & $\mathrm{Chi}^{2}$ & $\mathrm{dF}$ & $\mathrm{p}$ & Chi2 & $\mathrm{dF}$ & $\mathrm{p}$ \\
\hline & 11.840 & 3 & .006 & 28.805 & 3 & .000 \\
\hline \multicolumn{7}{|l|}{ C_T } \\
\hline treatment & & & $\mathrm{N}$ & & & $\mathrm{N}$ \\
\hline 0 & $0.46 a$ & 0.09 & 18 & $0.25 a$ & 0.05 & 16 \\
\hline 1 & $0.49 a$ & 0.10 & 10 & $0.26 a$ & 0.06 & 14 \\
\hline 2 & $0.57 a b$ & 0.24 & 10 & $0.35 a$ & 0.05 & 8 \\
\hline 3 & $0.82 b$ & 0.33 & 10 & $1.34 \mathrm{~b}$ & 1.10 & 10 \\
\hline Total & 0.56 & 0.24 & 48 & 0.50 & 0.65 & 48 \\
\hline \multirow[t]{2}{*}{ test statistic } & $\mathrm{Chi}^{2}$ & $\mathrm{dF}$ & $\mathrm{p}$ & Chi2 & $\mathrm{dF}$ & $\mathrm{p}$ \\
\hline & 10.704 & 3 & .011 & 30.720 & 3 & .000 \\
\hline
\end{tabular}

Further investigation of the pattern for total nitrogen and total carbon outside of the overall MANOVA analysis revealed significant "active treatment" effects for both parameters and both camps (Table 6). For N_T the "manure \& palm fronds" treatment showed significantly higher values compared to the three remaining groups at both camps. Total carbon was also highest under this treatment and could be separated to all other treatments for Quaggasfontein and to the "control" and "stones" treatment for Patrysegat. 
A discriminant analysis with treatment as grouping factor and $\log \mathrm{EC}, \mathrm{pH}$ and $\mathrm{C} / \mathrm{N}$ as independent variables showed that $94.2 \%$ of the variance can be explained by the first variate and $5.1 \%$ by the second one which is not significant (Wilks Lambda $\mathrm{p}=.416)$ (Appendix I).

Table 7 Standardized canoncial discriminant function coefficients and canonical variate correlation coefficients for the first and second function of the canonical discriminant analysis for $\mathrm{pH}, \log \mathrm{EC}$ and $\mathrm{C} / \mathrm{N}$ for the Soebatsfontein subplots, $\mathrm{N}=96$.

\begin{tabular}{lllll}
\hline & $\begin{array}{l}\text { standardized discriminant } \\
\text { function coefficients }\end{array}$ & $\begin{array}{l}\text { canonical variate correlation } \\
\text { coefficients }\end{array}$ \\
\hline parameter & function 1 & function 2 & function 1 & function 2 \\
pH & .609 & -.126 & .895 & -.060 \\
$\operatorname{logEC}$ & .545 & -.372 & .857 & .121 \\
C_N & -.032 & 1.131 & .381 & $.917^{*}$ \\
\hline
\end{tabular}

The standardized discriminant function coefficients which can be compared to the standardized betas in regression show the strong contribution of $\mathrm{pH}$ and $\operatorname{logEC}$ to the first variate (Table 7), the opposite is true for $\mathrm{C} / \mathrm{N}$ which has the highest contribution to the second variate. The canonical variate correlation coefficients, which are a measure of the relative contribution of each variable to group separation along the associated axis (Field 2005), show that pH contributes slightly more to group separation along the first axis as logEC and C_N has a low contribution (Table 7). For the second axis the pattern is inverse. The group centroids plotted in Figure 8 show that "manure \& palm fronds" can be separated to "brushpack", "control" and "stones" (in ascending magnitude) by the first function. The second (not significant axis) separates "brush" from the other two treatments and the control. These findings indicate that $\mathrm{pH}$ and EC contributed most to the separation to the other groups for the "manure \& palm fronds" treatment, whereas the separation of the "brushpack" subplots was more due to differences in $\mathrm{C} / \mathrm{N}$ ratios. 


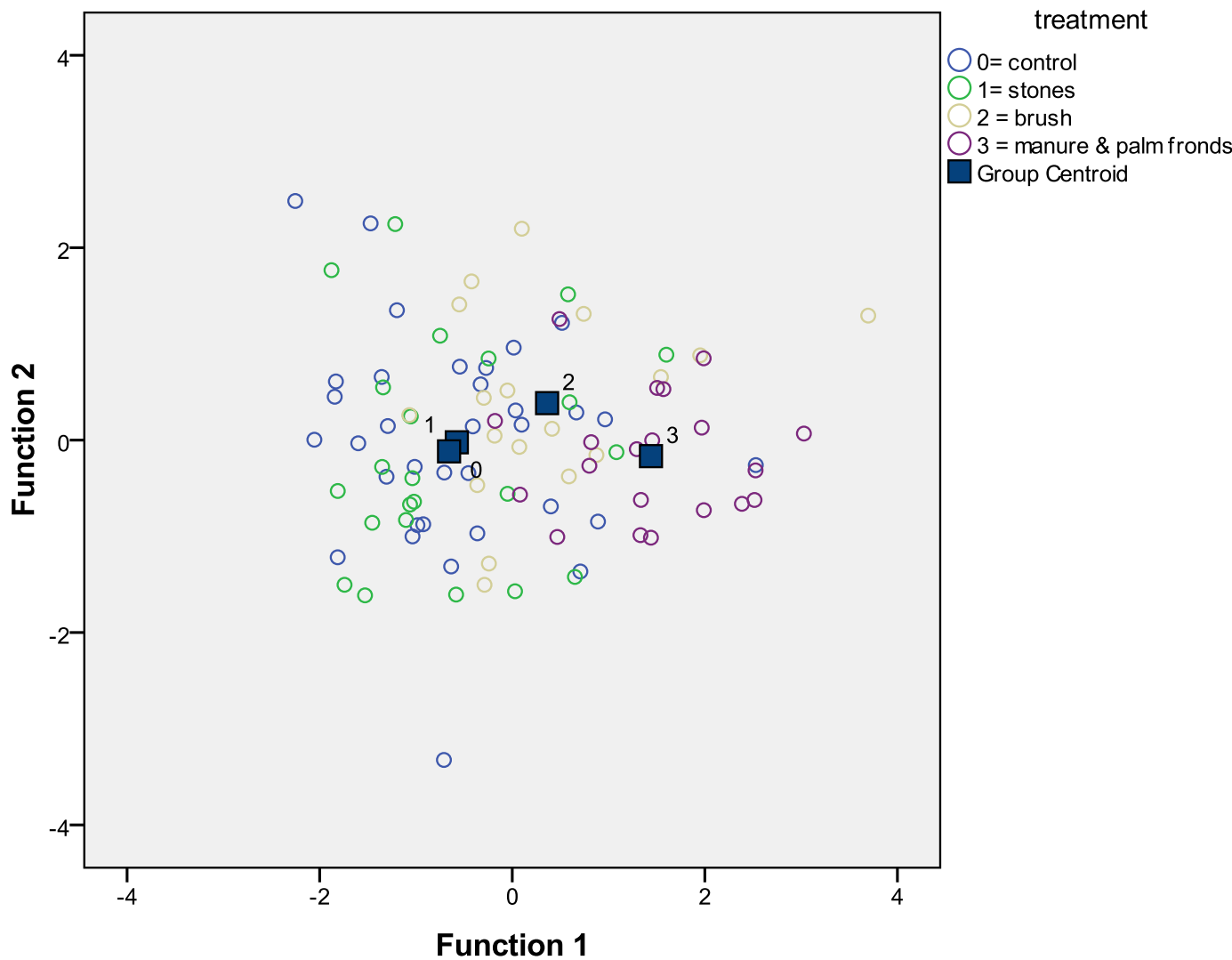

Figure 8 Plot of the canonical discriminant function and group centroids. The first axis represents the combined effect of $\mathrm{pH}$ and $\log \mathrm{EC}$, whereas the second function is more influenced by the $\mathrm{C} / \mathrm{N}$ values. The values for the group centroids can be found in Appendix II.

\subsubsection{Rainfall}

In Soebatsfontein the total annual rainfall for the period 2001-2008 was $130.25 \mathrm{~mm}$. The years 2001-2004 were below or average rainfall years, whereas 2006 and 2007 received above average rainfall, with 2006 being the wettest out of all examined years (Figure 9). 


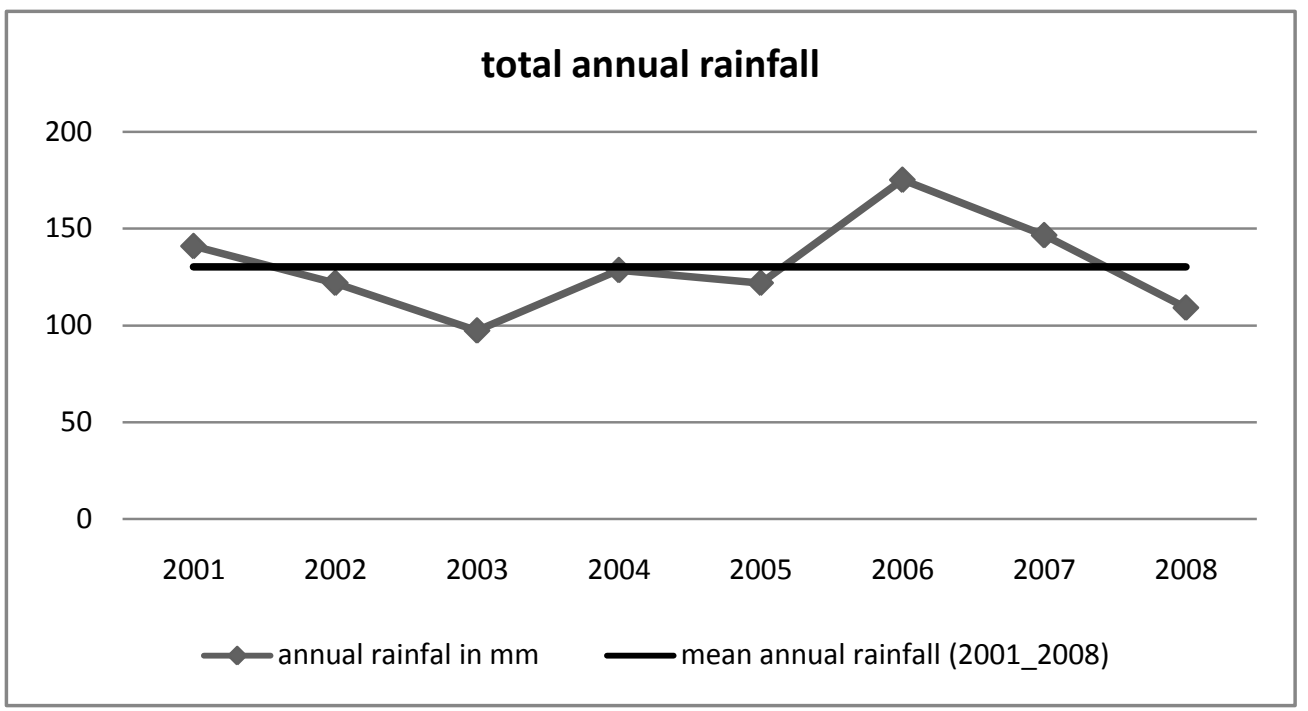

Figure 9 Amount of total annual rainfall for the climate station Soebatsfontein - Quaggafontein. Presented are the values for 2001-2008.

Summer, as the driest season for the study site received on average $6 \%$ of the total annual rainfall and showed little variation (Figure 10). Springtime with $21 \%$ and autumn with $26 \%$ are wetter seasons, but the main rain falls in winter with 46\%. Like for total annual rainfall high seasonal rainfall occurred in winter and autumn 2006.

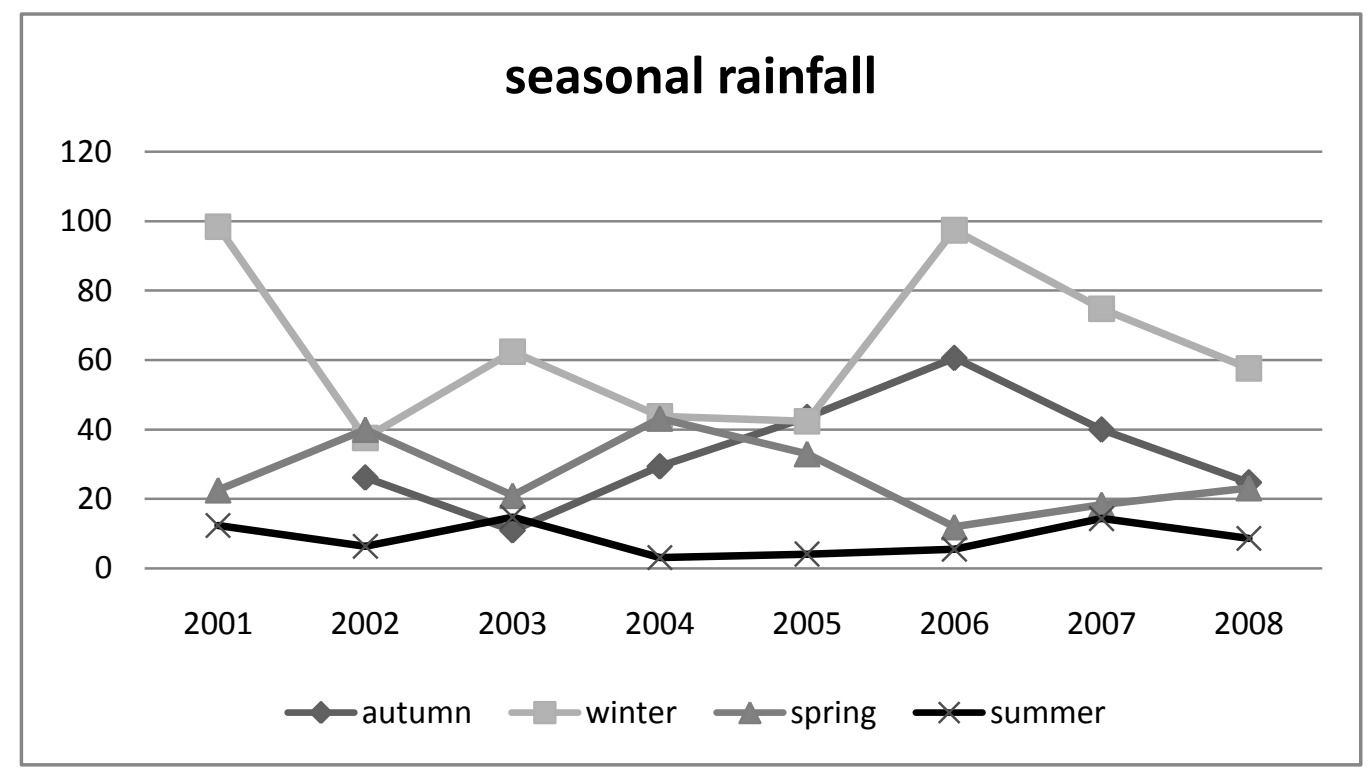

Figure 10 Amount of rainfall within the four seasons autumn (MAM), winter (JJA), spring (SON) and summer (DJF). Note that the value for autumn 2001 is missing 


\subsubsection{Linear regression}

\section{Total annual rainfall}

All five models for the regression between total annual rainfall and relative abundance of the life form groups were highly significant (Table 8 ) and the grouping of species into life-form groups improved the explained variance. Tolerances and variance inflation factors were checked for all coefficients and showed no reason for concern. Autocorrelation was a topic for the life form groups "all" and "geophytes". The explained variance for relative abundances was highest for "geophytes" and "hemicryptophytes" and lowest for "chamaephytes \& phanerophytes" (Table 8). While the rainfall of the previous year had a rather low but always positive influence on the relative abundance, this effect was only significant for "hemicryptophytes" and "geophytes". Rainfall of the year_x-2 showed highest positive influence on the last mentioned life form groups and also on the relative abundance of "all" and "therophytes". Rainfall of the same year reduced the relative abundance of all groups besides "geophytes".

A graphical examination of the relationship between rainfall and relative abundance of the life form groups revealed that "geophytes" had the highest and "chamaephytes \& phanerophytes" the lowest variation between years (Appendix V). "Geophytes" and "hemicryptophytes" follow closest the trend of annual rainfall except for 2008 where all life forms show a strong increase despite a decline in the amount of rainfall. These graphical impressions conform well to the above presented findings of high adjusted $\mathrm{R}^{2}$ for "geophytes" and "hemicryptophthes" and the low explainable variance for the "chamaephytes \& phanerophytes" model. Also the similarity of the model for "all" life forms and "therophyten" is visible in the figure (Appendix V).

Table 8 Results of the MLR's for relative abundance of the different life form groups against total annual rainfall. Model selection via forced entry, $F$ to enter: 3.84; F-to remove: 2.71. Presented are the goodness-of-fit parameters for the whole model for each life form group and the standardized beta coefficients for the model parameters (year_x; year_x_1, year_x_2) alongside with their significance values. $\mathrm{N}=480 ; \mathrm{dF}=(3,479)$. $\mathrm{ch}+\mathrm{ph}=$ chamaephytes \& phanerophytes; hemi= hemicryptophytes; geo= geophytes; thero= therophytes.

\begin{tabular}{lccccccccccc}
\hline & $\mathrm{R}_{\text {adj }}^{2}$ & $\mathrm{~F}$ & $\mathrm{p}$ & \multicolumn{2}{c}{ year_x-2 } & \multicolumn{2}{c}{ year_x-1 } & \multicolumn{2}{c}{ year_x } & Durbin/Watson \\
\hline & & & & beta & $\mathrm{p}$ & beta & $\mathrm{p}$ & beta & $\mathrm{p}$ & \\
all & .277 & 62.152 & .000 & .300 & .000 & .027 & .495 & -.355 & .000 & .749 \\
ch+ph & .040 & 7.626 & .000 & -.034 & .483 & .000 & 1.00 & -.221 & .000 & 1.764 \\
hemi & .472 & 143.930 & .000 & .603 & .000 & .115 & .001 & -.140 & .000 & 1.793 \\
geo & .515 & 170.783 & .000 & .652 & .000 & .168 & .000 & -.040 & .227 & .979 \\
thero & .248 & 53.678 & .000 & .289 & .000 & .021 & .607 & -.333 & .000 & .753 \\
\hline
\end{tabular}

\section{Seasonal rainfall}

In this section forward selected predictor variables of MLR models for the relative abundance of different life form groups are presented (Table 9). Full models would include the predictor variables spring, summer, winter and autumn rainfall of year_x, year_x-1 and year_x-2. All five models were highly significant.

Overall the obtained models were able to explain a high percentage of the variation in relative species abundances (50-65\%) within the life form groups (Table 9). Only the model for "chamaephytes \& 
phanerophytes" was an exception with $5 \%$. Winter and summer rainfall of the pre-previous year was entered in all five models and showed a positive relationship with the relative abundance of all groups besides the "hemicryptophytes" and "geophytes" for which summer rainfall of year_x-2 was negatively correlated. Winter rainfall had the strongest influence in all models besides for "chamaephytes \& phanerophytes" where summer rainfall of year_x-2 was highest correlated. Autumn rain of the same year was present in all models except for "hemicryptophytes" and showed a positive correlation for "all", "geophytes" and "therophytes" and a negative one for "chamaephytes \& phanerophytes". In contrast to the total annual rainfall models the grouping of species into life form groups did not further improve the explained variance of the models. Note that the low value for the Durbin-Watson statistic (1.097) for "geophytes" indicates the risk of autocorrelation and non independency of residuals.

In general the spring and winter rainfalls of the same year were often high correlated with each other and in this cases the spring rain was removed instead of the higher (therefore thought to be more important) winter rain. The models for seasonal and total rainfall of "chamaephytes \& phanerophytes" were by far the one with the lowest adjusted $\mathrm{R}^{2 \text { s }}$ (Table 9). This could be due to the fact that all three spring rain parameters and the summer rain of the same and previous year had to be removed to avoid collinearity and these variables might have been better suited to reflect the pattern of relative abundances for this group. Nevertheless a re-analysis with all 12 potential variables forced into the model made the situation not better with an adjusted $R^{2}$ of 0.42 and only DJF_x being added additionally to the three already existent parameters.

In comparison to the total annual rainfall models the further partition of the rainfall into seasons did not improve the quality of the models for the different life form groups. 
Table 9 Influence of seasonal rainfall on the relative abundance of different life form groups. Model selection via forced entry, $\mathrm{F}$ to enter: 3,84; F-to remove: 2,71. Full models would include the predictor variables spring (SON), summer (DJF), winter (JJA) and autumn (MAM) rainfall of year_x, year_x-1 and year_x-2. Excluded variables because of too high correlation $(r<.80)$ are given in brackets. Presented are the unstandardized $b$ coefficients with their Std. Error, the standardized beta coefficients, the t-test statistic and the Tolerance and VIF values to give an estimate of potential collinearity. ch+ ph =chamaephytes \& phanerophytes; hemi = hemicryptophytes; geo= geophytes; thero= therophytes. $\mathrm{SE}=\mathrm{Standard}$ Error

\begin{tabular}{|c|c|c|c|c|c|c|c|}
\hline & B & SE & Beta & $\mathrm{t}$ & $p$ & Tolerance & VIF \\
\hline \multicolumn{8}{|c|}{$\begin{array}{l}\text { all } \mathrm{N}=480 ; \text { Adjusted } \mathrm{R}^{2}=.647 ; \text { Durbin/Watson }=1,519 ; \\
\text { variables: SON_x,SON_x_1; SON_x_2; DJF_x and DFJ_x-1] }\end{array}$} \\
\hline Intercept & -1.441 & .126 & & -11.476 & .000 & & \\
\hline MAM_x & .018 & .002 & .287 & 8.160 & .000 & .595 & 1.680 \\
\hline MAM_x_1 & -.006 & .002 & -.116 & -3.373 & .001 & .622 & 1.608 \\
\hline JJA_x_2 & .032 & .001 & .891 & 25.914 & .000 & .623 & 1.604 \\
\hline DJF_x_2 & .018 & .006 & .096 & 3.019 & .003 & .736 & 1.359 \\
\hline \multicolumn{8}{|c|}{$\begin{array}{l}\text { ch+ph } N=480 ; \text { Adjusted } R^{2}=.044 ; \text { Durbin/Watson }=1.722 ; F(3,479)=8.403 . p=.000 \text { [excluded } \\
\text { variables: SON_x; SON_x-1; SON_x_2. DFJ_x and DJF_x-1] }\end{array}$} \\
\hline Intercept & .886 & .145 & & 6.093 & .000 & & \\
\hline MAM_x & -.004 & .002 & -.094 & -1.837 & .067 & .769 & 1.301 \\
\hline JJA_x_2 & .002 & .001 & .087 & 1.683 & .093 & .746 & 1.341 \\
\hline DJF_x_2 & .019 & .006 & .138 & 3.041 & .002 & .963 & 1.039 \\
\hline \multicolumn{8}{|c|}{ hemi $N=480 ;$ Adjusted $R^{2}=.501 ;$ Durbin/Watson $=1.892 ; F(2,479)=241.573 . p=.000$ [excluded } \\
\hline Intercept & -.846 & .139 & & -6.098 & .000 & & \\
\hline JJA_x-2 & .045 & .002 & .693 & 21.073 & .000 & .963 & 1.039 \\
\hline DJF_x-2 & -.116 & .011 & -.336 & -10.211 & .000 & .963 & 1.039 \\
\hline \multicolumn{8}{|c|}{ geo $N=480 ;$ Adjusted $R^{2}=.573 ;$ Durbin/Watson $=1.097 ; F(3,479)=215.407 . p=.000$. [excluded } \\
\hline \multicolumn{8}{|c|}{ variables: SON_x.SON_x_1; SON_x_2; DJF_x and DFJ_x-1] } \\
\hline Intercept & -1.139 & .235 & & -4.855 & .000 & & \\
\hline MAM_X & .009 & .004 & .088 & 2.583 & .010 & .769 & 1.301 \\
\hline JJA_x_2 & .047 & .002 & .765 & 22.145 & .000 & .746 & 1.341 \\
\hline DJF_x_2 & -.129 & .010 & -.398 & -13.096 & .000 & .963 & 1.039 \\
\hline \multicolumn{8}{|c|}{ thero $N=480 ;$ Adjusted $R^{2}=.623 ;$ Durbin/Watson $=1.485 ; F(4,479)=198.502 . p=.000$ [excluded } \\
\hline \multicolumn{8}{|c|}{ variables: SON_x.SON_x_1; SON_x_2; DJF_x and DFJ_x-1] } \\
\hline Intercept & -1.658 & .140 & & -11.848 & .000 & & \\
\hline MAM_x & .021 & .002 & .310 & 8.513 & .000 & .595 & 1.680 \\
\hline MAM_x-1 & -.006 & .002 & -.122 & -3.427 & .001 & .622 & 1.608 \\
\hline JJA_x-2 & .034 & .001 & .880 & 24.755 & .000 & .623 & 1.604 \\
\hline DJF_x-2 & .019 & .007 & .095 & 2.899 & .004 & .736 & 1.359 \\
\hline
\end{tabular}




\subsubsection{Vegetation}

On the 96 subplots in total 141 vascular plant taxa were recorded. Overall 28 families occurred with the six dominant families Asteraceae (30), Aizoaceae (14), Poaceae (11), Scrophulariaceae (11), Oxalidaceae (9) and Hyacinthaceae (9) accounting for over half of all species.

Dominant life forms are the therophytes with 68 species present, followed by geophytes (26) and chamaephytes (25). The most abundant species where the invasive Atriplex lindleyi ssp. inflata which is a alien chenopod saltbush introduced from Australia (Mills \& Cowling 2006) with 407 individual records, Karoochloa schismoides (328), Mesembryanthemum guerichianum (277), Salsola kali (243), Dimorphotheca sinuata (242), Galenia sarcophylla (229), Gazania tenuifolia (227), Ehrharta pusilla (217), Lebeckia multiflora (208), Aizoon canariense (203) and Helichrysum alsinoides (182).

\subsubsection{Total cover}

In general annuals accounted for a high percentage of mean total cover per subplot and year at Soebatsfontein with $51.15 \%$ in $2004,46.56 \%$ in $2005,27.3 \%$ in $2006,32.7 \%$ in 2007 and $42.59 \%$ in 2008 . Mean total cover was significantly higher at Patrysegat than at Quaggasfontein for all examined years (Appendix VI) and therefore the dataset was split according to camps for the following analysis.

\section{Patrysegat}

In 2008 unfenced subplots showed significantly higher mean total cover of perennials compared to fenced ones (Table 10). Because of these differences, the effect of the "active treatments" was analyzed separately for both plots.

Table 10 Differences between fenced and unfenced plots at Patrysegat for total cover, total cover annuals and total cover perennials. $\mathrm{p}$ values were obtained by Mann-Whitney- U-tests with applied Bonferroni-Holm correction. $\mathbf{N}=\mathbf{2 4}$. Note that the values for 2004 present the pre-treatment situation.

\begin{tabular}{lllllrllrlll}
\hline & & \multicolumn{4}{c}{ all } & \multicolumn{4}{c}{ annuals } & \multicolumn{5}{c}{ perennials } \\
year & grazing & mean & SD & $\mathrm{p}$ & mean & SD & $\mathrm{p}$ & mean & SD & $\mathrm{p}$ \\
2004 & fenced & 11,68 & 6,22 &, 821 & 6,63 & 5,89 &, 461 & 5,06 & 4,41 &, 058 \\
& unfenced & 11,79 & 5,01 & & 4,80 & 3,53 & & 6,99 & 4,52 & \\
2008 & fenced & 19,03 & 5,82 & \multirow{2}{*}{, 029} & 13,71 & 5,82 &, 144 & 5,32 & 4,29 &, 000 \\
& unfenced & 24,16 & 7,64 & & 16,27 & 7,48 & & 12,40 & 7,66 & \\
\hline
\end{tabular}

Mean total cover was significantly higher in 2008 compared to 2004 and this trend was existent for fenced and unfenced plots (Appendix VII). No effect of the active restoration treatments on annual or perennial cover could be detected in 2005- 2008, neither for the fenced nor for the unfenced part (Appendix VII). 


\section{Quaggasfontein}

Differences in vegetation cover between fenced and unfenced subplots in 2008 were found for annuals with higher mean total cover values for the fenced part (Table 11). An increase in mean total cover was found for 2008 compared to 2004 for both plots but only significant for the fenced part (Table 12).

Table 11 Differences between fenced and unfenced plots at Quaggasfontein regarding total cover, total cover annuals and total cover perennials. $p$ values were obtained by Mann-Whitney- U-tests with applied Bonferroni-Holm correction. $\mathbf{N}=\mathbf{2 4}$. Note that the values for $\mathbf{2 0 0 4}$ present the pre-treatment situation.

\begin{tabular}{llrlllllllll}
\hline & & \multicolumn{2}{c}{ all } & \multicolumn{4}{c}{ annuals } & \multicolumn{5}{c}{ perennials } \\
year & grazing & mean & SD & $\mathrm{p}$ & mean & SD & $\mathrm{p}$ & mean & SD & $\mathrm{p}$ \\
\multirow{2}{*}{2004} & fenced & 4.25 & 2.55 & .358 & 2.18 & 2.24 & .909 & 2.06 & 1.73 & .261 \\
& unfenced & 4.94 & 2.76 & & 2.19 & 1.45 & & 2.76 & 2.15 & \\
\multirow{2}{*}{2008} & fenced & 15.68 & 9.35 & .004 & 9.14 & 6.38 & .004 & 6.53 & 6.42 & .304 \\
& unfenced & 8.52 & 3.99 & & 4.50 & 4.11 & & 4.02 & 2.16 & \\
\hline
\end{tabular}

Mean annual cover of the fenced plot in 2006 was significantly higher under the "manure \& palm fronds" treatment. For the unfenced plot the "brushpack" treatment and to a lower degree the "manure \& palm fronds" treatment increased mean annual cover in 2006 (Table 12). 
Table 12 Results for differences between active treatments on mean total cover of annuals and perennials at fenced and unfenced subplots at Quaggasfontein. p-values were obtained by Kruskal-Wallis tests with applied Bonferroni-Holm correction; $\mathrm{dF}=3 ; \mathrm{N}=\mathbf{2 4}$. Small letters in bold behind the total means indicate group separation obtained by LFH tests with BonferroniHolm correction. The values for $\mathbf{2 0 0 4}$ are included to give an estimate of homogeneity of the subplots. MTC= mean total cover (annuals + perennials)

\begin{tabular}{|c|c|c|c|c|c|c|c|c|c|c|c|c|c|c|}
\hline \multirow[b]{2}{*}{ year } & \multicolumn{2}{|c|}{ control } & \multicolumn{2}{|c|}{ stones } & \multicolumn{2}{|c|}{ brushpack } & \multicolumn{2}{|c|}{ manure \& palm fronds } & \multicolumn{2}{|c|}{ annuals } & \multicolumn{2}{|c|}{ perennials } & \multicolumn{2}{|c|}{ MTC } \\
\hline & A & $P$ & A & $P$ & A & $P$ & A & $P$ & $\mathrm{Chi}^{2}$ & $p$ & $\mathrm{Chi}^{2}$ & $p$ & mean & SD \\
\hline \multicolumn{15}{|l|}{ fenced } \\
\hline 2004 & $1.92 \pm 2.00$ & $2.21 \pm 1.53$ & $2.02 \pm 2.12$ & $2.69 \pm 2.11$ & $1.58 \pm 2.55$ & $1.87 \pm 0.77$ & $3.21 \pm 2.97$ & $0.85 \pm 1.30$ & .642 & .897 & 3.697 & .300 & $4.25 a$ & 2.55 \\
\hline 2005 & $3.27 \pm 1.69$ & $1.89 \pm 1.41$ & $2.43 \pm 1.35$ & $1.79 \pm 1.57$ & $3.66 \pm 3.13$ & $2.36 \pm 3.15$ & $5.94 \pm 4.01$ & $0.97 \pm 1.31$ & 2.906 & .439 & 2.433 & .504 & $5.28 a$ & 2.69 \\
\hline 2006 & $3.51 a \pm 1.48$ & $2.77 \pm 1.65$ & $4.11 a \pm 3.22$ & $2.21 \pm 1.65$ & $5.82 \mathrm{a} \pm 2.24$ & $5.12 \pm 6.65$ & $18.92 \mathrm{~b} \pm 7.02$ & $4.27 \pm 1.99$ & 12.958 & .001 & 3.450 & .335 & $10.40 \mathrm{~b}$ & 7.99 \\
\hline 2007 & $6.03 \pm 3.47$ & $6.03 \pm 3.47$ & $3.39 \pm 2.18$ & $3.39 \pm 2.18$ & $7.57 \pm 6.61$ & $7.57 \pm 6.61$ & $12.39 \pm 7.94$ & $12.39 \pm 7.94$ & 3.587 & .330 & 6.426 & .082 & $14.48 c$ & 7.03 \\
\hline 2008 & $7.84 \pm 7.34$ & $5.76 \pm 4.27$ & $5.79 \pm 3.96$ & $4.10 \pm 1.75$ & $11.69 \pm 5.47$ & $10.98 \pm 15.86$ & $15.48 \pm 4.82$ & $9.32 \pm 6.21$ & 8.014 & .032 & 2.921 & .414 & $15.68 c$ & 9.35 \\
\hline \multicolumn{15}{|l|}{ unfenced } \\
\hline 2004 & $2.43 \pm 1.77$ & $2.84 \pm 2.51$ & $1.02 \pm 1.72$ & $4.38 \pm 2.54$ & $2.60 \pm 0.55$ & $2.03 \pm 0.98$ & $2.52 \pm 0.69$ & $1.70 \pm 1.07$ & 4.188 & .251 & 3.333 & .354 & $4.94 a b$ & 2.76 \\
\hline 2005 & $2.01 \pm 0.98$ & $1.68 \pm 1.36$ & $1.36 \pm 0.56$ & $2.93 \pm 2.53$ & $2.07 \pm 1.24$ & $1.31 \pm 0.79$ & $1.85 \pm 2.07$ & $2.02 \pm 1.34$ & 2.854 & .436 & 1.740 & .651 & $3.78 a$ & 1.82 \\
\hline 2006 & $2.25 a \pm 1.89$ & $1.76 \pm 1.30$ & $1.74 a \pm 0.97$ & $1.81 \pm 1.12$ & $14.23 c \pm 9.90$ & $5.09 \pm 5.78$ & $11.50 \mathrm{~b} \pm 4.49$ & $3.13 \pm 2.85$ & 14.351 & .001 & 2.564 & .477 & $9.32 \mathrm{bc}$ & 7.47 \\
\hline 2007 & $8.32 \pm 4.53$ & $3.31 \pm 2.26$ & $4.78 \pm 3.95$ & $5.06 \pm 4.40$ & $7.61 \pm 5.02$ & $5.40 \pm 3.37$ & $11.27 \pm 3.58$ & $2.86 \pm 1.07$ & 5.529 & .136 & 2.014 & .594 & $12.07 c$ & 4.02 \\
\hline 2008 & $3.88 \pm 3.35$ & $4.15 \pm 2.27$ & $3.77 \pm 3.86$ & $3.76 \pm 2.28$ & $6.88 \pm 7.05$ & $3.03 \pm 2.72$ & $3.94 \pm 1.17$ & $5.04 \pm 1.09$ & 2.678 & .464 & 2.609 & .469 & $8.52 b$ & 3.99 \\
\hline
\end{tabular}




\subsubsection{Number of Individuals}

Annuals accounted for over $70 \%$ of mean number of individuals per subplot in $2004,92 \%$ in $2005,88 \%$ in 2006 , $73 \%$ in 2007 and $89 \%$ in 2008.

The results showed significant higher number of individuals at Patrysegat compared to Quaggasfontein for 2008 and 2005 (Appendix VIII). In general the fluctuations between the years were strong with highest number of all individuals for 2008 [Patrysegat: $497.08 \pm 317.77$; Quaggasfontein: $344.13 \pm 175.624$ ].

\section{Patrysegat:}

The mean number of individuals at Patrysegat was higher for the fenced plot in 2008 but not significantly (Table 13). The higher numbers were caused by a higher abundance of annuals whereas perennials showed higher numbers in the unfenced part.

Table 13 Results for differences between fenced and unfenced plots for mean number of all individuals, annuals and perennials at Patrysegat. p-values were obtained by Mann-Whitney- U-tests, $\mathrm{N}=\mathbf{4 8}$.

\begin{tabular}{llllllllllll}
\hline & & \multicolumn{3}{c}{ all individuals } & \multicolumn{3}{c}{ annuals } & \multicolumn{4}{c}{ perennials } \\
year & grazing & mean & SD & $\mathrm{p}$ & mean & SD & $\mathrm{p}$ & mean & SD & $\mathrm{p}$ & \\
2004 & fenced & 59.75 & 38.74 & .099 & 28.57 & 21.79 & .062 & 31.07 & 34.43 & .488 \\
& unfenced & 44.17 & 34.48 & & 21.21 & 24.15 & & 23.08 & 23.50 \\
\multirow{2}{*}{2008} & fenced & 556.46 & 412.45 & .741 & 526.08 & 403.29 & .488 & 33.67 & 15.52 & .160 \\
& unfenced & 437.71 & 169.91 & & 396.29 & 161.16 & & 41.42 & 18.82 & \\
\hline
\end{tabular}

Mean number of individuals in fenced and unfenced subplots was was significantly higher in 2008 compared to 2004 (Table 14). Effects of the active restoration treatments for the fenced subplots were found for annuals in 2005, 2007 and 2008 (Table 14) but post-hoc tests were not able to separate groups. Nevertheless the mean number of annuals was lowest for the "brushpack" and "manure \& palm fronds" treatments. Also perennials in 2006 showed an overall significant treatment effect while no group separation could be achieved either. Here the "brushpack" treatment possessed the lowest mean cover values.

For the unfenced subplots a significant effect of the "active restoration treatments" was found for number of perennials in 2005 with significant lower values under the "brushpack" treatment. 
Table 14 Differences between active treatments on total number of annuals and perennials at fenced and unfenced subplots at Patrysegat. p-values are obtained by Kruskal-Wallis tests with

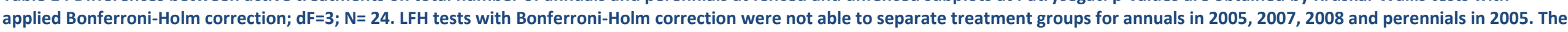
values for 2004 are included to give an estimate of homogeneity of the subplots. $\mathrm{MNI}=$ mean number of individuals

\begin{tabular}{|c|c|c|c|c|c|c|c|c|c|c|c|c|c|c|}
\hline & \multicolumn{2}{|c|}{ control } & \multicolumn{2}{|c|}{ stones } & \multicolumn{2}{|c|}{ brushpack } & \multicolumn{2}{|c|}{ manure \& fronds } & \multicolumn{2}{|c|}{ annuals } & \multicolumn{2}{|c|}{ perennials } & \multicolumn{2}{|c|}{$\mathrm{MNI}$} \\
\hline year & A & $P$ & $A$ & $P$ & A & $P$ & A & $P$ & $\mathrm{Chi}^{2}$ & $p$ & $\mathrm{Chi}^{2}$ & $p$ & mean & SD \\
\hline \multicolumn{15}{|c|}{ fenced } \\
\hline 2004 & $22,93 \pm 19,47$ & $41,44 \pm 48,05$ & $41,49 \pm 26,65$ & $17,77 \pm 16,68$ & $19,31 \pm 9,58$ & $24,60 \pm 29,32$ & $35,07 \pm 26,99$ & $32,20 \pm 23,30$ & 4,040 & ,266 & 1,905 & ,614 & $59,75 a$ & 38,74 \\
\hline 2005 & $454,11 \pm 243,31$ & $86,78 \pm 73,30$ & $538,40 \pm 369,66$ & $31,20 \pm 20,49$ & $145,40 \pm 25,32$ & $6,00 \pm 3,94$ & $104,60 \pm 42,79$ & $11,40 \pm 7,70$ & 15,400 & , 000 & 12,612 & ,001 & $377,21 b c$ & 289,32 \\
\hline 2006 & $330,54 \pm 412,39$ & $15,00 \pm 9,17$ & $471,10 \pm 721,11$ & $10,60 \pm 4,28$ & $103,92 \pm 50,36$ & $5,60 \pm 3,44$ & $99,06 \pm 49,11$ & $10,60 \pm 4,39$ & 2,932 & ,422 & 6,241 & 095 & $275,58 a b$ & 414,89 \\
\hline 2008 & $690,78 \pm 445,03$ & $42,67 \pm 17,20$ & $745,40 \pm 454,33$ & $32,20 \pm 10,62$ & $207,80 \pm 141,84$ & $20,20 \pm 3,63$ & $328,60 \pm 126,54$ & $32,40 \pm 15,95$ & 10,158 & ,010 & 7,077 & ,062 & $556,46 c$ & 412,45 \\
\hline \multicolumn{15}{|c|}{ unfenced } \\
\hline 2004 & $17,01 \pm 21,11$ & $27,22 \pm 23,22$ & $26,77 \pm 24,54$ & $36,66 \pm 37,43$ & $21,80 \pm 23,27$ & $12,93 \pm 9,50$ & $22,60 \pm 35,20$ & $12,20 \pm 7,73$ & 2,950 & ,419 & 2,075 &, 578 & $44,17 a$ & 34,48 \\
\hline 2005 & $474,05 \pm 455,68$ & $67,24 a \pm 39,85$ & $571,59 \pm 330,26$ & $55,73 a \pm 39,94$ & $374,59 \pm 132,69$ & $9,00 b \pm 5,66$ & $257,44 \pm 199,92$ & $22,48 a \pm 9,23$ & 3,460 & ,343 & 12,374 & ,002 & $471,92 d$ & 342,13 \\
\hline 2006 & $224,14 \pm 114,36$ & $31,44 \pm 22,34$ & $154,74 \pm 61,08$ & $37,40 \pm 15,50$ & $89,30 \pm 37,80$ & $13,60 \pm 5,94$ & $143,11 \pm 101,07$ & $24,60 \pm 7,50$ & 6,596 & ,082 & 7,501 & ,047 & $192,13 c$ & 99,39 \\
\hline 2008 & $494,44 \pm 161,43$ & $48,22 \pm 18,61$ & $409,80 \pm 135,76$ & $49,40 \pm 19,88$ & $297,60 \pm 169,43$ & $23,40 \pm 12,30$ & $304,80 \pm 74,50$ & $39,20 \pm 14,20$ & 8,462 & ,028 & 7,136 & ,059 & $437,71 \mathrm{~d}$ & 169,91 \\
\hline
\end{tabular}




\section{Quaggasfontein:}

At Quaggasfontein unfenced plots in 2008 showed significantly higher number of individuals than fenced ones (Table 15) and this effect was driven by annuals rather than perennials which showed even lower numbers for 2008. The further analysis was conducted with unfenced and fenced subplots separately.

Table 15 Results for differences between fenced and unfenced plots for mean number of all individuals, annuals and perennials at Quaggasfontein. p-values were obtained by Mann-Whitney- U-tests with applied Bonferroni-Holm correction, $\mathrm{N}=48$.

\begin{tabular}{|c|c|c|c|c|c|c|c|c|c|c|}
\hline \multirow[b]{2}{*}{ year } & \multirow[b]{2}{*}{ grazing } & \multicolumn{3}{|c|}{ all individuals } & \multicolumn{2}{|c|}{ annuals } & \multicolumn{4}{|c|}{ perennials } \\
\hline & & mean & SD & $p$ & mean & SD & $\mathrm{p}$ & mean & SD & $p$ \\
\hline \multirow[t]{2}{*}{2004} & fenced & 75.58 & 40.06 & .052 & 68.53 & 39.83 & .027 & 7.08 & 5.46 & .529 \\
\hline & unfenced & 56.33 & 25.65 & & 48.29 & 23.83 & & 7.96 & 8.81 & \\
\hline \multirow[t]{2}{*}{2008} & fenced & 261.46 & 98.38 & .001 & 199.50 & 89.83 & .000 & 62.50 & 46.81 & .713 \\
\hline & unfenced & 426.79 & 197.70 & & 369.88 & 198.74 & & 57.46 & 41.67 & \\
\hline
\end{tabular}

Mean number of individuals were significantly higher in 2008 compared to 2004 within fenced and unfenced plots (Appendix X). No clear pattern among treated subplots and control was visible and no significant differences between treatment groups neither for annuals nor for perennials were found for fenced or unfenced plots (Appendix X).

\subsubsection{Species richness}

Species richness was significantly higher at Quaggasfontein than at Patrysegat for 2007 and 2008 (Table 16). In general annuals accounted for a high percentage of species at Soebatsfontein with $44.01 \%$ in $2004,60.46 \%$ in $2005,68.43 \%$ in $2006,67.51 \%$ in 2007 and $65.44 \%$ of mean species richness in 2008.

Table 16 Differences in species richness between Patrysegat and Quaggasfontein for 2004-2008. p values were obtained by Mann-Whitney $\mathrm{U}$ tests with applied Bonferroni-Holm correction; $\mathbf{N}=48$.

\begin{tabular}{llllll}
\hline & \multicolumn{4}{l}{ Patreisegat } & \multicolumn{4}{l}{ Quaggasfontein } \\
\hline year & \multicolumn{2}{l}{ mean \pm SD } & \multicolumn{2}{l}{ mean \pm SD } & $\mathrm{p}$ \\
2004 & 5.81 & 2.18 & 4.85 & 1.49 & .030 \\
2005 & 9.88 & 3.68 & 9.35 & 2.40 & .949 \\
2006 & 12.71 & 3.50 & 13.23 & 2.55 & .163 \\
2007 & 15.87 & 3.73 & 17.98 & 3.22 & .001 \\
2008 & 17.13 & 4.01 & 23.21 & 4.68 & .000 \\
\hline
\end{tabular}




\section{Patrysegat:}

Species richness at Patrysegat was significantly higher for the unfenced plot for 2008 (Table 17) and this difference was caused by significantly higher values of annuals and perennials.

Table 17 Difference in species richness of annuals, perennials and all species between fenced and unfenced subplots at Patrysegat. $\mathrm{p}$ values were obtained by Mann-Whitney-U tests, $\mathrm{N}=\mathbf{2 4}$.

\begin{tabular}{llllllllllll}
\hline & & \multicolumn{3}{c}{ all species } & \multicolumn{3}{c}{ annuals } & \multicolumn{5}{c}{ perennials } \\
year & grazing & mean & SD & $p$ & mean & SD & $p$ & mean & SD & $p$ & \\
2004 & fenced & 6.04 & 2.71 & .877 & 2.96 & 1.60 & .062 & 3.08 & 1.53 & .228 \\
& unfenced & 5.58 & 1.50 & & 2.08 & 0.72 & & 3.50 & 1.35 & \\
\multirow{2}{*}{2008} & fenced & 15.25 & 3.81 & .001 & 10.63 & 3.10 & .022 & 4.63 & 1.66 & .001 \\
& unfenced & 19.00 & 3.32 & & 12.71 & 2.61 & & 6.29 & 1.68 & \\
\hline
\end{tabular}

No effect of the "active treatments" on species richness in 2005-2008 neither for annuals nor for perennials was found for Patrysegat (Appendix $\mathrm{XI}$ ). Species richness of both life form groups and for both plots was significantly higher in 2008 than 2004 (Appendix XI).

\section{Quaggasfontein:}

Species richness of annuals and perennials was significantly higher for fenced subplots compared to unfenced ones in 2008 and for annuals in 2004 (Table 18).

Table 18 Difference in species richness of annuals and perennials between fenced and unfenced plots at Quaggasfontein. $\mathrm{p}$-values were obtained by Mann-Whitney-U tests, $\mathrm{N}=\mathbf{2 4}$; dF =1.

\begin{tabular}{llllllllllll}
\hline & & \multicolumn{3}{c}{ all species } & \multicolumn{3}{c}{ annuals } & \multicolumn{5}{c}{ perennials } \\
year & grazing & mean & SD & $p$ & mean & SD & $p$ & mean & SD & $p$ \\
2004 & fenced & 5.14 & 1.52 & 0.880 & 2.41 & 0.73 & .015 & 2.73 & 1.39 & .546 \\
& unfenced & 4.83 & 1.37 & & 1.91 & 0.60 & & 2.91 & 1.38 & \\
\multirow{2}{*}{2008} & fenced & 25.68 & 4.86 & .000 & 15.95 & 3.70 & .007 & 9.73 & 2.14 & .001 \\
& unfenced & 20.96 & 3.24 & & 13.61 & 2.59 & & 7.35 & 1.53 \\
\hline
\end{tabular}

For 2005 species richness of perennial plants in the fenced plot was significantly lower under the "brushpack" and "manure \& palm fronds" treatments compared to the "control" (Table 19). In 2007 annual species richness on fenced subplots was significantly lower under the "manure \& palm fronds" treatment compared to the "control" and "stones" one. No significant "active treatment" effect was found for the unfenced plot. Mean species richness increased from year to year (2004-2008) significantly within both plots (Table 19).

The general impression is that the "manure \& palm fronds" and the "brushpack" treatment had the strongest effect, whereas the "stones" treatment was never significantly different to the "control" for any of the examined parameters. While the latter mentioned treatments had a positive effect on total cover of annuals and perennials in some years their effect on species richness and abundances was throughout negative 
Table 19 Differences between active treatments for mean species richness of annuals and perennials at fenced and unfenced subplots at Quaggasfontein. $p$ values were obtained by Kruskal-Wallis tests; $\mathrm{dF}=\mathbf{3}$. Small letters in bold behind group means indicate group separation by LSH with applied Bonferroni-Holm correction. MSR= mean species richness

\begin{tabular}{|c|c|c|c|c|c|c|c|c|c|c|c|c|c|c|}
\hline & control & & stones & & brush & & manure \& palm & ronds & annuals & & perenni & & MSR & \\
\hline $\begin{array}{l}\text { year } \\
\text { fenced }\end{array}$ & A & $P$ & A & $P$ & A & $P$ & A & $P$ & $\mathrm{Chi}^{2}$ & $p$ & $\mathrm{Chi}^{2}$ & $p$ & mean & SD \\
\hline 2004 & $2.29 \pm 0.76$ & $3.29 \pm 1.98$ & $2.50 \pm 0.76$ & $2.75 \pm 1.04$ & $2.67 \pm 0.58$ & $2.33 \pm 0.58$ & $2.25 \pm 0.96$ & $2.00 \pm 1.15$ & 1.034 & .814 & 2.942 & .421 & $4.92 a$ & 1.64 \\
\hline 2005 & $6.71 \pm 1.38$ & $6.14 a \pm 2.04$ & $5.67 \pm 1.12$ & $3.89 a b \pm 1.69$ & $6.00 \pm 2.00$ & $2.00 b \pm 1.00$ & $5.40 \pm 0.55$ & $2.60 b \pm 1.14$ & 4.586 & .213 & 11.222 & .005 & $10.00 \mathrm{~b}$ & 2.48 \\
\hline 2006 & $9.29 \pm 1.11$ & $5.86 \pm 1.68$ & $5.67 \pm 1.12$ & $3.56 \pm 1.67$ & $9.67 \pm 1.15$ & $3.67 \pm 2.08$ & $9.80 \pm 1.10$ & $4.40 \pm 1.52$ & .896 & .845 & 6.953 & .066 & $13.88 \mathrm{c}$ & 2.01 \\
\hline 2007 & $12.00 \mathrm{a} \pm 1.83$ & $8.57 \pm 2.76$ & $12.33 a \pm 1.73$ & $4.89 \pm 2.09$ & $10.67 a b \pm 1.53$ & $5.00 \pm 2.65$ & $8.20 b \pm 1.48$ & $5.40 \pm 1.14$ & 11.087 & .004 & 7.925 & .035 & $17.25 \mathrm{~d}$ & 4.02 \\
\hline $\begin{array}{l}2008 \\
\text { unfen }\end{array}$ & $14.71 \pm 3.50$ & $10.57 \pm 2.76$ & $16.75 \pm 3.15$ & $9.13 \pm 1.64$ & $15.67 \pm 4.04$ & $9.33 \pm 2.08$ & $16.75 \pm 5.56$ & $9.75 \pm 2.22$ & 1.525 & .700 & 1.488 & .713 & $25.54 \mathrm{e}$ & 4.82 \\
\hline 2004 & $2.38 \pm 0.52$ & $2.38 \pm .06$ & $1.60 \pm 0.55$ & $2.40 \pm 1.34$ & $1.60 \pm 0.55$ & $3.40 \pm 1.14$ & $1.80 \pm 0.45$ & $3.80 \pm 1.79$ & 3.961 & .294 & 3.107 & .404 & 4.79a & 1.35 \\
\hline 2005 & $5.56 \pm 1.33$ & $3.56 \pm 1.59$ & $5.20 \pm 0.45$ & $4.40 \pm 1.67$ & $5.20 \pm 1.30$ & $2.60 \pm 1.67$ & $4.80 \pm 1.10$ & $3.20 \pm 1.30$ & .806 & .861 & 2.566 & .486 & $8.71 b$ & 2.18 \\
\hline 2006 & $9.89 \pm 1.62$ & $3.67 \pm 1.22$ & $8.80 \pm 2.49$ & $3.20 \pm 2.28$ & $8.00 \pm 2.35$ & $3.00 \pm 1.41$ & $9.60 \pm 0.89$ & $3.40 \pm 1.52$ & 2.153 & .560 & .685 & .892 & $12.58 \mathrm{c}$ & 2.89 \\
\hline 2007 & $14.00 \pm 1.12$ & $5.00 \pm 0.71$ & $14.40 \pm 2.19$ & $4.80 \pm 2.28$ & $12.00 \pm 2.00$ & $4.80 \pm 1.30$ & $13.40 \pm 1.52$ & $6.20 \pm 0.84$ & 4.736 & .192 & 4.696 & .205 & $18.71 d$ & 1.97 \\
\hline 2008 & $14.50 \pm 2.45$ & $7.50 \pm 2.07$ & $13.60 \pm 1.82$ & $7.60 \pm 1.34$ & $12.00 \pm 1.58$ & $7.60 \pm 1.34$ & $13.80 \pm 3.96$ & $7.60 \pm 0.89$ & 2.171 & .560 & 2.057 & .583 & $20.88 \mathrm{e}$ & 3.19 \\
\hline
\end{tabular}




\subsection{Ratelgat}

In total 170 vascular plant taxa were recorded for the experimental plots at Ratelgat. 25 families occurred with the three dominant families Aizoaceae (63), Asteraceae (37) and Chenopodiaceae (15) accounting for over two third of all species. Dominant life forms are chamaephytes (106) followed by theroyphtes (41) and geophytes (15). The most abundant species occurring were Ruschia burtonia with 1289 individuals, Antimima solida (70), Ruschia lasti (54), Cephalophyllum staminodiosum (29), Atriplex lindleyi ssp. inflata (31) and Tetragonia fruticosa (35).

Note that the vegetation records for the two quartz field communities in 2004 present the pre-treatment situation. They are nevertheless included in some graphs and analyses if the focus is on differences between years rather than treatment effects.

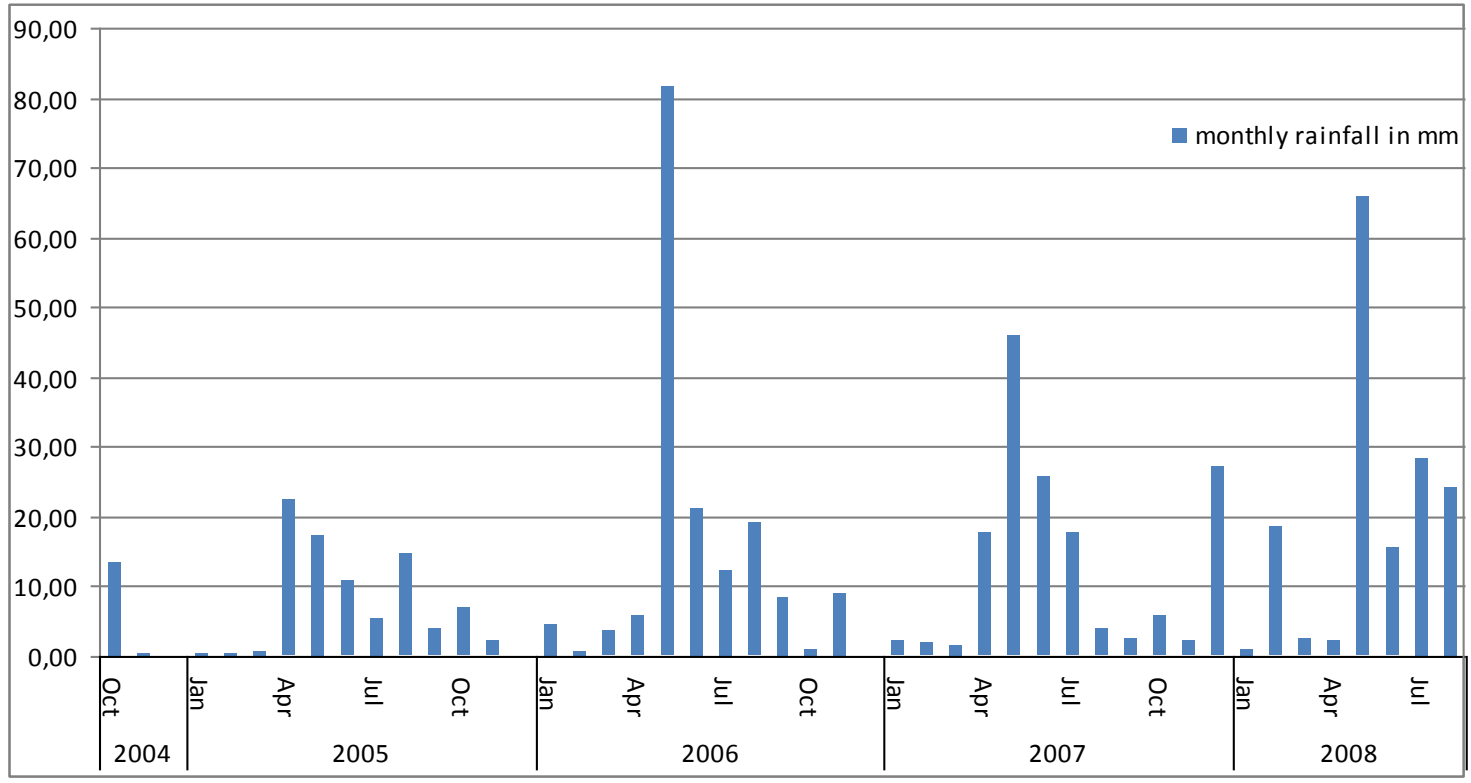

Figure 11 Monthly precipitation for the climate station Ratelgat from October 2004 when the treatments were installed until August 2008.

At Ratelgat the mean total annual rainfall for the period April 2001- August 2008 was 124.5 mm (Appendix XII). The years 2006, 2007 and 2008 (in ascending magnitude) were above average rainfall years while 2003 with $69.2 \mathrm{~mm}$ and 2004 with $73.84 \mathrm{~mm}$ annual rainfall were comparably dry. Note the poor rainfall conditions following the treatment installation in October 2004 (Figure 11). 


\subsubsection{Ruschia burtoniae Community}

\section{Effect of treatments}

There was no significant treatment effect on number of individuals or species richness in 2005 and 2008 (Table 20).

Table 20 Differences between treatments for number of individuals and species richness of the Ruschia burtoniae community plots at Ratelgat. $\mathrm{p}$-values were obtained by Kruskal-Wallis tests; $\mathrm{dF}=2 ; \mathrm{N}=30$.

\begin{tabular}{lcccccccc}
\hline parameter & \multicolumn{2}{c}{ control } & \multicolumn{2}{c}{ stones } & \multicolumn{2}{c}{ leveling } & \multicolumn{2}{c}{$\mathrm{p}$} \\
\hline individuals_04 pre-treatment & 3.10 & 3.70 & 4.30 & 5.03 & & 4.40 & 5.52 & \\
individuals_05 & 12.80 & 13.36 & 28.50 & 42.07 & 21.50 & 39.51 & 1.724 & .429 \\
individuals_08 & 43.60 & 48.73 & 37.50 & 35.37 & 33.10 & 36.62 & .473 & .797 \\
species richness 04 & 1.30 & 1.06 & 1.90 & 2.03 & 1.30 & 1.25 & .420 & .813 \\
species richness 05 & 4.30 & 3.95 & 5.50 & 5.44 & 4.80 & 6.48 & .412 & .823 \\
species richness 08 & 2.60 & 1.71 & 3.40 & 2.07 & 2.70 & 2.00 & .946 & .628 \\
\hline
\end{tabular}

The effect of treatments on total cover per plot in 2005 was analyzed with a one-way ANOVA and revealed no significant change of mean total cover, although the values under the "stones" and "levelling" treatment were higher as the control (Table 21).

Table 21 Summary of the one-way ANOVA results for total cover (2005) for differences between treatments of the Ruschia burtoniae community plots at Ratelgat, $\mathrm{dF}=2 ; \mathrm{N}=30 .{ }^{1}$ Result for sqrt transformed data.

\begin{tabular}{llllllllll}
\hline parameter & \multicolumn{2}{c}{ control } & \multicolumn{2}{c}{ stones } & \multicolumn{2}{c}{ levelling } & $F$ & $p$ \\
& mean \pm SD & \multicolumn{2}{c}{ mean \pm SD } & \multicolumn{2}{c}{ mean \pm SD } & \\
\hline total_cover_2004_(pre-treatment) & 1.41 & 1.80 & 1.35 & 1.71 & 1.19 & 1.324 & & \\
total_cover_2005 & 1.70 & 1.51 & 3.06 & 3.59 & 2.72 & 4.139 & .128 & $.881^{1}$ \\
\hline
\end{tabular}

The effect of the restoration treatments on the number of individuals of the keystone species Ruschia burtoniae was not significant (Table 22).

Table 22 Differences for number of individuals of Ruschia burtonia at Ratelgat under the three different treatments for $\mathbf{2 0 0 5}$ and 2008. p-values were obtained by Kruskal-Wallis tests; dF=2.

\begin{tabular}{lccccccccc}
\hline parameter & \multicolumn{2}{c}{ control } & \multicolumn{2}{c}{ stones } & \multicolumn{2}{c}{ levelling } & $F$ & P \\
& \multicolumn{2}{c}{ mean \pm SD } & \multicolumn{2}{c}{ mean \pm SD } & \multicolumn{2}{c}{ mean \pm SD } & \\
\hline Ruschia_individuals_2004 & 2.00 & 3.266 & 2.20 & 2.741 & 2.60 & 4.033 & \\
Ruschia_individuals_2005 & 3.70 & 3.199 & 13.30 & 19.04 & 8.20 & 11.053 & 2.748 & .260 \\
Ruschia_individuals_2008 & 40.50 & 48.523 & 33.10 & 33.89 & 29.60 & 33.745 & .183 & .913 \\
\hline
\end{tabular}

\section{Effect of time}

Numbers of individuals in 2008 were significantly higher as 2004 (Table 23). Species richness increased towards 2005 and was 2008 on a higher level than 2004 but lower than in 2005. Total cover in 2005 was not significantly different to 2004 but showed a slight positive trend (Table 23). 
Table 23 Differences between years for number of individuals, species richness and total cover of the Ruschia burtoniae community plots at Ratelgat. p-values were obtained by Kruskal-Wallis and Mann-Whitney $U$ tests ${ }^{1}$ test statistic for log transformed data. $\mathrm{N}=30 ; \mathrm{dF}=2 / 1$. Small letters in bold behind means indicate significant differences according to LSH tests with Bonferroni-Holm correction.

\begin{tabular}{|c|c|c|c|c|c|c|c|c|}
\hline parameter & 2004 & & 2005 & & 2008 & & $\mathrm{H} / \mathrm{U}$ & $p$ \\
\hline & mean & SD & mean & SD & mean & SD & & \\
\hline individuals & $3.93 a$ & 4.68 & $20.93 a b$ & 33.64 & $38.07 b$ & 39.50 & 34.627 & .000 \\
\hline species richness & $1.77 a$ & 1.25 & $4.93 b$ & 5.17 & $2.90 \mathrm{ab}$ & 1.90 & 13.940 & $.001^{1}$ \\
\hline total cover & 1.31 & 1.57 & 2.49 & 3.22 & & & 343.500 & 0.562 \\
\hline
\end{tabular}

\subsubsection{Cephalophyllum spissum Community}

\section{Effect of treatments}

Treatment showed a significant effect on number of individuals in 2005 with a significant increase under the "planting" treatment (Table 24). In 2008 the "stones" treatment had significantly higher number of individuals and a significant treatment effect was stated, but post-hoc tests were too conservative to separate this treatment from the remaining two groups (Table 24). Species richness and total cover showed no significant treatment effect, but the development under the "stones", "planting" and "leveling" treatment was better than within the "control" plots.

Table 24 Summary of the results for species richness, number of individuals and total cover for the Cephalophyllum spissum community plots at Ratelgat. ANOVA with $\mathrm{F}(3,43 / 39)$ and ${ }^{1}$ Kruskal-Wallis tests were performed. Bold small letters behind the mean values indicate significant differences according to LSH tests with Bonferroni-Holm correction (no group separation could be achieved for individuals 2008).

\begin{tabular}{|c|c|c|c|c|c|c|c|c|c|c|}
\hline parameter & \multicolumn{2}{|c|}{ control } & \multicolumn{2}{|c|}{ stones } & \multicolumn{2}{|c|}{ planting } & \multicolumn{2}{|c|}{ leveling } & $\mathrm{F} / \mathrm{H}$ & $\mathrm{p}$ \\
\hline species_richness_2004 & 1.67 & 1.83 & 1.30 & 1.34 & 1.27 & 1.62 & 1.60 & 1.51 & & \\
\hline species_richness_2005 & 5.00 & 3.41 & 5.60 & 2.88 & 5.82 & 4.09 & 4.00 & 2.54 & .619 & .607 \\
\hline species_richness_2008 & 4.40 & 1.27 & 5.30 & 2.26 & 5.60 & 2.675 & 5.44 & 2.35 & 2.282 & .530 \\
\hline individuals_2004 & 3.50 & 3.23 & 3.70 & 4.19 & 2.55 & 3.48 & 3.60 & 4.25 & & \\
\hline individuals_2005 & $12.92 \mathrm{a}$ & 11.10 & $31.40 a b$ & 25.03 & $37.45 b$ & 22.68 & $12.60 \mathrm{a}$ & 7.49 & 12.67 & $.005^{1}$ \\
\hline individuals_2008 & 17.60 & 11.11 & 35.70 & 14.81 & 31.10 & 18.72 & 26.11 & 13.49 & 9.019 & $.029^{1}$ \\
\hline cover_total_2004 & 1.90 & 2.76 & 2.33 & 4.10 & 1.03 & 1.69 & 1.59 & 1.17 & & \\
\hline cover_total_2005 & 4.35 & 5.40 & 2.89 & 2.37 & 4.21 & 1.85 & 2.26 & 1.74 & 5.097 & $.161^{1}$ \\
\hline
\end{tabular}

The trend of the Cephalophyllum spissum individuals alone was similar to "all" species with significant higher number of individuals under the "planting" treatment in 2005 and significantly lower individuals in 2005 for the "levelling" treatment (Table 25). Although a trend of higher individual numbers for all three restoration treatments is visible in 2008 it is not significant contrary to the findings for "all" individuals together in the same year. 
Table 25 Differences between the treatments for number of Cephalophyllum spissum individuals at Ratelgat. p values were obtained by Kruskal-Wallis tests. $\mathrm{N}=\mathbf{4 3}$ for 2004 and 2005 and $\mathbf{3 9}$ for 2008 . Bold small letters behind the means indicate significant differences according to LSH tests with Bonferroni-Holm correction.

\begin{tabular}{lrlrlrrrrrr}
\hline & control & & stones & & planting & & leveling & $H$ & $\mathrm{p}$ \\
\hline & mean & SD & mean & SD & mean & SD & mean & SD & & \\
C.spissum_04 & .83 & 1.12 & .56 & .88 & .09 & .30 & .90 & .302 & \\
C.spissum_05 & $1.85 \mathrm{ac}$ & 2.54 & $5.33 \mathrm{a}$ & 7.30 & $16.18 \mathrm{~b}$ & 4.02 & $.10 \mathrm{c}$ & .316 & 27.353 & .000 \\
C.spissum_08 & 1.30 & 1.42 & 3.33 & 3.97 & 9.10 & 11.86 & 4.89 & 7.66 & 4.328 & .229 \\
\hline
\end{tabular}

\section{Effect of time}

Differences between years were significant for number of individuals, species richness and total cover showing a significant increase from 2004 to 2005 and a further not significant increase of individuals and species richness compared to 2008 (Table 26).

Table 26 Differences between years for species richness, number of individuals and total cover of the Cephalophyllum spissum community, Ratelgat. p-values were obtained by ${ }^{1}$ Kruskal-Wallis or ${ }^{2}$ Mann-Whitney U-test; $d F=2 / 1 . N=43 / 39$. Small letters in bold behind means indicate groups according to LSH tests with applied Bonferroni-Holm correction.

\begin{tabular}{|c|c|c|c|c|c|c|c|c|}
\hline \multirow[t]{2}{*}{ parameter } & \multicolumn{2}{|c|}{2004} & \multicolumn{2}{|c|}{2005} & \multicolumn{2}{|c|}{2008} & \multirow[t]{2}{*}{$\mathrm{H} / \mathrm{U}$} & \multirow[t]{2}{*}{$p$} \\
\hline & mean & SD & mean & SD & mean & SD & & \\
\hline individuals & $3,33 a$ & 3,67 & $23,42 b$ & 20,67 & $27,67 b$ & 15,80 & 62,726 &, $000^{1}$ \\
\hline species richness & $1,45 a$ & 1,53 & $5,12 b$ & 3,27 & $5,18 b$ & 2,16 & 52,303 &, $000^{1}$ \\
\hline total_cover & $1,71 \mathrm{a}$ & 2,61 & $3,49 b$ & 3,33 & & & 453,000 &, $000^{2}$ \\
\hline
\end{tabular}

\section{Brushpack treatment}

For the 19 plots the combined treatment effect of levelling and brushpacking and the potential negative impact of their installation are examined. Two of the 19 brushpack plots have not been revisited in 2008. Imputing of the missing values was not possible. Thus, 8 control and 9 treatment plots remained within the analysis for 2008.

Out of the 775 individual records for 9 records the life form type could not be identified unambiguously and they were grouped into a separate "unknown" class. "Hemicryptophytes" occurred only in one plot in 2008 and were not analyzed separately.

\section{Effect of treatments}

The only significant treatment effect on number of individuals was found for "therophytes" in 2005 (Table 27). All other life form groups showed no significant treatment effect for 2005 or 2008. In general the tendency to higher number of individuals under the "brushpack" treatment was given for "all individuals" and "therophytes", but not for "geophytes", "chamaephytes" or the unidentified unknown species. 
Table 27 Differences between "control" and "brushpack" treatment plots for number of individuals of different life form groups at Ratelgat (zonal habitat). $p$ values were obtained by ANOVAs with $F(1,19)^{1}, F(1,17)^{2}$ or Mann-Whitney U-tests ${ }^{3}$.

\begin{tabular}{lrlrlll}
\hline parameter & \multicolumn{2}{c}{ control } & brushpacking & $\mathrm{F} / U$ & $\mathrm{p}$ \\
\hline & mean & SD & mean & SD & & \\
all_2004 (pre treatment) & 86.67 & 153.75 & 42.80 & 43.08 & & \\
all_2005 & 240.22 & 216.68 & 303.40 & 129.97 & .609 & $.446^{1}$ \\
all_-2008 & 79.75 & 42.26 & 94.33 & 43.57 & .488 & $.495^{2}$ \\
therophytes_2004 & 20.22 & 45.86 & 21.80 & 29.99 & & \\
therophytes_2005 & 89.89 & 66.98 & 168.20 & 69.68 & 6.205 & $.0^{1}$ \\
therophytes_2008 & 19.38 & 27.85 & 24.33 & 19.85 & 26.000 & $.190^{3}$ \\
chamaephytes_2004 & 65.89 & 108.12 & 20.44 & 16.64 & & \\
chamaephytes_2005 & 145.56 & 169.60 & 139.89 & 98.65 & 33.000 & $.276^{3}$ \\
chamaephytes_2008 & 60.37 & 33.98 & 56.38 & 24.10 & 31.500 & $.491^{3}$ \\
unknown_2004 & .11 & .33 & .10 & .32 & & \\
unknonw_2005 & .11 & .33 & .60 & 1.27 & $36.000^{3}$ & .255 \\
geophytes_2004 & .25 & .71 & .00 & .000 & & \\
geophytes_2005 & 5.00 & 6.82 & 2.50 & 2.84 & 34.500 & $.325^{4}$ \\
\hline
\end{tabular}

\subsection{Species richness}

As for number of individuals a general trend to higher species richness under the brushpacks is visible except for "geophytes" in 2005 (Table 28). The only significant treatment effect was given for "geophytes" in 2008 and for "all individuals" in 2008, but latter one only if the double control plot 2c/3c, which showed highest number of individuals and is seen as an outlier, was excluded. Also the treatment effect on "geophytes" in 2008 is driven by a lose of species in the control plots and no real improvement in terms of species numbers under the brushpacks.

Table 28 Differences between "brushpack" and "control" plots for species richness within different life form groups at Ratelgat (zonal habitat). p-values were obtained by ANOVAs with ${ }^{1} \mathrm{~F}(1,19)$ or ${ }^{2} \mathrm{~F}(1,17)$ and ${ }^{3}$ Mann-Whitney-U-test. ${ }^{4}$ ANOVA without outlier $F(1,16)$. Note that for all individuals in 2008 two analysis are presented one with the "outlier" plot 3c included and one without.

\begin{tabular}{|c|c|c|c|c|c|c|}
\hline \multirow[t]{2}{*}{ parameter } & \multicolumn{2}{|c|}{ control } & \multicolumn{2}{|c|}{ brushpacking } & \multirow[t]{2}{*}{$\mathrm{F} / \mathrm{H}$} & \multirow[t]{2}{*}{$p$} \\
\hline & mean & SD & mean & SD & & \\
\hline all_04 & 11.67 & 10.52 & 9.00 & 3.56 & & \\
\hline all_2005 & 20.00 & 7.33 & 21.20 & 5.35 & .169 & $.686^{1}$ \\
\hline all_outlier_2008 & 8.00 & 2.24 & 9.89 & 2.42 & 14.500 & $.037^{4}$ \\
\hline all plots_08 & 8.75 & 2.96 & & & 23.500 & $.116^{2}$ \\
\hline therophytes_2004 & 2.63 & 3.16 & 2.70 & 1.16 & & \\
\hline therophytes_2005 & 5.00 & 2.39 & 6.60 & 2.46 & 25.000 & $.096^{3}$ \\
\hline therophytes_2008 & 1.57 & .54 & 1.88 & .35 & 19.500 & $.222^{3}$ \\
\hline chamaephytes_2004 & 8.89 & 6.97 & 6.20 & 3.12 & & \\
\hline chamaephytes_2005 & 12.89 & 4.86 & 13.30 & 3.40 & .046 & $.832^{2}$ \\
\hline chamaephytes_2008 & 7.13 & 2.59 & 8.11 & 2.42 & .659 & $.430^{2}$ \\
\hline unknown_2004 & .13 & .35 & .10 & .32 & & \\
\hline unknonw_2005 & .14 & .38 & 1.10 & 1.20 & 29.500 & $.437^{1}$ \\
\hline geophytes_2004 & .40 & .89 & .00 & .000 & & \\
\hline geophytes_2005 & 1.63 & 1.77 & 1.00 & 1.05 & 34.500 & $.324^{3}$ \\
\hline geophytes_2008 & .00 & .000 & .60 & .52 & 16.000 & $.012^{3}$ \\
\hline
\end{tabular}


Note that "hemicryptophytes" are not analyzed because only one species occurred in 2008 under the "brushpack" treatment.

\section{Effect of time}

The general trend over the years is a significant increase of the number of individuals in all life form classes from 2004 to 2005 besides for "geophytes" (Table 29). For 2005 compared to 2008 abundance decreased significantly for all groups except "geophytes".

For species richness the pattern is very similar with a highly significant effect of time for all life form groups besides "hemicryptophytes" (Table 29). Species richness significantly increased from 2004 to 2005 and decreased from 2005 to 2008

Table 29 Differences between years for species richness and number of individuals in the different life form groups at Ratelgat (zonal habitat). p-values were obtained by Kruskal-Wallis tests. $d F=2$; $N=$ 19/17. No group separation could be achieved for number of geophytes Small letters in bold behind the means indicate groups according to LSH tests with Bonferroni-Holm correction.

\begin{tabular}{|c|c|c|c|c|c|c|c|c|}
\hline \multirow[t]{2}{*}{ parameter } & \multicolumn{2}{|c|}{2004} & \multicolumn{2}{|c|}{2005} & \multicolumn{2}{|c|}{2008} & \multirow[t]{2}{*}{$\mathrm{H} / \mathrm{U}$} & \multirow[t]{2}{*}{$p$} \\
\hline & mean & SD & mean & SD & mean & SD & & \\
\hline \multicolumn{9}{|c|}{ number of individuals } \\
\hline all & $34.84 a$ & 38.09 & $273.47 b$ & 174.25 & $87.53 a$ & 42.25 & 31.320 & .000 \\
\hline chamaephytes & $21.05 a$ & 23.38 & $137.21 b$ & 131.60 & $63.41 a$ & 36.57 & 23.757 & .000 \\
\hline geophytes & .00 & .00 & 2.79 & 4.39 & 1.29 & 5.34 & 17.849 & .000 \\
\hline hemicryptophytes & $.05 a$ & .23 & $2.47 \mathrm{~b}$ & 3.89 & $.00 a$ & .00 & 14.126 & .000 \\
\hline theropyhtes & $13.63 a$ & 23.21 & $130.79 b$ & 77.19 & $22.00 a$ & 23.30 & 28.970 & .000 \\
\hline unknown & $.16 a$ & .50 & $1.95 b$ & 2.84 & $.00 a$ & .00 & 19.396 & .000 \\
\hline \multicolumn{9}{|l|}{ species richness } \\
\hline all & $8.68 a$ & 3.47 & $20.63 b$ & 6.21 & $9.41 a$ & 2.69 & 30.896 & .000 \\
\hline chameaphyten & $6.37 a$ & 3.13 & $12.42 b$ & 3.44 & $7.65 a$ & 2.47 & 22.774 & .000 \\
\hline geophytes & $.11 a$ & .46 & $1.16 \mathrm{~b}$ & 1.39 & $.00 \mathrm{a}$ & .00 & 21.287 & .000 \\
\hline hemicryptophytes & .00 & .00 & .00 & .00 & .06 & .24 & 2.235 & $.312^{\mathrm{a}}$ \\
\hline theropyhtes & $2.16 a$ & 1.21 & $5.95 b$ & 2.46 & $1.65 a$ & .61 & 33.221 & .000 \\
\hline unknown & $.11 a$ & .46 & $1.00 \mathrm{~b}$ & 1.11 & $.00 \mathrm{a}$ & .00 & 21.197 & .000 \\
\hline
\end{tabular}

\section{Installation effect of the "brushpack" treatment}

The number of individuals after installation of the "brushpack" treatment was significantly lower Mean $_{\mathrm{after}}=$ $18.90 \pm 12.56$ than before Mean $_{\text {before }}=42.80 \pm 4.08[U=24.500, p=.023]$ (Figure 12). For species richness the paired t-test showed that number of species before treatment installation Mean $_{\text {before }}=9.00 \pm 3.56$ were significantly higher than afterwards Mean $_{\text {after }}=5.50 \pm 2.12[t(9)=-5.093 p=.001]$. 
a) species richness

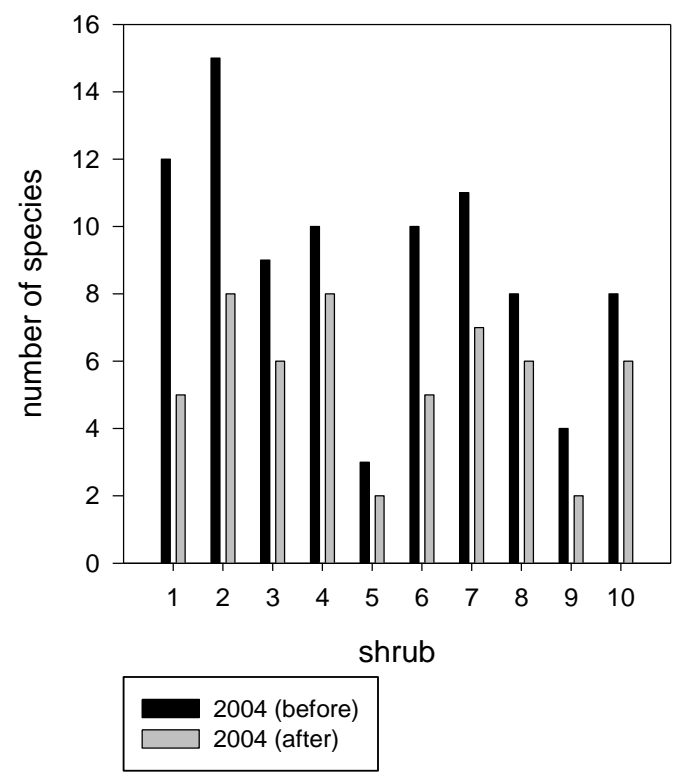

b) number of individuals

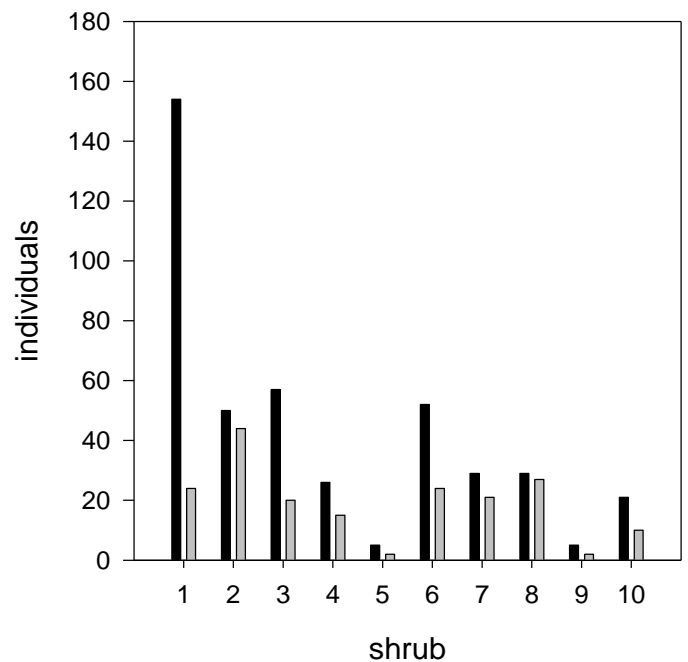

Figure 12 Number of species and individuals per plot before and after installation of the brushpack + levelling treatment at Ratelgat. 


\section{Discussion}

\subsection{Soebatsfontein}

\subsubsection{Soil}

\section{Characterization of the soils of the study sites}

The soil parameters of the two study sites showed a very narrow range compared to the high variance observed by Petersen (2008), Herpel (2008) and Labitzky (2009) for soils from the same communal area. Petersen (2008) and Herpel (2008) studied the soil parameters for plots sampled within the BIOTA Observatory Soebatsfontein (size: $1 \mathrm{~km}^{2}$ ), which is situated a few hundred meters north of Patrysegat. Generally, the soil conditions are moderate and very homogenous compared to the much more extreme and broad spectrum of values found by Herpel (2008) and Petersen (2008) for the surrounding area. The soil pH was neutral to moderately acidic and the EC values indicated a low to medium salinity. The mean values for total nitrogen $(0.06 \%)$ and carbon (0.5\%) can be rated as very low after a classification of Landon (1991) for tropical soils and are close to the findings by Herpel (2008) for the BIOTA Observatory Soebatsfontein $\left(C_{\text {org }}=1.33 \pm 1.24 ; N_{-} T=\right.$ $0.10 \pm 0.06)$.

The soil parameters found for both farms match the characteristics for an Endopetric Durisol which Petersen (2008) described for soils in immediate vicinity of heuweltjies at Soebatsfontein. They possess a sandy-loamy texture (around $70 \%$ sand) with neutral pH and a low electrical conductivity in the upper horizon. The profile is non-calcareous meaning that the values for total carbon and organic carbon are identical. The values for total carbon of $0.5 \%$ and a neutral $\mathrm{pH}$ within the first $10 \mathrm{~cm}$ found by Petersen (2008) are very close to my own findings.

Although the MANOVA revealed a significant difference between electrical conductivity at the two farms, both values (Patrysegat: $139.30 \pm 88.75 \mu \mathrm{S} / \mathrm{cm}$; Quaggasfontein: $99.40 \pm 104.06 \mu \mathrm{S} / \mathrm{cm}$ ) were rather low compared to the general range of $15-3000 \mu \mathrm{S} / \mathrm{cm}$ found by Petersen (2008). In an area with such a high variability in salinity, the differences between Patrysegat and Quaggasfontein seem to be minor and ecologically not relevant.

The significantly higher $\mathrm{C} / \mathrm{N}$ ratios found for Patrysegat $(10.21 \pm 0.66)$ compared to Quaggasfontein $(9.01 \pm$ 0.81) are surprising as Quaggasfontein is situated closer to a stockpost and thus exposed to a higher density of animals. The surrounding of water points is often associated with accumulating effects of nitrogen and organic carbon, as shown by Smet \& Ward (2006) for a semi-arid savanna in South Africa. They showed for commercial cattle ranches significantly higher nitrogen and organic carbon levels within 1-100m from water-points. It is notable that the differences between the two farms of this study although significant are rather small and might be favored by the low standard deviations of the values. It has to be questioned whether these differences have an ecological impact. 
Effect of the treatment "grazing exclosure" on soil parameters

They only soil parameter found to be significantly different by the MANOVA between grazed and fenced subplots was the $\mathrm{C} / \mathrm{N}$ ratio.

The analysis for this parameter revealed for Patrysegat significantly higher values for the fenced compared to the unfenced plot, whereas for Quaggasfontein the trend was opposite but not significant. Examination of total nitrogen and total carbon values revealed that the higher $\mathrm{C} / \mathrm{N}$ ratios for the fenced part at Patrysegat originate from significantly higher values for total carbon and total nitrogen These findings are in contrast to Labitzky (2009), who found for different farms of the Soebatsfontein community an increase of the C/N ratio for topsoil samples at sites under intensified grazing pressure alongside with increased total nitrogen and organic carbon levels. He highlighted though that these differences were not significant for all soil reference groups and that also opposite trends were existing. The range of values found by Labitzky (2009) for total nitrogen (0.017-0.16 $\%)$ organic carbon (0.1-2.3\%) and $\mathrm{C} / \mathrm{N}$ ratio $(6-16)$ is similar to my findings. However, the comparability with Labitziky's findings regarding carbon content has to be done with cautioun because he reports differences for the organic carbon fraction, whereas I measured total carbon. This could be a problem for comparableness, but Petersen (2008) reports identical total carbon and organic carbon values for the Endopetric Durisol at Soebatsfontein.

The findings of the present study concur with results from Hiernaux et al. (1999) for grazing experiments in the Sahel zone (Niger). They report slightly lower organic carbon and markedly lower total nitrogen contents under grazing pressure. The timeframe of four years for the grazing / grazing exclusion experiments and the fact that grazing was due to sheep and goats in a semi-arid environment make this study similar to my one.

Another study on the effect of grazing on $\mathrm{C}$ and $\mathrm{N}$ stocks for 15 grazing-exclosures in South America (Pineiro et al. 2003) revealed variable trends for upland and lowland soils and offers some explanations for these different reactions. The first one is the $\mathrm{N}$-loss hypothesis which states that grazing increases the removal of nitrogen out of the system. Dung and urine concentrate the existing nitrogen in small patches which lose part of the nitrogen through volatilization or leaching (Pineiro et al 2003). The total nitrogen amount in the system decreases and might constrain further formation of soil organic matter. However the potentially positive reaction to increased $\mathrm{N}$ availability at ungrazed sites might not occur if soils are not able to transform the nutrients into soil organic matter because of other constraints (seed bank, rainfall). Another mechanism, called the root- $\mathrm{N}$-retention-hypothesis states, that grazing increases the allocation of $\mathrm{C}$ and $\mathrm{N}$ to belowground biomass-pools, increasing the amount of carbon input into the soil and preventing nitrogen loss (Pineiro et al 2003). The balance of these processes, in addition to others will determine the reaction of a system to grazing. For Patrysegat nitrogen was lost under grazing which could support the $\mathrm{N}$-loss-hypothesis. In general the $\mathrm{C} / \mathrm{N}$ ratios for both sites are rather small which is favorable for the plant availability of nitrogen. 


\section{Effect of active treatments on soil $\mathrm{pH}$}

Soil pH was significantly increased under the active treatments "manure \& palm fronds" and "brushpacking" in decreasing magnitude. This is in line with previous studies which have shown that the addition of organic matter like plant material, animal manure form cattle, pigs, and poultry, compost and industrial waste as organic amendments (Naramabuye \& Haynes 2006), cattle manure (Whalen et al. 2000) as well as plant residue compost and manure (Wong et al. 1999) can increase the soil pH. The ameliorating effect of organic amendments on soil acidity can be explained by the substantial $\mathrm{CaCO}_{3}$ content of the amendments (Whalen et al. 2000), the ability of organic acids to consume protons by decarboxylation of their associated carboxyl and phenolic hydroxylgroups (Narambuye \& Haynes 2007) or by the adsorption of organic anions and the following release of hydroxid ions into the soil solution (Hue 1992).

Although acidity is not a pronounced problem for the soils of this study site, the effects of increased soil $\mathrm{pH}$, like improved availability of plant nutrients and lowered $\mathrm{Al}$ and $\mathrm{Mn}$ toxicity are rated to be generally positive for vegetation (Whalen et al. 2000). It is therefore valuable to know that organic amendments prove to be an alternative to conventional liming material (Whalen et al. 2000, Mokolobate \& Haynes 2002) which is often not available or too expensive in developing countries (Hue 1992, Naramabuye \& Haynes 2007).

\section{Effect of active treatments on EC}

While the trend for electrical conductivity was the same for both farms with highest EC values under the "manure \& palm fronds" treatment followed by the one for "brushpack", these differences were only significant for Quaggasfontein. The raise in electrical conductivity through the application of organic residues concurs with findings of Mokolobate \& Haynes (2002), which showed increased levels of exchangeable Ca, Mg, $\mathrm{K}$ and $\mathrm{Na}$ under the application of grass residues and poultry manure. As a result of the input of these exchangeable cations, soluble salts might accumulate and raise the electrical conductivity of the soil solution (Mokolobate \& Haynes 2002). The lower raise of EC under the "brushpack" treatment compared to "manure \& palm fronds" one could be due to the faster release of organic matter from the already further processed manure.

Even though an increase of soluble salts in the soils is of potential concern in arid areas, the low to medium range of the values occurring at the study sites indicates that salinity is not a major issue here. The high sand content of the soils will prevent increased salt accumulation in the upper horizons due to its good drainage qualities.

\section{Effect of active treatments on $C / N$ ratio}

The "manure \& palm fronds" and "brushpack" treatments resulted in significantly higher C/N ratios compared to "stones" and "control" on the farm Quaggasfontein. However, the two components of the $\mathrm{C} / \mathrm{N}$ ratio, total nitrogen and total carbon, increased significantly under the "manure \& palm fronds" treatment on both farms. 
This deviation from the effect on $\mathrm{C} / \mathrm{N}$ ratio could indicate that the $\mathrm{C} / \mathrm{N}$ ratio is not as suitable to reflect the trends for nitrogen and carbon when the differences are small or go into opposite directions.

The increase in total nitrogen and total carbon under the manure treatment is in accordance to the findings by Hao et al. (2003), Christensen (1988) and Mbagwu (1992), who all report an increase of these two parameters after animal manure application. However, Zink \& Allen (1998) report no change of total nitrogen after organic mulch application but a significant increase in microbial activity and nitrogen immobilization. They ascribe this effect to the fact that soil biota decrease the amount of nitrogen in its more mobile form as nitrate and lead to an immobilization and storage of nitrogen in the increasing microbial biomass. For brushpacks Ludwig \& Tongway (1996a) report an increase in organic carbon and nitrogen after 3 years under a brushpack treatment conducted in the semi-arid woodlands of Australia but only significant within the first $1 \mathrm{~cm}$ depth. As expected, the "stones" treatment showed no significant effect on any of the examined soil parameters.

\subsubsection{Vegetation}

The overall trend during the study period (2004-2008) revealed an increase in total cover, species richness and number of individuals for both sites at open and fenced subplots. This was accompanied by above average total annual rainfall in 2006 and to a lesser degree in 2007. The years 2004, 2005 and 2008 were comparable dry.

\section{Interaction between rainfall and relative abundance}

The highly predictable but low winter rainfall of Namaqualand has some consequences for the life form composition of its flora. Most of the dwarf succulent shrubs (chamaephytes, $<0.5 \mathrm{~m}$ ) dominating the vegetation of the lowland succulent Karoo have rather shallow roots (0.1-0.2m) (Esler \& Rundel 1999) and are therefore vulnerable to mortality in below average rainfall years (von Willert et al. 1985). A high mortality of succulent shrubs was also reported by Milton et al. (1995b) after a severe drought for the summer rainfall dominated Steytlerville Karoo. As a consequence and in contrast to other desert ecosystems, most of the leaf succulent shrubs of Namaqualand have a rather short life span of 5-15 years (Jürgens et al. 1999).

Despite this evidence for a strong dependency of chamaephytes on rainfall patterns the linear regression models obtained for relative abundances of "chamaephytes \& phanerophytes" have a poor ability to explain the variation of these life forms compared to the models for all other life form groups. This could not be explained by the exclusion of certain seasons to avoid collinearity. The results suggest that inter-annual rainfall variability and seasonality did not strongly influence the occurrence of these perennials during the study period. The same was observed by Schmiedel et al. (in prep.) for chamaephytes in comparison to geophytes and therophytes.

Geophytes of Namaqualand are reported to have small water storage organs of $1-3 \mathrm{~cm}$ in diameter and might be functionally interpreted as underground succulents which depend on a predictable moisture regime (Cowling et al. 1999). The reliable rainfall events and mild temperatures during winter have formed a flora of annuals and perennials showing a winter growth phenology. Vegetative development of annuals and 
perennials starts during autumn rains and they continue their growth to a reproductive stage during the winter months (Cowling et al. 1999). The strong positive relationship between the autumn rain of the last year for the overall model with the relative abundance of all life forms fits into this growth phenology concept. The positive relationship between the winter rainfall of the pre-previous year and the relative abundance of all life forms however, seems to be difficult to interpret and might be an artifact due to the short observation period of this study. If one does not interpret it as an artifact caused by the low number of observation years, one explanation could be that the seedlings were only visible and counted two years after their emergence.

Other factors like the competition between shrubs and grasses (Maestre et al. 2003), availability of safe sites and seed banks (O`Connor 1991), competition between established plants (Milton 1995) and also interactions of rainfall amount, seasonality and grazing (O`Connor \& Roux 1995) are known to control vegetation composition.

\section{Differences between the two sites}

In general, the site at Patrysegat seems to be in a better condition in 2008 than the Quaggasfontein site with significantly higher total cover and number of individuals. Species richness was significantly lower though for Patrysegat compared to Quaggasfontein.

Both farms possess a similar historic grazing intensity until 1999 which was rated as "high" by Labitzky (2009). The closer situation of Quaggasfontein to the nearest stock post presumably creates a higher concentration of animals (Samuels et al. 2007) with the associated effects of trampling, defecation and defoliation (Hendricks et al. 2005) at this site. Therefore one could expected to find a decrease in abundance of (palatable) perennials, increase in the abundance of ephemeral and alien species and a decrease in species richness and canopy cover of palatable perennials at the Quaggasfontein site, as this are reported effects of high grazing pressure for the vicinity of stockposts in the Karoo (Todd 2006, Hendricks et al. 2005). The transfer of these findings to the observations of this study is difficult though because no classification into palatability or origin of species was done.

The lower species richness at Patrysegat compared to Quaggasfontein contrasts with the findings of Hendricks et al. (2005) who report an increase of the mean species richness with increased distance to stock posts for communal rangelands of the Richtersveld (Namaqualand). It could be linked though to the theory of Navey \& Whittaker (1979) which states that grazing up to intermediate intensity increases species richness in communities adapted to grazing pressure.

Nevertheless the lower total cover and lower abundances of individuals on the Quaggasfontein site could indicate that this site is in a more degraded condition resulting from either higher grazing pressure in the past (long term effect explanation) and/or exposition to heavier grazing pressure today. However, this question was not the focus of this study and was therefore not followed up further. 
For a better understanding of grazing effects, the use of fence-line contrasts is a common method to examine vegetation communities exposed to different grazing pressures under otherwise similar conditions (Sasaki et al. 2009, Todd \& Hoffman 1999, Todd 2006).

Fence-line contrasts

Total cover of "perennials" and insignificantly "annuals" was higher for the unfenced, grazed part at Patrysegat. These findings are contrary to Todd \& Hoffman (1999), who report for fence-line contrasts in Namaqualand grazing tolerant species like annuals and geophytes to be "grazing increasers" but large shrubs and leaf succulents to exhibit decrease in plant cover and species richness. For Quaggasfontein total cover of "all species" and "annuals" was lower at the unfenced part though and conforms Todd \& Hoffman`s findings as well as many other studies (Eccard et al. 2000, Kraaij \& Milton 2006, Anderson \& Hoffman 2007) for the comparison of grazed to protected vegetation.

Number of individuals was not significantly different at Patrysegat although more annuals were counted within the fenced plots. The short exclusion time of this study does not seem to be sufficient to explain the observed differences in abundance as changes due to grazing exclusion for this site. For Quaggasfontein the trend in abundance was inverse with significantly lower number of "annuals" and "all species" for the fenced part. Since the abundance was lower but total cover higher within the fenced plot at Quaggasfontein, the exclusion of grazers might have lead to a vegetation consisting of fewer individuals but allowing them to grow better and to develop a larger canopy.

Species richness of "perennials" and "annuals" was significantly higher at Patrysegat for the unfenced part which is in contrast to Quaggasfontein and also to the reported findings of Todd \& Hoffman (1999) above. It is important to consider that the difference in annual species richness at Quaggasfontein was already existent (significantly) in 2004 before the fence was set-up and does therefore rather represent natural occurring inhomogeneity than a treatment effect. The effect of grazing on plant diversity is reported for Israel with a very long history of intensive land use to be a two-slope one with a certain optimum of grazing pressure leading to maximum species diversity (Naveh \& Whittaker 1979). Below this optimum, diversity is reduced by the dominance of some woody plants or taller grasses; while above it, the severe grazing pressure allows only a limited number of species most of which being unpalatable and /or aggressive to survive. One could speculate that the generally higher species richness for the area under grazing pressure at Patrysegat compared to the part in the grazing enclosure indicates that the grazing intensity is close to this described optimum and that the known effect of reduced competition as a result of light to moderate grazing leads to a larger species diversity of annuals (Kraaij \& Milton 1999) and more seedling survival (Milton \& Dean 1994) there. An explanation for lower species richness in from grazing protected plots is given by Hoffman \& Cowling (1990) which make selective grazing responsible for a shift towards only a few grazing tolerant species dominating the vegetation (Hoffman \& Cowling 1990). I don' t want to state this to be true for Quaggasfontein because the differences were already given before the experimental manipulation started and the observation time of four years is too 
short to allow the safe detection of such transitions which are reported to take decades to become evident especially for perennial species (Wiegand \& Milton 1996).

The diverging trends found for species richness at the two site to either increase or decrease under grazing pressure could be ascribed to the fact that the vegetation of Namaqualand is thought to be highly resistant to grazing due to its long co-evolution (Desmet 2007). A shift towards ephemeral communities replacing the shrubland is reported to be equally divers in species with a high percentage of species indigenous to Namaqualand (Todd \& Hoffman, 1999). This implies that the vegetation is highly adapted to this disturbance with many species especially annuals taking advantage of herbivory (Desmet 2007, Todd \& Hoffman 1999) making it difficult to detect a decrease in species richness. Another possible explanation for the different trends could be the higher grazing pressure at Quaggasfontein, which might prevents the establishment of grazing sensitive and palatable species. The exclusion of grazers at Quaggasfontein has therefore a significantly positive influence on species richness and cover whereas at Patrysegat grazing is a less strong factor and other forces (like historical disturbances) might drive the differences between plots inside and outside the fence. Since grazing works due to defoliation of palatable species which might be annuals or perennials a re-analysis of a sub-dataset with an additional classification of frequent species into palatable or unpalatable species might be helpful to better understand the observed patterns at fenced and unfenced plots of the two camps. The effect of grazing on vegetation change in semi-arid environments is generally thought to be smaller than the ones induced by rainfall variability (Kraaij \& Milton 2006, Snymann 1999). In addition their detection is known to be hampered by variability of other parameters such as nutrients, salinity and precipitation (Bastin et al. 1993).

\section{Effect of active restoration treatments}

The results show that the "manure \& palm fronds" treatment increased total cover of annuals in the good rainfall year 2006 within the grazed and protected plots of Quaggasfontein but lowered perennial and annual species richness in the fenced plot. Number of individuals, mainly annuals, at Patrysegat was lower under the “manure \& palm fronds" treatment.

The general expectation was that the "manure \& palm fronds" treatment would improve the establishment and size of the plants due to an enhanced nutrient status, increased aeration of the soil and retention of water as described by van den Berg \& Kellner (2005). My findings show that only annuals during the wet year 2006 were able to benefit from this assistance and this is in line with O Connor \& Roux (1995), who report on to the positive interaction between sufficient rainfall and recruitment and germination events of annuals. Because total cover of annuals at Quaggasfontein increased under the treatment but not significantly more individuals were found this indicates that not more individuals emerged and survived but those that did were in a better condition.

The "brushpack" treatment significantly lowered species richness of perennial plants in 2005 for the fenced plot at Quaggasfontein. Also the number of perennials in 2005 and 2006 were lowest under this treatment and despite the fact that post-hoc test were too conservative to reveal a group separation to the other three 
treatments this outcome will be discussed. The failure of multiple unplanned comparisons to reveal significant differences between groups although an ANOVA or non-parametric test stated these is common, especially if conservative post-hoc tests with adjusted Type I error rates are used and the ANOVA or other tests were only marginally significant $(0.01<p>0.05)$ (Quinn \& Keough 2002). The lower abundance of perennials is in contrast to the findings from van den Berg \& Kellner (2005), who report a positive response of shrub species by organic and organic + brushpack treatments after two years with good rainfall for the summer rainfall region in the Eastern Cape Province. An explanation for this dying of individuals might be the negative impact of the treatment installation itself which was investigated and found to be significant for the parameters species richness and number of individuals at Ratelgat (see 5.2.1.2 Zonal habitats). In contrast to the brushpacks experiments here, the negative installation impact was made up there within a year by a positive development of the vegetation.

In general, the use of brushpacks as a restoration treatment is based on the principle that semi-arid landscapes are organized in patches forming a source-sink system. Adult shrubs form fertile islands which are nutrient enriched (Ludwig \& Tongway 1996b), primarily in nitrogen as reported for Namaqualand by Stock et al. (1999). In degraded areas this nurse function of adult shrubs might be lost and can be overtaken by brushpacks (Ludwig \& Tongway 1996a), which are thought to possess similar positive effects as reported for nurse-plants (Yeaton \& Esler 1990). These qualities are: protection from high surface air temperatures, solar radiation and predation as well as improved soil fertility (Moro et al. 1997, Vetaas 1992, Yeaton \& Esler 1990), catching of wind-blown seeds and mycorrhizal spores (Call \& Roundy 1991). Additionally, they offer resting sites for animals to bring in seeds and nutrients (Call \& Roundy 1991) and form a barrier against the erosive forces of wind which are particularly working on the bare surfaces of degraded areas and hamper vegetation establishment there (Carrick \& Krüger 2007). At the same time brushpacks do not compete with living plants for scare resources. However, also negative effects of perennial shrubs on their understorey are reported (de Villiers et al. 2001) and some of them like deprivation of light, changes in the quality of light or mechanical effects by litter (Moro et al. 1997) which could constrict emerging seedlings could also apply to brushpacks and help to explain their partial poor performance in this study. The latter three arguments might also apply to the "manure \& palm fronds" treatment, because the additional covering of the manure with palm fronds make this treatment similar to brushpacks. A suggestion for further experiments with brushpacks would be to create a sparser thicket with enough spaces in between the branches to guarantee that light levels in the shadowed parts do not limit plant growth and allow seedlings to grow up without mechanical interference.

The fact that the two restoration treatments were able to improve plant cover in the year with highest precipitation but in none of the others would be in line with results from Ludwig \& Tongway (1996b), who report a very positive response of semi-arid woodland vegetation (perennials and grasses) in eastern Australia to brushpack treatments in no-drought times but no ability of them to prevent the general decline in vegetation during droughts. An additional treatment with plant mulch alone was not able to improve vegetation cover in Ludwig \& Tongway's (1996b) study. 
The failure of the active restoration treatments to demonstrate an unambiguous, positive influence on total cover, abundances and species richness within four years could also be to the absence of external seed introduction or plant individuals, which is a frequently applied and advised restoration method (Milton \& Dean 1994, Anderson et al. 2004, Beukes \& Cowling 2003, Snyman 2003). There is evidence that the majority of seeds of Namaqualand's vegetation is stored in the upper $5 \mathrm{~cm}$ of the topsoil (de Villiers et al. 1994) which might be lost by soil erosion processes. Short-living species tend to have effective long distance dispersal mechanism (von Willert et al. 1992), while seed dispersal distances for Namaqualand`s perennial species are reported to be typically short (Cowling et al.1999). Therefore, even without soil erosion recruitment mainly of annuals in contrast to perennials might occur and treatments such as the specific seeding and re-introduction of perennial species should be taken into account when restoring such communities (Carrick \& Krüger 2007, Visser et al. 2004).

Another aspect seen as important for the revegetation of arid rangeland (Snyman 2003, Visser et al. 2004) not addressed in this study is the breaking of impenetrable soil crusts and compacted layers to improve soil permeability due to ripping, ploughing or creation of hollows and pits. For sandy soils like they occur in Soebatsfontein this aspect is not as important as for clay soils (Snyman 2003) and it is not thought that seed germination was hindered by soil compaction.

The combination of seed introduction and brushpacks has shown to be most successful in a study by Visser et al. (2004) to restore bare patches of sandy soils in the Nama Karoo followed by tilling and the combination of tilling, seeding and covering with branches. The same experiments conducted on clayey soils revealed a higher relevance of the treatment tilling for these soils as compared to sandy soils (Visser et al. 2004). This highlights the relevance of seed introduction alongside with the provision of shelter and organic matter due to the brushpacks for successful re-vegetation on sandy soils.

\subsection{Ratelgat}

\subsubsection{Vegetation}

\subsubsection{Quartz fields}

The significant increase of number of individuals under the "planting" treatment in 2005 for all species together and for the $C$. spissum individuals reveals its short term success. This outcome is remarkable against the background of the poor rainfall conditions in the months after the treatments were set in place and the general importance of follow up rainfall for plant survival after germination and emergence of seedlings though as reported by Beukes \& Cowling (2003) for the Ceres Karoo and Milton (1995) for the Great Karoo. Etzold (2006) reports an average survival rate of $55 \%$ for the 20 C. spissum individuals one year after transplantation and although the number of $C$. spissum individuals decreased towards 2008, there were still on average nine times more individuals present on the replanted plots as compared to the control. Species richness was insignificantly higher under the "planting" treatment but species richness is not regarded as an important 
parameter for this community because the communities of saline quartz fields of the Knersvlakte are in general known to be species poor and often dominated by one singular species ( =monodominance) (Schmiedel 2002).

The benefits of transplanting instead of seeding although more expensive can be seen in the more rapid achievement of a later-successional community structure (Carrick \& Krüger 2007) and the higher success rate of the transplantation of mature plants compared to seedlings experiments which often failed in the Succulent (Burke 2008, Milton \& Dean 1994, Simons \& Allsopp 2007) and Nama Karoo (Visser et al. 2004). As an example; from 20,000 oversown seeds of five palatable species (Asteraceae, Mesembryanthemaceae, Sterculiaceae) in a restoration trial at Paulshoek only 90 seedlings emerged in the following two years (Simons \& Allsopp 2007). Land users in Namaqualand interviewed for a study which aimed to capture their informal knowledge, named the transplanting of leaf succulent species as an easy and successful method (Botha et al. 2008).

The treatment "levelling" seems to have damaged some $C$. spissum individuals and lead to their dying. The insignificantly higher number of "all" and C. spissum individuals in 2008 compared to the "control" plots under "levelling" indicates a trend of the levelling treatment to be beneficial in the longer term though. Because also the "stones" and "planting" treatments included levelling of the soil surface and yet showed higher number of individuals as "levelling" alone in 2005 and 2008 this treatment was seen as successful but its connection with the other two treatments is advised.

The combination of levelling and planting is already successfully used in the rehabilitation of strip mined areas on the coast of Namaqualand (Mahood 2001). Here, formerly excavated material is returned after heavy metal extraction and leveling of the soil surface. Stock piled topsoil is returned and indigenous plants from the surrounding area are transplanted by hand, additional protection from wind erosion is achieved by nylon nets as windbreaks. Today this technique is routinely applied by the mining companies of the west coast (Mahood 2001).

The success of the scattered quartz stones in increasing the abundance of species and to some extend species richness is seen in their potential to serve as microhabitat where seedlings can establish adjacent or under the edge of the stones and profit from soil particles and organic material which accumulates there (Yeaton \& Esler 1990). They are thought to fulfill similar functions as brushpacks but to be less labor intensive and cheaper if suitable stones are available in the surrounding area.

The creation of small-scale microtopography is seen as crucial for concentrating scarce resources like water, nutrients and seeds (Carrick \& Krüger 2007). Restoration trials by mining operators of Namaqualand used gravel spreaded over the burden soils and tracks formed by bulldozers to recreate this small scale topography (Carrick \& Krüger 2007). Milton \& Dean (1994) found, that smaller seeds of low-growing succulents [Mesembryanthemaceae (i.e., currently part of Aizoaceae)] are mainly trapped by soil particles and occur in inter-shrub areas. Winged or bristled seeds are primarily wind-dispersed and trapped in the canopy or stems of other plants (Milton 1994), litter or excavated holes made by mammals (Dean \& Milton 1991, Milton \& Dean 1994). The short dispersal distances of the Mesembryanthemaceae and the tendency of perennial species of 
Namaqualand to produce no dormant, soil stored seeds make a reintroduction of their seeds or adult plants even more important (Carrick \& Krüger 2007, de Villiers et al. 2001, von Willert et al. 1992). Because the mechanical disturbance on Ratelgat was rather at a small scale, migration of propagules from adjacent, undisturbed areas can be expected.

Although no significant treatment effects for either "stones" or "levelling" was found for the Ruschia burtoniaeCommunity a positive trend under the "stones" and to a smaller extend under the "levelling" treatment was visible for species richness and total cover.

The result that the $C$. spissum-Community responded significantly positive on all three restoration treatments whereas the $R$. burtoniae-Community did not show any significant response, could be attributed to their very different strategy types. The differences in life form between $C$. spissum as a compact nano-chamaephyte (up to $5 \mathrm{~cm}$ high) and Ruschia burtoniae as a fruticose meso-chamaephyte which can reach $50 \mathrm{~cm}$ in height are considerable. The dwarf life form of $C$. spissum with its slow growth rates makes this species more susceptible to soil disturbance and mobilized soils due to erosion. In contrast to $C$. spissum which occurrence is restricted to quartz fields of the Knersvlakte, Ruschia burtoniae occurs on a broad range of acid quartz field types and is widespread in the Knersvlakte, but also found in other parts of Namaqualand and the Nama Karoo (Schmiedel 2002). It can be assumed that this shrubby species is less vulnerable to erosion and trampling effects and more tolerate towards disturbances of the soil surface. The significant improvements for the $C$. spissum-in contrast to the $R$. burtoniae-Community are therefore remarkable and give hope for the restoration potential of the quartz field vegetation in the Succulent Karoo in general which is dominated by compact, leaf-succulent dwarf shrubs similar to C. spissum (Schmiedel \& Jürgens 1999).

\subsubsection{Zonal habitats}

Despite a slight visible positive trend of species richness for most life forms, which was significant for "geophytes" in 2008 under the brushpacks, no prominent improvement due to the treatment was found. This is in contrast to many positive results of other experiments with either brushpacks alone as Ludwig \& Tongway (1996b) have shown for the establishment and growth of perennial grasses in eastern Australia, the combination of brushpacks and subsequent seeding (Visser et al. 2004), or the combination of brushpacking, ripping, oversowing and mulching (van den Berg \& Kellner 2005). Brushpacks are therefore a common and effective applied restoration method which is, however, cost intensive. Time and labor is needed to cut the branches, transport them to their site of action and pack them. In contrast to other restoration methods like seeding and tilling, brushpacking is rated as a comparable expensive treatment (Visser et al. 2004).

Van den Berg \& Kellner (2005) report for the Nama Karoo that most notably shrub species were favored by brushpacks and organic amendments. One restoration trial which aimed to rehabilitate overgrazed rangelands near Paulshoek, Upland Namaqualand, used also Galenia africana shrubs to form brushpacks in combination with seed introduction, but with low success (Simons \& Allsopp 2007). The brushpacks were successful in increasing cover of ephemerals at two out of three experimental sites and cover of grasses at one site, but no 
advantage on perennial seedlings was found. Geophytes showed no treatment effect and were absent in another treatments which included the digging of microcatchments. This was seen as an indication that treatments which disrupt the soil surface might be detrimental to geophytes due to the uproot of their bulbs (Simons \& Allsopp 2007) and could be an indication that the application of mechanical soil treatments is not favorable for this life form.

The installation of restoration treatments is associated with unavoidable short-term negative impacts on the soil surface and plant growth due to the effects of trampling, dislocation of stones, soil particles and seedlings. Therefore it is valuable to know how severe this installation effect is and whether its positive influence compensates the negative impact of implementation. This study showed that the "brushpack" and "leveling" treatment installation significantly reduced species richness and number of individuals in the plots. Despite these disadvantageous initial conditions of the "brushpack" plots in contrast to the "controls", the development of species richness and number of individuals was very positive under this treatment. All examined life form groups, besides chamaephytes were able to catch up with the control plots after only one year in terms of abundance and species richness. This trend went along with a general positive development of the vegetation from 2004 to 2005 despite comparable low autumn and winter rainfall. These results show that the use of brushpacks in combination with levelling to restore zonal habitats along the pipeline at Ratelgat is worthwhile and an even more confirmative development is expected to become apparent within the next years. However, the "levelling" treatment is labor intensive but might be improvable in terms of time requirement and costs due to the employment of suitable machinery.

The decision which level of effort and technique to apply depends on several environmental conditions like the amount of precipitation, harshness of the site and the question which species shall be (re-)established and in which time frame (Anderson \& Ostler 2002). Even if successful methods are identified they will only find widespread acceptance and application if they are sustainable and cost-effective. Whether a method is seen as cost-effective or not depends on the site's priority in terms of utilisation after restoration and the price willing to be paid for this achievement (Anderson \& Ostler 2002). 


\section{Conclusion}

This study emphasizes that soil parameters are suitable to detect restoration treatment effects at an early stage where vegetation composition might still be unaffected or the changes not yet visible. All investigated parameters $\left(\mathrm{pH}, \mathrm{EC}, \mathrm{C} / \mathrm{N}, \mathrm{C}_{-} \mathrm{T}, \mathrm{N}_{-} \mathrm{T}\right)$ increased markedly with increased values under the "manure \& palm fronds" and "brushpack" treatment in Soebatsfontein. The effect on the measured vegetation parameters was less pronounced.

Differences between the two sites in terms of grazing pressure due to different distances to the nearest stock posts and the fence-line contrast along the grazing enclosures are thought to have obscured a clearer detection of treatment effects. The exclusion of livestock had a positive influence on species richness and total vegetation cover at Quaggasfontein where a stronger impact of grazing and trampling has to be assumed. Protection from grazing resulted here in a significant increase of annual and insignificantly perennial cover. In contrast, for Patrysegat these two parameters were significantly higher for the grazed, unfenced part. This leads to the conclusion that light grazing (as at Patrysegat) has a positive influence on species diversity whereas higher grazing pressure around water points and stock posts as assumed for the Quaggasfontein site results in a shift towards a vegetation with less individuals and a lower canopy cover. The exclusion of grazers at Quaggasfontein had therefore a positive influence on species richness and cover whereas at Patrysegat grazing seems to be a less strong determinant and the differences between the plots inside and outside the enclosure are driven by other factors that have not been investigated (e.g., historical disturbances).

The investigation of the relationship between abundance of species and rainfall amount revealed that relative abundance of species can be best explained by a regression against total annual rainfall. A further partition into seasonal rainfall brought no statistical improvement and less gain in insight into the relationship, besides the expected and confirmed positive relationship for all species with the amount of autumn rainfall of the previous year.

The effect of the active restoration treatments on the vegetation was difficult to interpret. There were positive effects such as increase of annual cover under the "manure \& palm fronds" treatment during the high rainfall year 2006 and at the same time negative effects on species richness and abundance of perennial and annual species under the "manure \& palm fronds" and particularly the "brushpack" treatment. This negative effect of the "brushpack" treatment on perennial species is ascribed to the negative impact during its installation and potential shading and mechanical effects impeding plant growth after installation. Remarkable is the difference to the outcome of the "brushpack" treatment at Ratelgat, where the negative installation effect was clearly detectable but the vegetation still able to benefit from the treatment. For future restoration trials at Soebatsfontein it would be advised to include seeding or transplantation of indigenous species into the trial and create lighter brushpacks. 
The restoration treatments on the quartz fields at Ratelgat showed success within the $C$. spissum-Community in terms of increased abundance and, to a lesser extent, species richness. For $C$. spissum individuals alone also canopy cover was positively influenced. The treatments "planting", "stones" and "levelling", listed by descending effect improved the vegetation of the $C$. spissum-Community on quartz fields and can be assumed to be also suitable for the restoration of other quartz field communities. All three treatments can be recommended for future quartz field restoration projects but in terms of cost-effectiveness the "stones" or "leveling" treatments are advised. The "brushpack" treatment increased species richness and abundance of most life forms and was able to compensate losses which occurred due to installation effects within just one year. Hence it is recommended for future restoration of zonal soils. Unlike other restoration treatments such as wind breaks, furrows or micro-catchments which may need maintenance actions from time to time, the here applied treatments required no further input after installation. Although the tested restoration methods might not be cost-effective in the short-term, their value has to be seen in the long-term improvement of veld conditions, erosion control, increased biodiversity and ecotourism potential, higher carrying capacity for livestock, and thus increased monetary value of the land. 


\section{Abstract}

Introduction: The aim of this study was to examine the effects of different (active and passive) restoration techniques on soil and vegetation of degraded rangeland at two sites in the Namaqualand of the Succulent Karoo, four years after their implementation. Also, the effects of total annual and seasonal rainfall on the relative abundance of individuals of species within different life form groups were investigated for the four subsequent years after treatment implementation.

Methods: One study site is located in the Knersvlakte and aims to reverse the negative effects created through the construction of an underground water pipeline through quartz fields and zonal vegetation on communal rangeland of the farm Ratelgat. The other study site is located in the Soebatsfontein commonage within the Hardeveld bioregion and intends to restore communal farm land which is degraded due to overgrazing by sheep in the past, before the farmland had been handed over to the community. The applied treatments for Ratelgat were "scattering of quartz stones + levelling", "planting + levelling", "levelling" and "no treatment" for plots located on quartz fields and "brushpacking + levelling" on non quartz field plots. At Soebatsfontein one part was fenced to exclude grazing the other part was left unfenced. Within each part four treatments were implemented: "small stones heaps", "brushpacking", "covering of the plots with manure and palm leaves" and "controls". The effect of the restoration treatments on soil properties of Soebatsfontein was examined with a MANOVA with $\mathrm{pH}, \operatorname{logEC}$ and $\mathrm{C} / \mathrm{N}$ ratio as dependent variables, the active treatments and grazing as fixed factors and study site as covariate. Differentiating effects of the active restoration treatments and grazing (only Soebatsfontein) on vegetation parameters (total cover, number of individuals and species richness) were assessed with ANOVAs', Kruskal-Wallis or Mann-Whitney $U$ tests, respectively. The relationship between total annual or seasonal rainfall and relative abundance of species at Soebatsfontein was quantified using multiple linear regressions. The potential negative setup effect of the "brushpack and leveling" treatment at Ratelgat was assessed with a comparison of species richness and number of individuals before and immidiately after treatment installation.

Results: For Soebatsfontein, the treatments "manure \& palm fronds" and "brushpacking" increased $\mathrm{pH}$, electrical conductivity, total nitrogen and total carbon content of the soil at both camps significantly. If compared to resting, grazing significantly increased total cover of perennial species at Patrysegat but significantly lowered total cover of all species and annuals at Quaggasfontein in 2008. Resting at Quaggasfontein resulted in significantly lowered number of "annual species" and "all species". Species richness was significantly positive influenced by grazing at Patrysegat and negative at Quaggasfontein. Also the results for the active treatments were ambiguous. The "brushpack" treatment showed significant negative effects on individual numbers of perennials as well as perennial species richness in 2005 and significantly increased annual cover in 2006. For the "manure \& palm fronds" treatment annual cover increased significantly in 2006 but perennial species richness was significantly negative influenced in 2005.The obtained models for annual or seasonal rainfall and relative abundance of different life form groups were highly significant but further partition into seasons did not improve the quality of the models.

For Ratelgat significant treatment effects were found for the Cephalophyllum spissum-Community with a 
significant increase of individual numbers under the "planting" treatment in 2005. The installation of the "brushpack" treatment significantly lowered number of individuals and species richness immediately after installation but the development under the treatment was very positive over the subsequent years.

Conclusion: Grazing exclusion as a passive restoration treatment seems to be more important for areas under high grazing pressure than for light grazed ones. The applied treatments "brushpacking" and "manure \& palm fronds" cannot be recommended without caution because of the significant negative effects which are ascribed to destructive impacts during their installation and potential shading effects. The positive effect of the brushpack treatment on the zonal vegetation at Ratelgat leads to the conclusion that brushpacks are a valuable restoration method and it is advised to apply them in the future less dense as it had been applied in Soebatsfontein (i.e., 90\%). The treatments "planting" (significant), "stones" and "levelling", listed by descending effect were able to improve number of individuals for all species within the $C$. spissum-Community and can be assumed to be also suitable for the restoration of other quartz field communities. 


\section{Acknowledgements}

I would like to deeply thank the various people who helped me through this thesis, provided me with helpful assistance and friendly encouragement.

First and foremost by Dr. Ute Schmiedel, who supervised my thesis and always gave me support and advice, answered my questions and introduced me to the very special flora and locality of the Namaqualand. It was a pleasure to work with you, to profit from your expert knowledge in the subject and great experience in academic work and scientific writing.

I further would like to thank Prof. Dr. Dieter Burger for making it possible to conduct my thesis in Hamburg and enabling me to analyze my soil samples in the laboratory of the "Institute für Geographie und Geoökologie".

I cordially thank Prof. Dr. Norbert Jürgens for taking over the task as my second evaluator and Jürgen Dengler for the discussion of statistical matters.

Manfred Kull I would like to thank for his patience, interest in my analysis and intensive assistance during my three weeks at the soil laboratory. Thanks also to the "Institute of Soil Science" in Hamburg for the carbon and nitrogen analysis of my soil samples.

Many thanks to Sophia Etzold for handing over me her research work, Wiebke Hanke and Daniela Haarmeyer for their help with statistics and valuable suggestions and Inga Ute Röwer, Jona Luther-Mosebach and Daniela Haarmeyer for the provision of shape files and details on local facts.

I would like to thank the whole working group of the Plant Systematic in Hamburg for their warm welcome and friendly accommodation.

Thanks to CapeNature and Northern Cape Nature Conservation for supplying the research permits and special thanks to the communities Soebatsfontein and Ratelgat for support and the permission to work on their land.

Finally I would like to express my deep gratitude to my beloved family, cousin and boyfriend, who supported me, gave me confidence and encouragement especially during these last intense weeks. 


\section{References}

Allen, EB 1995, Restoration ecology: limits and possibilities in arid and semiarid lands. In: Round, BA, McArthur, ED, Haley, JS \& Man, DK (Comps.), Proceedings: wildland shrub and arid land restoration symposium. U.S. Department of Agriculture, Ogden, Utah, pp. 7-13.

Anderson, DC \& Ostler, WK 2002, Revegetation of Degraded Lands at U.S. Department of Energy and U.S. Department of Defense Installations: Strategies and Successes, Arid Land Research and Management, vol. 16, pp. 197-212.

Anderson, P, Hoffman, T \& Holmes, P 2004, The Potential of Cephalophyllum inaequale (L.Bolus) for the Restoration of Degraded Arid Landscapes in Namaqualand, South Africa, Restoration Ecology, vol. 12(3), pp. 343-351.

Anderson, PML \& Hoffman, MT 2007, The impacts of sustained heavy grazing on plant diversity and composition in lowland and upland habitats across the Kamiesberg mountain range in the Succulent Karoo, South Africa, Journal of Arid Environments, vol. 70, pp. 686-700.

Backhaus, K, Erichson, B, Plinke, W \& Weiber, R 1996, Multivariate Analysemethoden: Eine anwendungsorientierte Einführung, Springer Verlag, Berlin.

Bärlocher, F 2000, Biostatistik: Praktische Einführung in Konzepte und Methoden, 2. Auflage, Thieme Verlag, Stuttgart.

Bastin, GN, Pickup, G, Chewings, VH \& Pearce, G 1993, Land degradation assessment in central Australia using a grazing gradient method, The Rangeland Journal, vol. 15(2), pp. 190-216.

Betteridge, K, MacKay, AD, Barker, DJ, Shepherd, TG, Budding, PJ, Devantier, BP \& Costall, DA 1999, Effect of cattle and sheep treading on surface configuration of a sedimentary hill soil, Australian Journal of Soil Research, vol. 37, pp. 743-760.

Beukes, PC \& Cowling, RM 2003, Evaluation of Restoration Techniques for the Succulent Karoo, South Africa, Restoration Ecology, vol. 11(3), pp. 308-316.

Boonzaier, EA, Malherbe, C, Berens, P, Smith, AB 1996, The Cape Herders: A History of the Khoikhoi of Southern Africa, David Phillip Publishers, Cape Town

Botha, MS, Carrick, PJ \& Allsopp, N 2008, Capturing lessons from land-users to aid the development of ecological restoration guidelines for lowland Namaqualand, Biological Conservation, vol. 141, pp. 885-895.

Burke, A 2008, The effect of topsoil treatment on the recovery of rocky plain and outcrop plant communities of Namibia, Journal of Arid Environments, vol. 72(8), pp.1531-1536.

Call, CA \& Roundy, BA 1991, Perspectives and processes in revegetation of arid and semiarid rangelands, Journal of Range Management, vol. 44(6), pp. 543-549.

Carrick, PJ \& Krüger, R 2007, Restoring degraded landscapes in lowland Namaqualand: Lessons from the mining experience and from regional ecological dynamics, Journal of Arid Environments, vol. 70, pp. 767-781.

Christensen, BT 1988, Effects of animal manure and mineral fertilizer on the total carbon and nitrogen contents of soil size fractions, Biology and Fertility of Soils, vol. 5, pp. 304-307.

Coetzee, K 2005 Caring for natural rangelands, University of KwaZulu-Natal Press, pp. 1-129.

Cowling, RM, Esler, KJ \& Rundel, PW 1999, Introductory paper: Namaqualand, South Africa- an overview of a unique winterrainfall desert ecosystem. Plant Ecology, vol. 142, pp. 3-21.

de Villiers, AJ, van Rooyen, MW \& Theron, GK, 1994 Comparison of two methods for estimating the size of the viable seed bank of two plant communities in the Strandveld of the west coast, South Africa, South African Journal of Botany, vol. 60 , pp. $81-84$

de Villiers, AJ, Van Rooyen, MW \& Theron, GK 2001, The role of facilitation in seedling recruitment and survival patterns, in the Strandveld Succulent Karoo, South Africa, Journal of Arid Environments, vol. 49, pp. 809-821. 
Dean, WRJ \& Milton, SJ 1991, Disturbances in semi-arid shrubland and arid grassland in the Karoo, South Africa: mammal diggings as germination sites, African Journal of Ecology, vol. 29, pp. 11-16.

Dean, WRJ, Milton, SJ, Plessis, M \& Siegfried, WR 1995, Dryland Degradation: Symptoms, Stages, and Hypothetical Cures. In: Round, BA, McArthur, ED, Haley, JS \& Man, DK (Comps.), Proceedings: wildland shrub and arid land restoration symposium. U.S. Department of Agriculture, Ogden, Utah, pp. 178-182.

Desmet, PG 2007, Namaqualand - A brief overview of the physical and floristic environment, Journal of Arid Environments, vol. 70, pp. 570-587.

Dormaar, JF \& Willims, WD 1998, Effect of forty-four years of grazing on fescue grassland soils, Journal of Range Management, vol. 51, pp. 112-126.

du Toit, GVN, Snyman, HA \& Malan, PJ 2009, Physical impact of grazing by sheep on soil parameters in the Nama Karoo subshrub/grass rangeland of South Africa, Journal of Arid Environments, vol.73, pp. 804-810.

Eccard, JA, Walther, ARB \& Milton, SJ 2000, How livestock grazing affects vegetation structures and small mammal distribution in the semi-arid Karoo, Journal of Arid Environments, vol. 46, pp. 103-106.

Esler, KJ \& Rundel, PW 1999, Phenological and growth form divergence in convergent desert ecosystems: a Succulent Karoo and Mojave desert comparison, Plant Ecology, vol. 142, pp. 97-104.

Etzold, S 2006, Dynamics on Quartz Fields in the Knersvlakte/South Africa, With Special Reference to Disturbance and Restoration, Diploma thesis, University of Hamburg, Biocentre Klein Flottbek \& Botanical Garden.

Farmer, H. 2005. An investigation into factors influencing spatial use of the landscape by indigenous herbivores in the Little Karoo, South Africa, Unpublished MSc Project, University of Cape Town, South Africa.

Field, A 2005, Discovering Statistics Using SPSS, and sex, drugs and rock ' $n$ ' roll), [ ${ }^{\text {rd }}$ edn], SAGE Publications, London.

Field, A 2009, Discovering Statistics Using SPSS, and sex, drugs and rock ' $n$ ' roll), [ $3^{\text {rd }}$ edn], SAGE Publications, London.

Friedel, MH 1991, Range condition assessment and the concept of thresholds: A viewpoint, Journal of Range Management, vol. 44, pp. 442-426.

Germishuizen G, Meyer NL (eds) 2003, Plants of southern Africa: an annotated checklist, National Botanical Institute, Pretoria.

Gotelli, NJ, Ellison, AM 2004, A Primer of Ecological Statistics, Sinauer Associates Inc., Sunderland, Massachusetts, USA.

Haarmeyer, D 2009, Effects of domestic livestock on the vegetation of the Knersvlakte, South Africa, Diploma thesis, University of Hamburg, Biocentre Klein Flottbek \& Botanical Garden.

Hälbich, TFJ 2003, Mine rehabilitation in the arid Succulent Karoo vegetation zone on the South African west coast, Namakwa Sands- case study, Heavy Minerals, South African Institute of Mining and Metallurgy, pp. 113-118.

Hao, X, Chang, C, Travis, GR,\& Zhang, F 2003, Soil carbon and nitrogen response to 25 annual cattle manure applications, Journal of Plant Nutrition and Soil Science, vol. 166 (2), pp. 239-245.

Harrell, FEJ 2001, Regression Modeling Strategies With Applications to Linear Models, Logistic Regression, and Survival Analysis, Springer New York, New York.

Hendricks, HH, Bond, WJ, Midgley, JJ \& Novellie, PA 2005, Plant species richness and composition along livestock grazing intensity gradients in a Namaqualand (South Africa) protected area, Plant Ecology, vol. 176, pp. 19-33.

Herpel, N 2008, The Scale-Dependent Variability of Topsoil Properties Reflecting Ecosystem Patchiness in Drylands of Southern Africa, Dissertation, University of Hamburg, department of geosciences.

Hiernaux, P, Bielders, CL, Valentin, C, Bationo, A \& Fernández-Rivera, S 1999, Effects of livestock grazing on physical and chemical properties of sandy soils in Sahelian rangelands, Journal of Arid Environments, vol. 41, pp. 231-245.

Higgs, E 2005, The Two-Culture Problem: Ecological Restoration and the Integration of Knowledge, Restoration Ecology, vol. 13(1), pp. 159-164. 
Hilton-Taylor, C 1996, Patterns and characteristics of the flora of the Succulent Karoo Biome, southern Africa, In: van der Maesen, L, van der Burgt, X, van Medenbach de Rooy, J (eds), The Biodiversity of African Plants, Kluwer Academic Publishers, Dordrecht, pp. 58-72.

Hobbs, RJ \& Norton, DA 1996, Commentary Towards a conceptual framework for restoration ecology, Restoration Ecology, vol. 4, pp. 93-110.

Hoffman, MT \& Cowling, RM 1990, Desertification in the lower Sundays River valley, South Africa, Journal of Arid Environments, vol. 19,pp. 105-117.

Hoffman, M \& Todd, S 1999, The South African environment and land use. In: Hoffmann, MT, Todd, SW, Ntshona, Z \& Turner, S (eds), A national review of land degradation in South Africa, National Botanical Institute, Cape Town, pp. 17-36.

Hoffman, MT \& Ashwell, A 2001, Nature Divided Land Degradation in South Africa, University of Cape Town Press, Cape Town, South Africa, pp. 168.

Houba, VJG, Temminghoff, EJM, Gaikhorst, GA \& van Vark, W 2000, Soil analysis procedures using 0.01 M calcium chloride as extraction reagent, Communications in Soil Science and Plant Analysis, vol. 31(9), pp. 1299-1396.

Hue, NV 1992, Correcting soil acidity of a highly weathered Ultisol with chicken manure and sewage sludge, Communications in Soil Science and Plant Analysis, vol. 23 (3\&4), pp. 241-264.

Huntington, HP 2000, Using traditional ecological knowledge in science: methods and applications, Ecological Applications, vol. 10(5), pp. 1270-1274.

ISO 10390 2005, Soil quality- Determination of pH.

ISO 112651994 + ISO 11265 1994/Cor.1: 1996, Soil quality- Determination of the specific electrical conductivity.

ISO 114646 2006, Soil quality -Pretreatment of samples for physico-chemical analyses.

Jürgens, N 1986 Untersuchungen zur Ökologie sukkulenter Pflanzen des südlichen Afrika, Mitteilungen aus dem. Institut für Allgemeine Botanik Hamburg, vol. 21, pp. 139-365.

Jürgens, N 1991, A new approach to the Namib Region. I Phytogeographic subdivision. Vegetatio, vol. 97, pp. 21-38.

Jürgens, N, Gotzmann, IH \& Cowling, RM 1999, Community, structure and dynamics, Remarkable medium-term dynamics of leaf succulent Mesembryanthemaceae shrubs in the winter-rainfall desert of northwestern Namaqualand, South Africa, Plant Ecology, vol. 142, pp. 87-96.

Köhler, W, Schachtel, G \& Voleske, P 1996, Biostatistik: Eine Einführung für Biologen und Agrarwissenschaftler, 2.Auflage, Springer-Verlag Berlin Heidelberg.

Kraaij,T \& Milton, SJ 2006, Vegetation changes (1995-2004) in semi-arid Karoo shrubland, South Africa: Effects of rainfall, wild herbivores and change in land use, Journal of Arid Environments, vol. 64, pp. 174-192.

Labitzky, T 2009, Natural features and land use impact on soils of the Soebatsfontein region (Namaqualand, South Africa), Diploma thesis, University of Hamburg, department of geosciences.

Landon, JR (ed.) 1991, Booker Tropical Soil Manual, Booker Agriculture International, Ltd., London.

le Roux, A 2005, Namaqualand South African Wild Flower Guide 1, [ $3^{\text {rd }}$ edn $]$ Botanical Society of South Africa, Cape Town.

Lombard, AT, Hilton-Taylor, C, Rebelo, AG, Pressey, RL \& Cowling, RM 1999, Reserve selection in the Succulent Karoo, South Africa: coping with high compositional turnover, Plant Ecology, vol. 142, pp. 35-55.

MacKellar, NC, Hewitson, BC \& Tadross, MA 2007, Namaqualand's climate: Recent historical changes and future scenarios, Journal of Arid Environments, vol. 70, pp. 604-614.

Maestre, FT, Bautista, S \& Cortina, J 2003, Positive, negative, and net effects in grass-shrub interactions in Mediterranean semiarid grasslands. Ecology, vol. 84(12), pp. 3186-3197.

Mahood, K 2001, Strip mine rehabilitation by plant translocation, WOCAT, http://www.fao.org/ag/agl/agll/wocat/wqtsum.asp?questid=RSA47, last access: 22.08.09. 
May, H \& Lahiff, E 2007, Land reform in Namaqualand, 1994-2005: a review, Journal of Arid Environments, vol. 70(4), pp. $782-798$

Mbagwu, JSC 1992, Improving the Productivity of a Degraded Ultisol in Nigeria using Organic and Inorganic Amendments. Part 1: Chemical Properties and Maize Yield, Bioresource Technology, vol. 42, pp. 149-154.

Mills, AJ, Cowling, RM, Fey, MV, Kerley, GIH, Donaldson, JS, Lechmere-Oertel, RG, Sigwela, AM, Skowno, AL \& Rundel, P 2005 Effects of goat pastoralism on ecosystem carbon storage in semiarid thicket, Eastern Cape, South Africa, Austral Ecology, vol. 30, pp. 797-804.

Mills, AJ \& Cowling, RM 2006, Rate of Carbon Sequestration at Two Thicket Restoration Sites in the Eastern Cape, South Africa, Restoration Ecology, vol. 14(1), pp.38-49.

Milton, SJ \& Dean, WRJ 1994, Factors influencing recruitment of forage plants in arid Karoo shrublands, South Africa. In: Roundy, BA, McArthur, DE, Haley, JS \& Mann, DK (eds). Proceedings: wildland shrub and arid land restoration symposium. U.S. Department of Agriculture, Ogden, Utah, pp. 216-222.

Milton, SJ 1994, Growth, flowering and recruitment of shrubs in grazed and in protected rangeland in the arid Karoo, South Africa, Vegetation, vol. 111, pp. 17-27.

Milton, SJ, Dean, WRJ, du Plessis, MA \& Siegfried, WR 1994, A Conceptual Model of Arid Rangeland Degradation, The escalating cost of declining productivity, BioScience, vol. 44(2), pp. 70-76.

Milton, SJ 1995, Spatial and temporal patterns in the emergence and survival of seedlings in arid Karoo shrubland, Journal of Applied Ecology, vol. 32, pp. 145-156.

Milton, SJ \& Dean, WR 1995, South Africa`s Arid And Semiarid Rangelands: Why Are They Changing And Can They Be Restored? Environmental Monitoring and Assessment, vol. 37, pp. 245-264.

Milton, SJ, Dean, WRJ, Marincowitz, CP \& Kerley, GIH 1995, Effects of the 1990/91 drought on rangeland in the Steytlerville Karoo, South Africa. South African Journal of Science, vol. 91, pp. 78-84.

Mokolobate, MS \& Haynes, RJ 2002, Comparative liming effect of four organic residues applied to an acid soil, Biology and Fertility of Soils, vol. 35,pp. 79-85.

Moro, MJ, Pugnaire, Fl, Haase, P \& Puigdefabregas, J 1997, Mechanisms of interaction between a leguminous shrub and its understorey in a semi-arid environment, Ecograph, vol. 20, pp. 175-184.

Mucina, L, Jürgens, N, Le Roux, A, Rutherford, MC, Schmiedel, U, Esler, KJ, Powrie LW, Desmet, PG and Milton, SJ 2006, Succulent Karoo Biome. In: Mucina, L \& Rutherford, MC (eds) 2006, The Vegetation of Southern Africa, Lesotho and Swaziland, Strelitzia 19. South African National Biodiversity Institute, Pretoria, pp 220-299.

Myers, N, Mittermeier, RA, Mittermeier, CG, da Fonseca, GAB \& Kent, J 2000, Biodiversity hotspots for conservation priorities, Nature, vol. 403, pp. 853-858.

Naramabuye, FX \& Haynes, RJ 2006, Effect of organic amendments on soil pH and Al solubility and use of laboratory indices to predict their liming effect, Soil Science, vol. 171(10), pp. 754-763.

Naramabuye, FX \& Haynes, RJ 2007, The liming effect of five organic manures when incubated with an acid soil, Journal of. Plant Nutrition and. Soil Sciecnes, vol. 170, pp. 615-622.

Naveh, Z \& Whittaker, RH 1979, Structural And Floristic Diversity Of Shrublands And Woodlands In Northern Israel And Other Mediterranean Areas, Vegetatio, vol. 41(3), pp. 171-190.

O'Connor, TG 1991, Local extinction in perennial grasslands: a life-history approach, American Naturalist, vol. 137, pp. 753773.

O'Connor, TG \& Roux, PW 1995, Vegetation changes (1949-71) in a semi-arid, grassy dwarf shrubland in the Karoo, South Africa: influence of rainfall variability and grazing by sheep, Journal of Applied Ecology, vol. 32, pp. 612-626.

Petersen, A 2008, Pedodiversity of southern African drylands, Dissertation, University of Hamburg, department of geosciences. 
Pineiro, G, Paruelo, JM, Jobbagy, EG, Jackson, RB \& Oesterheld, M 2009 Grazing effects on belowground C and N stocks along a network of cattle exclosures in temperate and subtropical grasslands of South America, Global Biogeochemical Cycles, vol. 23, GB2003.

Quinn, GP \& Keough, MJ 2002, Experimental Design and Data Analysis for Biologists, Cambridge University Press, Cambridge.

Rahlao, SJ, Hoffman, MT, Todd, SW \& McGrath, K 2007, Long-term vegetation change in the Succulent Karoo, South Africa following 67 years of rest from grazing, Journal of Arid Environments, vol. 72, pp. 808-819.

Richardson, FD, Hahn, BD \& Hoffman, MT 2007, Modelling the sustainability and productivity of pastoral systems in the communal areas of Namaqualand, Journal of Arid Environments, vol. 70, pp. 701-717.

Riginos, C \& Hoffman, MT 2003, Changes in population biology of two succulent shrubs along a grazing gradient, Journal of Applied Ecology, vol. 40, pp. 615-625.

Röwer, IU 2009, Small-scale vegetation and biodiversity patterns of termitaria (heuweltjies) under different grazing pressures in the communal area of Soebatsfontein, South Africa, Diploma thesis, University of Hamburg, Biocentre Klein Flottbek \& Botanical Garden.

Samuels, MI, Allsopp, N \& Knight, RS 2007, Patterns of resource use by livestock during and after drought on the commons of Namaqualand, South Africa, Journal of Arid Environments, vol. 70, pp. 728-739.

Sasaki, T, Okayasu, T, Ohkuro, T, Shirato, Y, Jamsran, U \& Takeuchi, K 2009, Rainfall variability may modify the effects of long-term exclosure on vegetation in Mandalgobi, Mongolia, Journal of Arid Environments, vol. 73, pp. 949-954.

Schmiedel, U \& Jürgens, 1999, Community structure on unusual habitat islands: quartz-fields in the Succulent Karoo South Africa, Plant Ecology, vol. 142(1\&2), pp. 57-69.

Schmiedel, U 2002, The Quartz Fields Of Southern Africa flora, phytogeography, vegetation, and habitat ecology, Dissertation, University of Cologne, Cologne.

Schmiedel, U \& Jürgens, N 2004, Habitat ecology of southern African quartz fields: studies on the thermal properties near the ground, Plant Ecology, vol. 170(2), pp. 153-166.

Schmiedel, U, Dengler, J \& Etzold, S (in prep.) Long term trends in the population dynamics of endemic succulent plants of Namaqualand, South Africa in response to an increase in rainfall variability and temperature. To be submitted to Journal of Ecology.

Simons, L \& Allsopp, N 2007, Rehabilitation of Rangelands in Paulshoek, Namaqualand: Understanding vegetation change using biophysical manipulations, Journal of Arid Environments, vol. 70, pp. 755-766.

Smet, M \& Ward, D 2006, Soil quality gradients around water-points under different management systems in a semi-arid savanna, South Africa, Journal of Arid Environments, vol. 64, pp. 251-269.

Snyman, HA 1998, Literature review Dynamics and sustainable utilization of rangeland ecosystems in arid and semi-arid climates of southern Africa, Journal of Arid Environments, vol. 39, pp. 645-666.

Snyman, HA 1999, Short-term effects of soil water, defoliation and rangeland condition on productivity of a semi-arid rangeland in South Africa, Journal of Arid Environments, vol. 43, pp.47-62.

Snyman, HA 2003, Revegetation of bare patches in a semi-arid rangeland of South Africa: an evaluation of various techniques, Journal of Arid Environments, vol. 55, pp. 417-432.

Stock, WD, Dlamini, TS \& Cowling, RM 1999, Plant induced fertile islands as possible indicators of desertification in a succulent desert ecosystem in northern Namaqualand, South Africa, Plant Ecology, vol. 142, pp. 161-167.

Todd, SW \& Hoffmann, MT 1999, A fence-line contrast reveals effects of heavy grazing on plant diversity and community composition in Namaqualand, South Africa, Plant Ecology, vol. 142, pp. 169-178.

Todd, SW 2006, Gradients in vegetation cover, structure and species richness of Nama-Karoo shrublands in relation to distance from livestock watering points, Journal of Applied Ecology, vol. 43, pp. 293-304. 
Tongway, DJ \& Ludwig, JA 1996a, Rehabilitation of Semiarid Landscapes in Australia. I. Restoring Productive Soil Patches, Restoration Ecology, vol. 4(4), pp. 338-397.

Tongway, DJ \& Ludwig, JA 1996b, Rehabilitation of Semiarid Landscapes in Australia. II. Restoring Vegetation Patches, Restoration Ecology, vol. 4(4), pp. 398-406.

van den Berg, L \& Kellner, K 2005, Restoring degraded patches in a semi-arid rangeland of South Africa, Journal of Arid Environments, vol. 61, pp. 497-551.

van Rooyen, MW 2002, Management of the old field vegetation in the Namaqua National Park, South Africa: conflicting demands of conservation and tourism, The Geographical Journal, vol. 168(3), pp. 221-223.

van Tonder, C 2007, Factors influencing quartz field vegetation diversity in northern Namaqualand, South Africa, Magister Technologiae: Nature Conservation, Nelson Mandela Metropolitan University, Saasveld, South Africa.

Vetaas, OR 1992, Micro-site effects of trees and shrubs in dry savannas, Journal of Vegetation Science, vol. 3, pp. 337-344.

Visser, N, Botha, JC, \& Hardy, MB 2004, Re-establishing vegetation on bare patches in the Nama Karoo, South Africa, Journal of Arid Environments, vol. 57, pp. 15-37.

von Willert, DJ, Brinckmann, E, Scheitler, B \& Eller, BM 1985, Availability of water controls CAM in succulents of the Richtersveld (Namib desert, South Africa), Jahrbücher für Wissenschaftliche Botanik, vol. 84, pp. 58-222.

von Willert, DJ, Werger, MJA, Brinckmann, E, Ihlenfeldt, H-D \& Eller, BM 1992, Life strategies of succulents in deserts: with special reference to the Namib Desert. Cambridge University Press, Cambridge.

Warren, SD, Thurow, TL, Blackburn, WH \& Garza, NE 1986, The Influence of Livestock Trampling under Intensive Rotation Grazing on Soil Hydrologic Characteristics, Journal of Range Management, vol. 39(6), pp. 491-495.

Westman, WE 1977, How much are nature's services worth? Science, vol. 197, pp. 960-964.

Whalen, JK, Chang, C, Clayton, WC \& Carefoot, P 2000, Cattle Manure Amendments Can Increase the pH of Acid Soils, Soil Science Society of America Journal, vol. 64,pp. 962-966.

Wiegand, T \& Milton, SJ 1996, Vegetation change in semiarid communities, Simulating probabilities and time scales, Vegetatio, vol. 125, pp. 169-183.

Wiegand, T, Jeltsch, F, Bauer, S \& Kellner, K 1998, Simulation models for semi-arid rangelands of Southern Africa, African Journal of Range and Forage Science, vol. 15(1\&2), pp. 48-60.

Wong, MTF, Nortcliff, S \& Swift, RS 1999 Method for determining the acid ameliorating capacity of plant residue compost, urban waste compost, farmyard manure, and peat applied to tropical soils, Communications in Soil Science and Plant Analysis, vol. 29(19), pp. 2927-2937.

Yeaton, RI \& Esler, KJ 1990, The dynamics of a succulent karoo vegetation, A study of species association and recruitment, Vegetatio, vol. 88, pp. 103-113.

Zink, AT, Allen, MF 1998, The Effects of Organic Amendments on the Restoration of a Disturbed Coastal Sage Scrub Habitat, Restoration Ecology, vol. 6(1), pp. 52-58. 


\section{Appendix}

Appendix I Results of the discriminant analysis for treatment as grouping variable and logEC, $\mathrm{pH}$ and $\mathrm{C} / \mathrm{N}$ as independent variables for the Soebatsfontein dataset. Presented are Eigenvalues of the first three functions and the percentage of variance they explain. $\mathrm{N}=96$.

\begin{tabular}{lcccc}
\hline Function & Eigenvalue & \% of Variance & Cumulative \% & Canonical Correlation \\
1 & .714 & 97.2 & 97.2 & .645 \\
2 & .020 & 2.7 & 99.9 & .140 \\
3 & .001 & .1 & 100.0 & .023 \\
\hline
\end{tabular}

Appendix II Values for the group centroids along the first and second axis found by the canonical discriminant analysis for the four treatment groups of the Soebatsfontein restoration subplots. $\mathrm{N}=96$.

\begin{tabular}{lcc}
\hline treatment & function 1 & function 2 \\
\hline control & -.586 & -.149 \\
stones & -.649 & .211 \\
brush & .374 & -.014 \\
manure \& palm fronds & 1.438 & .014 \\
\hline
\end{tabular}

Appendix III Total annual rainfall for the climate station Soebatsfontein for 2001-2008. Note that in 2001 the values January-March and in $\mathbf{2 0 0 8}$ values for November-December are missing.

\begin{tabular}{lccccccccc}
\hline rain in $\mathrm{mm}$ & 2001 & 2002 & 2003 & 2004 & 2005 & 2006 & 2007 & 2008 & mean \\
\hline annual & 141.0 & 122.0 & 97.4 & 128.6 & 122.0 & 175.2 & 146.6 & 109.2 & 130.25 \\
\hline
\end{tabular}

Appendix IV Seasonal rainfall data for the climate station Soebatsfontein for 2001-2008. Values for MAM 2001, SON and DJF 2008 are imputed.

\begin{tabular}{lrrrrrrrrr}
\hline rain in mm & 2001 & 2002 & 2003 & 2004 & 2005 & 2006 & 2007 & 2008 & \multicolumn{2}{l}{ mean } \\
\hline MAM & N.N. & 26.2 & 11 & 29.4 & 43.6 & 60.6 & 40 & 24.8 & 33.66 \\
JJA & 98.4 & 37.6 & 62.4 & 43.8 & 42.4 & 97.4 & 74.8 & 57.6 & 59.43 \\
SON & 22.6 & 40 & 21 & 43.2 & 33 & 12 & 18.4 & 23.2 & 27.26 \\
DJF & 12.4 & 6.4 & 14.8 & 3.2 & 4.2 & 5.6 & 14.4 & 8.7 & 8.19 \\
\hline
\end{tabular}


Appendix V Relationship between annual rainfall and mean relative abundance of different life form groups for all 96 restoration subplots at Soebatsfontein for 2004-2008.

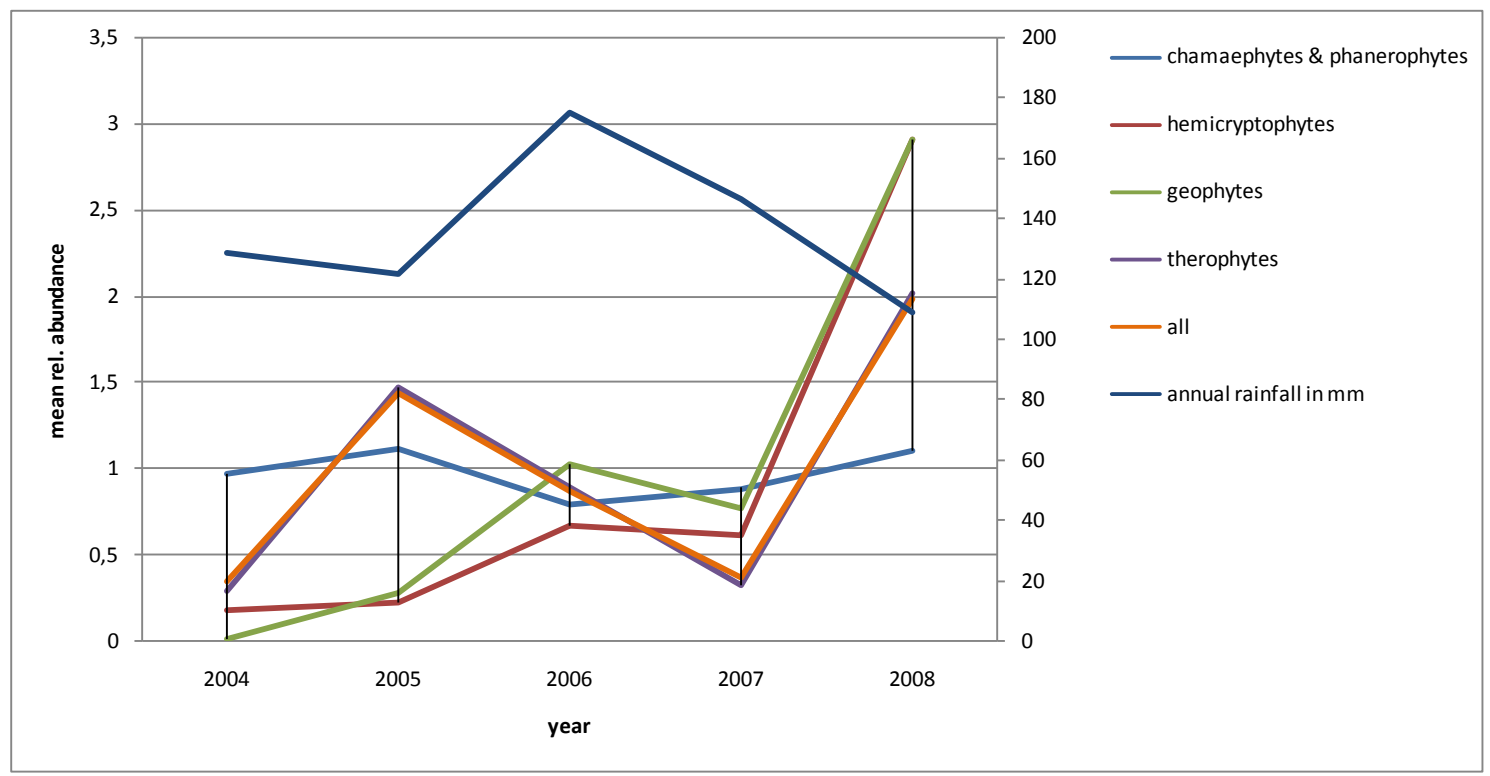

Appendix VI Comparison of the mean total cover at Patrysegat and Quaggasfontein for 2004-2008. $p$ values were obtained by Mann-Whitney-U tests. dF=3.

\begin{tabular}{|c|c|c|c|}
\hline & Patrysegat & Quaggasfontein & \\
\hline year & mean SD & mean SD & $p$ \\
\hline 2004 & $11.74 \quad 5.58$ & $4.94 \quad 2.76$ & .000 \\
\hline 2005 & $12.37 \quad 5.67$ & 3.781 .82 & .000 \\
\hline 2006 & $25.38 \quad 11.14$ & $9.32 \quad 7.47$ & .000 \\
\hline 2007 & $32.07 \quad 11.44$ & $12.07 \quad 4.02$ & .000 \\
\hline 2008 & 21.607 .20 & 12.107 .98 & .000 \\
\hline
\end{tabular}


Appendix VII Differences between active treatments on mean total cover of annuals and perennials at fenced and unfenced subplots at Patrysegat. $p$-values are obtained by Kruskal-Wallis tests with applied Bonferroni-Holm correction; $\mathrm{dF}=3$; $\mathrm{N}=\mathbf{2 4}$. Small letters in bold behind the total means indicate group separation obtained by LFH tests with Bonferroni-Holm correction. The values for 2004 are included to give an estimate of homogeneity of the subplots. MTC= mean total cover.

\begin{tabular}{|c|c|c|c|c|c|c|c|c|c|c|c|c|c|}
\hline \multirow[b]{2}{*}{ year } & \multicolumn{2}{|c|}{ control } & \multicolumn{2}{|c|}{ stones } & \multicolumn{2}{|c|}{ brush } & \multicolumn{2}{|c|}{ manure $\&$ palm fronds } & \multicolumn{2}{|c|}{ annuals } & \multicolumn{2}{|c|}{ perennials } & \multirow[t]{2}{*}{ MTC } \\
\hline & A & $P$ & A & $P$ & A & $P$ & $\mathrm{~A}$ & $P$ & $\mathrm{Chi}^{2}$ & $\mathrm{p}$ & $\mathrm{Chi}^{2}$ & $p$ & \\
\hline \multicolumn{14}{|l|}{ fenced } \\
\hline 2004 & $3.70 \pm 3.29$ & $5.77 \pm 5.01$ & $11.76 \pm 8.09$ & $1.64 \pm 1.34$ & $8.25 \pm 4.28$ & $7.83 \pm 5.14$ & $5.13 \pm 6.03$ & $4.42 \pm 2.72$ & 7.861 & .039 & 6.400 & .086 & $11.68 \pm 6.21$ \\
\hline 2005 & $5.15 \pm 2.57$ & $5.05 \pm 4.07$ & $11.54 \pm 5.42$ & $1.84 \pm 1.55$ & $5.96 \pm 2.83$ & $4.08 \pm 3.37$ & $5.03 \pm 3.25$ & $2.89 \pm 2.99$ & 6.046 & .105 & 2.845 & .434 & $10.35 a \pm 4.76$ \\
\hline 2006 & $18.47 \pm 9.10$ & $4.84 \pm 4.37$ & $20.40 \pm 6.82$ & $4.14 \pm 2.88$ & $23.78 \pm 15.27$ & $6.81 \pm 3.11$ & $21.91 \pm 9.22$ & $5.16 \pm 5.89$ & .328 & .961 & 1.851 & .626 & $25.86 \mathrm{~b} \pm 10.94$ \\
\hline 2007 & $21.53 \pm 10.16$ & $9.16 \pm 6.04$ & $34.05 \pm 5.03$ & $5.20 \pm 1.69$ & $32.65 \pm 13.22$ & $6.97 \pm 2.24$ & $31.67 \pm 19.46$ & $7.14 \pm 8.66$ & 5.385 & .140 & 2.857 & .432 & $36.03 c \pm 12.85$ \\
\hline 2008 & $13.33 \pm 4.48$ & $5.29 \pm 4.40$ & $18.31 \pm 7.48$ & $3.80 \pm 1.49$ & $9.81 \pm 5.49$ & $6.06 \pm 3.95$ & $13.69 \pm 4.74$ & $6.17 \pm 6.70$ & 4.640 & .202 & .736 & .880 & $19.03 d \pm 5.82$ \\
\hline \multicolumn{14}{|l|}{ unfenced } \\
\hline 2004 & $4,52 \pm 3,24$ & $5,57 \pm 4,02$ & $4,56 \pm 2,47$ & $6,85 \pm 2,14$ & $3,83 \pm 4,32$ & $6,67 \pm 5,55$ & $6,51 \pm 4,54$ & $10,00 \pm 5,79$ & 1,427 & ,719 & 2,283 & ,536 & $11,79 \pm 5,01$ \\
\hline 2005 & $6,70 \pm 3,36$ & $8,18 \pm 5,04$ & $7,73 \pm 1,80$ & $8,44 \pm 5,32$ & $4,60 \pm 1,97$ & $5,69 \pm 3,12$ & $6,98 \pm 3,37$ & $8,83 \pm 4,25$ & 4,712 & 195 & 1,602 & 679 & $14,39 a \pm 5,87$ \\
\hline 2006 & $13,00 \pm 8,47$ & $7,52 \pm 4,09$ & $14,68 \pm 9,81$ & $11,19 \pm 3,06$ & $23,24 \pm 13,57$ & $7,04 \pm 3,03$ & $19,75 \pm 7,27$ & $8,14 \pm 5,01$ & 5,822 & ,117 & ,702 & 887 & $24,90 b \pm 11,56$ \\
\hline 2007 & $16,69 \pm 6,93$ & $12,53 \pm 7,33$ & $9,84 \pm 7,28$ & $14,42 \pm 7,79$ & $21,13 \pm 7,11$ & $9,97 \pm 3,50$ & $17,08 \pm 6,32$ & $9,95 \pm 2,52$ & 5,812 & 117 & 878 & ,848 & $28,12 b \pm 8,35$ \\
\hline 2008 & $10,94 \pm 4,20$ & $11,51 \pm 7,86$ & $11,19 \pm 3,06$ & $13,21 \pm 9,36$ & $14,67 \pm 13,02$ & $14,35 \pm 9,81$ & $10,90 \pm 2,93$ & $11,23 \pm 4,55$ & 140 & ,990 & ,420 & ,943 & $24,16 b \pm 7,64$ \\
\hline
\end{tabular}


Appendix VIII Comparison of the mean number of individuals at Patrysegat and Quaggasfontein for 2004-2008. $p$ values were obtained by Mann-Whitney-U tests with applied Bonferroni-Holm correction; dF=3.

\begin{tabular}{lrlrll}
\hline & \multicolumn{2}{c}{ Patrysegat } & \multicolumn{3}{c}{ Quaggasfontein } \\
\hline year & mean & SD & mean & SD & \multicolumn{1}{l}{$\mathrm{p}$} \\
2004 & 51.96 & 37.12 & 65.96 & 34.67 & .042 \\
2005 & 424.56 & 317.07 & 245.35 & 287.03 & .000 \\
2006 & 233.85 & 301.41 & 144.08 & 54.50 & .308 \\
2007 & 77.04 & 43.64 & 70.06 & 39.54 & .315 \\
2008 & 497.08 & 317.77 & 344.13 & 175.62 & .005 \\
\hline
\end{tabular}

Appendix IX Selected pictures of the restoration subplots at Patrysegat (Soebatsfontein) top left fenced subplot with "stones" treatment; top right fenced subplot with" brushpacks"; down left fenced subplot "control" and down right unfenced subplot with treatment "manure \& palm fronds from 26.09.05.
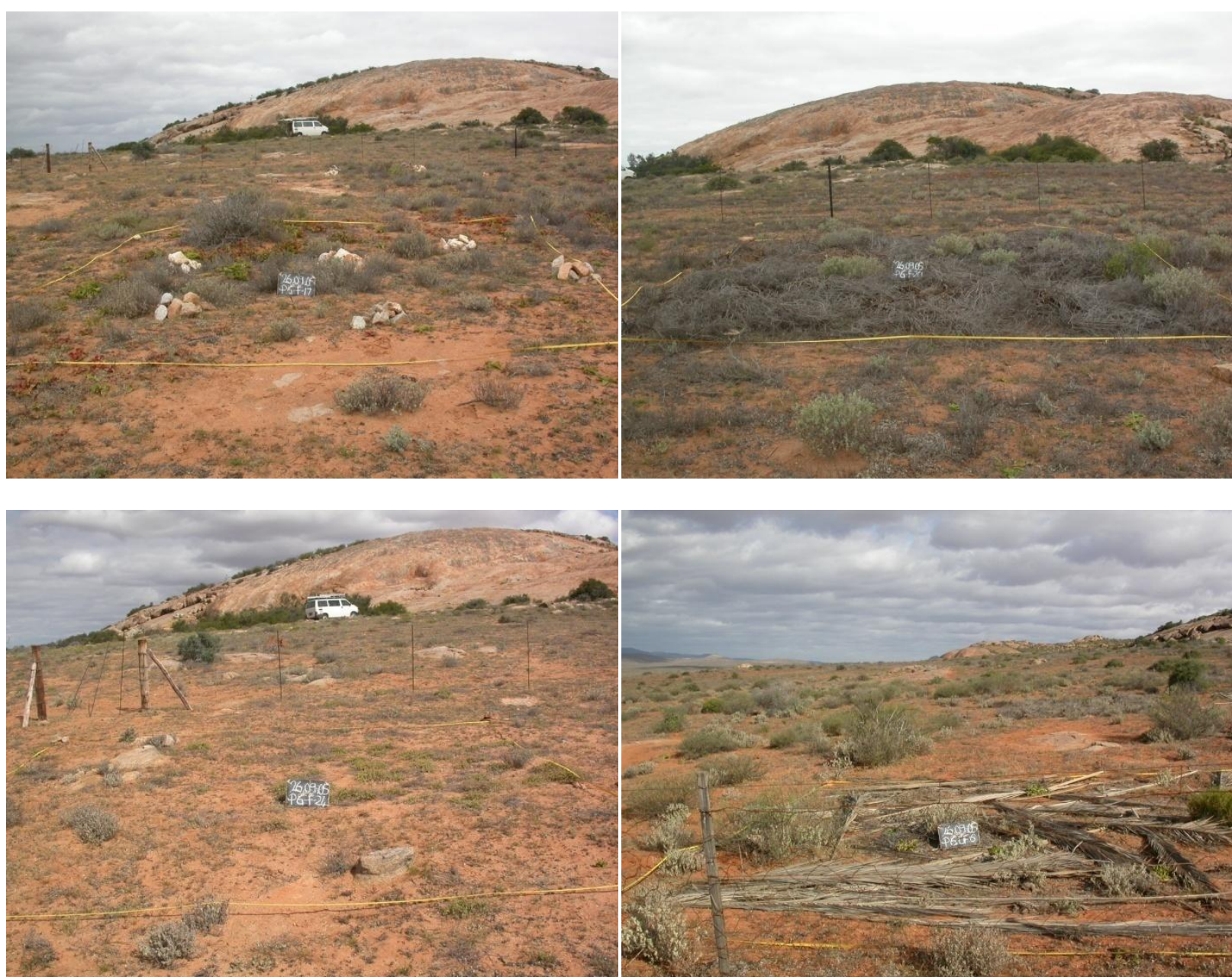


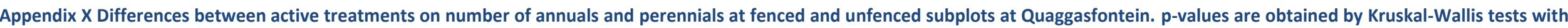

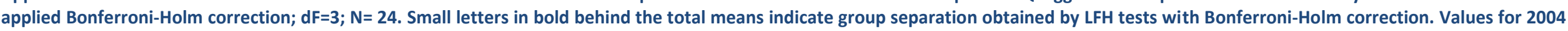
present the pre-treatment situation and are included to give an estimate of homogeneity of the subplots. MNI= Mean number of individuals.

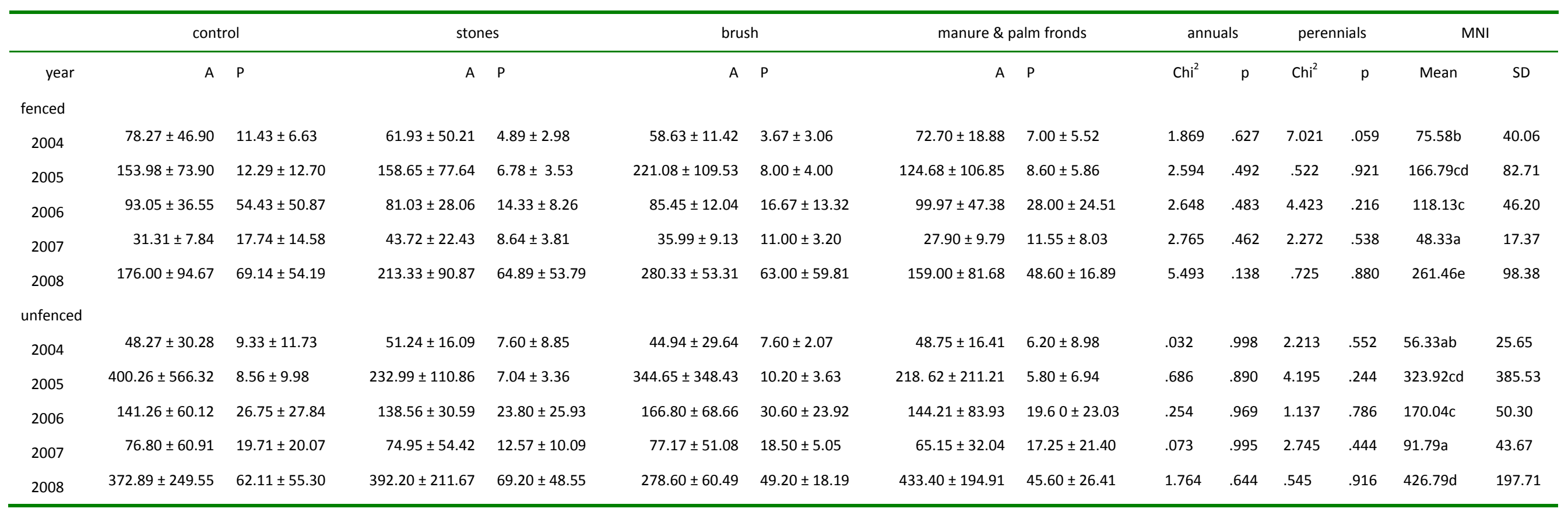


Appendix XI Differences in species richness of annuals and perennials between active treatments at fenced and unfenced subplots at Patrysegat. $p$ values were obtained by Kruskal-Wallis tests with $\mathrm{dF}=3$. Small letters in bold behind the means indicate homogenous groups obtained by LSH with Bonferroni-Holm correction. MSR= mean species richness

\begin{tabular}{|c|c|c|c|c|c|c|c|c|c|c|c|c|c|c|}
\hline \multirow[b]{2}{*}{ year } & \multicolumn{2}{|c|}{ control } & \multicolumn{2}{|c|}{ stones } & \multicolumn{2}{|c|}{ brush } & \multicolumn{2}{|c|}{ manure \& palm fronds } & \multicolumn{2}{|c|}{ annuals } & \multicolumn{2}{|c|}{ perennials } & \multicolumn{2}{|c|}{ MSR } \\
\hline & A & $\mathrm{P}$ & A & $\mathrm{P}$ & A & $P$ & A & $\mathrm{P}$ & $\mathrm{Chi}^{2}$ & $p$ & $\mathrm{Chi}^{2}$ & $p$ & mean & SD \\
\hline \multicolumn{15}{|l|}{ fenced } \\
\hline 2004 & $3.00 \pm 1.32$ & $3.56 \pm 1.59$ & $4.00 \pm 2.35$ & $3.20 \pm 2.17$ & $3.00 \pm 1.58$ & $2.80 \pm 0.84$ & $1.80 \pm 0.45$ & $2.40 \pm 1.34$ & 5.185 & .156 & 1.930 & .613 & $6.04 a$ & 2.71 \\
\hline 2005 & $7.56 \pm 4.36$ & $3.67 \pm 1.66$ & $8.20 \pm 4.87$ & $3.80 \pm 2.05$ & $4.40 \pm 1.14$ & $3.00 \pm 1.87$ & $4.00 \pm 0.71$ & $2.80 \pm 0.84$ & 6.464 & .086 & 1.665 & .672 & $9.67 b$ & 4.37 \\
\hline 2006 & $8.00 \pm 2.45$ & $3.67 \pm 2.00$ & $8.40 \pm 2.97$ & $4.60 \pm 1.82$ & $7.20 \pm 1.92$ & $2.80 \pm 1.30$ & $6.20 \pm 2.17$ & $3.20 \pm 0.84$ & 1.625 & .676 & 3.558 & .333 & $11.13 c$ & 3.17 \\
\hline 2007 & $11.33 \pm 2.78$ & $5.11 \pm 1.27$ & $14.00 \pm 2.00$ & $5.40 \pm 1.82$ & $10.00 \pm 4.64$ & $5.00 \pm 1.41$ & $7.80 \pm 1.92$ & $5.80 \pm 1.10$ & 8.376 & .028 & .993 & .821 & $16.17 d$ & 3.89 \\
\hline 2008 & $11.22 \pm 2.91$ & $5.11 \pm 1.83$ & $12.40 \pm 2.41$ & $5.20 \pm 1.79$ & $7.40 \pm 3.13$ & $4.20 \pm 0.84$ & $11.00 \pm 2.24$ & $3.60 \pm 1.67$ & 6.063 & .102 & 2.622 & .483 & $15.25 d$ & 3.81 \\
\hline \multicolumn{15}{|c|}{ unfenced } \\
\hline 2004 & $1.89 \pm 0.78$ & $3.44 \pm 1.67$ & $2.20 \pm 0.45$ & $2.80 \pm 0.84$ & $2.60 \pm 0.55$ & $4.00 \pm 1.22$ & $1.80 \pm 0.84$ & $3.80 \pm 1.30$ & 4.093 & .255 & 2.640 & .475 & $5.58 a$ & 1.50 \\
\hline 2005 & $6.67 \pm 2.18$ & $4.78 \pm 1.56$ & $5.20 \pm 1.92$ & $3.80 \pm 1.30$ & $5.00 \pm 2.00$ & $3.80 \pm 1.10$ & $5.40 \pm 1.52$ & $4.60 \pm 1.14$ & 2.672 & .462 & 2.703 & .463 & $10.08 \mathrm{~b}$ & 2.90 \\
\hline 2006 & $8.89 \pm 1.27$ & $4.44 \pm 1.74$ & $10.40 \pm 2.07$ & $4.40 \pm 1.82$ & $8.20 \pm 1.92$ & $4.80 \pm 1.48$ & $10.00 \pm 3.16$ & $6.80 \pm 1.30$ & 3.198 & .378 & 6.528 & .086 & $14.29 \mathrm{c}$ & 3.13 \\
\hline 2007 & $11.00 \pm 2.55$ & $5.78 \pm 1.39$ & $10.00 \pm 3.81$ & $5.40 \pm 2.61$ & $10.00 \pm 2.35$ & $4.60 \pm 0.55$ & $8.80 \pm 1.30$ & $5.80 \pm 2.28$ & 2.725 & .454 & 2.461 & .512 & $15.58 \mathrm{c}$ & 3.63 \\
\hline 2008 & $11.67 \pm 1.32$ & $6.11 \pm 1.96$ & $12.80 \pm 3.83$ & $6.00 \pm 1.58$ & $13.60 \pm 2.51$ & $6.00 \pm 1.58$ & $13.60 \pm 3.21$ & $7.20 \pm 1.48$ & 2.400 & .511 & 1.902 & .621 & $19.00 \mathrm{~d}$ & 3.32 \\
\hline
\end{tabular}


Appendix XII Total annual rainfall for the climate station Luiperskop (Ratelgat) montly rain data before April 2001 and after August 2008 are missing.

\begin{tabular}{lrrrrrrrrr}
\hline rain in $\mathrm{mm}$ & 2001 & 2002 & 2003 & 2004 & 2005 & 2006 & 2007 & 2008 & mean \\
\hline annual & 145,40 & 146,00 & 69,20 & 73,84 & 84,40 & 166,60 & 152,95 & 157,80 & 124.52 \\
\hline
\end{tabular}

Appendix XIII Organization of electronic appendices

\begin{tabular}{lcl}
\hline No & \multicolumn{1}{c}{ file name } & \multicolumn{1}{c}{ content } \\
\hline 1 & soil_parameters_Soebatsfontein & Compilation of $\mathrm{pH}, \mathrm{EC}, \mathrm{N} \_\mathrm{T}, \mathrm{C} \mathrm{T}_{\mathrm{T}}$ and $\mathrm{C} / \mathrm{N}$ values of all 96 subplots at \\
& & $\begin{array}{l}\text { Soebatsfontein. And overview of the applied treatments for each } \\
\text { subplot. }\end{array}$
\end{tabular}

2 rainfall_data_Soebatsfontein

3

imputed_abundance_data_Soebatsfontein

calculated_sum_vegetation_ parameters_Soebatsfontein

5

imputed_cover_abundance_data_Soebatsfontein

6

rainfall_data_Ratelgat

7

Ruschia_burtoniae_community_Ratelgat

8

Cephalophyllum_spissum_community_Ratelgat

9 zonal_vegetation_plots_Ratelgat

10

transfer_specieslist_fieldnames_Ratelgat
List of monthly precipitation for the climate station Soebatsfontein April 2001- December 2008.

Calculation of missing abundance values after the procedure described in the methods section. Full species list with abundance values per subplot.

Compilation of total cover, species richness and abundances of annual and perennial species per subplot and year at Soebatsfontein.

List of missing abundance values, the imputed cover values and a final list with all individuals found in the subplots with their (corrected) abundance and cover values.

List of monthly precipitation for the climate station Ratelgat April 2001- August 2008.

Raw data for the Ruschia burtoniae community plots at Ratelgat, with abundances and cover values. Calculated sum parameters per plot (species richness, number of individuals and total cover) for all species and R. burtoniae individuals only.

Raw data for the Cephalophyllum spissum community plots at Ratelgat, with abundances and cover values. Calculated sum parameters per plot (species richness, number of individuals and total cover) for all species and C.spissum individuals only.

Raw data for all plots with abundances and life form. Calculation of species richness and number of individuals within different life form groups. Abundances and species composition before and after treatment installation in 2004.

List with final species names as utilized in the species list and different fieldnames 
Appendix XIV Species names, family, life form and author of recorded species from Soebatfsfontain. Life forms: T= therophyte; C: chamaephyt ; $\mathrm{Cmac}=30-50 \mathrm{~cm} ; \mathrm{Cmes}=15-30 \mathrm{~cm}, \mathrm{Cmic}=5-15 \mathrm{~cm}, \mathrm{Cnan}=\langle 5 \mathrm{~cm} ; \mathrm{G}=$ geophyte; $\mathrm{H}=$ hemicryptophyte; $\mathrm{L}=$ liane; $\mathrm{P}=$ phanerophyte; Pmes = 100-200cm; Pmic, Pnan= 50-100 cm. Nomenclature follows the annotated checklist "Plants of southern Africa" (Germishuizen \& Meyer 2003) besides the fact that the Mesembryanthemaceae are included in the Aizoaceae.

\begin{tabular}{|c|c|c|c|c|c|}
\hline Name & Life form & Author & Name & Life form & Author \\
\hline Dicotyledonae & & & Pteronia divaricata & Cmes & (P.J. Bergius) Less. \\
\hline Aizoaceae & & & Rhynchopsidium pumilum & $\mathrm{T}$ & (L.f.) DC. \\
\hline Aizoon canariense & $\mathrm{T}$ & L. & Senecio abruptus & $\mathrm{T}$ & Thunb. \\
\hline Cleretum papulosum & $\mathrm{T}$ & (L.f.) L.Bolus & Sonchus oleraceus & $\mathrm{T}$ & L. \\
\hline ssp. papulosum & & & Trichogyne lerouxiae & $\mathrm{T}$ & Beyers \\
\hline Dorotheanthus bellidiformis & $\mathrm{T}$ & (Burm.f) N.E.Br. & Tripteris amplectens & $\mathrm{T}$ & Harv. \\
\hline ssp. bellidiformis & & & Tripteris clandestina & $\mathrm{T}$ & Less. \\
\hline Drosanthemum hispidum & Cmic & (L.) Schwantes & Tripteris hyoseroides & $\mathrm{T}$ & DC. \\
\hline Eberlanzia cyathiformis & Cmes & (L.Bolus) H.E.K. Hartmann & Tripteris sp. & $\mathrm{T}$ & Less. \\
\hline Galenia africana & Cmes & L. & Brassicaceae & & \\
\hline Galenia fruticosa & Cmes & (L.f.) Sond. & Brassicaceae ann. borstig & $\mathrm{T}$ & \\
\hline Galenia meziana & Cmic & K. Müll. & Heliophila variabilis & $\mathrm{T}$ & Burch. ex DC. \\
\hline Galenia sarcophylla & Cmes & Fenzl & Lepidium desertorum & $\mathrm{T}$ & Eckl. \& Zeyh. \\
\hline Mesembryanthemum & $\mathrm{T}$ & Pax & Campanulaceae & & \\
\hline guerichianum & & & Wahlenbergia sp. & $\mathrm{T}$ & Schrad. ex Roth \\
\hline Psilocaulon dinteri & Cmes & (Engl.)Schwantes & Wahlenbergia androsacea & $\mathrm{T}$ & A.DC. \\
\hline Tetragonia fruticosa & Cmes & L. & Wahlenbergia prostrata & $\mathrm{T}$ & A.DC. \\
\hline Tetragonia microptera & $\mathrm{T}$ & Fenzl & Wahlenbergia sessiliflora & $\mathrm{T}$ & Brehmer \\
\hline Tetragonia verrucosa & Cmes & Fenzl & Caryophyllaceae & & \\
\hline Anacardiaceae & & & Dianthus klein & $\mathrm{T}$ & L. \\
\hline Rhus incisa & Pmic & (C.Presl) R.Fern. & Silene burchellii var. angustifolia & H & Otth Sond. \\
\hline Rhus undulata & Pmes & Jacq. & Chenopodiaceae & & \\
\hline Apocynaceae & & & Atriplex lindleyi ssp. inflata & $\mathrm{T}$ & Moq. subsp.(F.Muell.) \\
\hline Microloma sagittatum & Cmes & (L.) R.Br. & & & Paul G. Wilson \\
\hline Asteraceae & & & Atriplex semibaccata & $\mathrm{T}$ & R.Br. \\
\hline Amellus microglossus & $\mathrm{T}$ & DC. & Chenopodium album & $\mathrm{T}$ & L. \\
\hline Arctotheca calendula & $\mathrm{T}$ & (L.) Levyns & Chenopodium murale & $\mathrm{H}$ & L. \\
\hline Arctotis fastuosa & $\mathrm{T}$ & Jacq. & Manochlamys albicans & Cmes & (Aiton) Aellen \\
\hline Arctotis undulata & $\mathrm{T}$ & Jacq & Salsola kali & $\mathrm{T}$ & L. \\
\hline Berkheya fruticosa & Cmes & (L.) Ehrh. & Salsola sp. & Cmes & L. \\
\hline Didelta spinosa & Pnan & (L.f.) Aiton & Crassulaceae & & \\
\hline Dimorphotheca sinuata & $\mathrm{T}$ & DC. & Crassula vaillantii & $\mathrm{T}$ & (Willd.) Roth \\
\hline Felicia merxmuelleri & $\mathrm{T}$ & Grau & Cucurbitaceae & & \\
\hline Foveolina dichotoma & $\mathrm{T}$ & (DC.) Källersjö & Citrullus lanatus & $\mathrm{T}$ & (Thunb.) Matsum. \& Nakai \\
\hline Gazania krebsiana var. & $\mathrm{H}$ & Less. Subsp. & Fabaceae & & \\
\hline krebsiana & & & Crotalaria humilis & $\mathrm{T}$ & Eckl. \& Zeyh. \\
\hline Gazania tenuifolia & $\mathrm{T}$ & Less & Crotalaria meyeriane & $\mathrm{H}$ & Steud. \\
\hline Gorteria diffusa & $\mathrm{T}$ & Thunb. & Indigofera fein gelb & $\mathrm{T}$ & L. \\
\hline Helichrysum alsinoides & $\mathrm{T}$ & DC. & Lebeckia multiflora & Pnan & E.Mey. \\
\hline Helichrysum dregeanum & $\mathrm{T}$ & Sond. \& Harv. & Lessertia diffusa & $\mathrm{T}$ & R.Br. \\
\hline Helichrysum leontonyx & $\mathrm{T}$ & DC. & Melolobium humile & Cmes & Eckl. \& Zey. \\
\hline Lasiospermum brachyglossum & $\mathrm{T}$ & DC. & Geraniaceae & & \\
\hline
\end{tabular}




\begin{tabular}{|c|c|c|c|c|c|}
\hline Name & Life form & Author & Name & Life form & Author \\
\hline Leysera tenella & $\mathrm{T}$ & DC. & Pelargonium minimum & $\mathrm{T}$ & (Cav.) Willd. \\
\hline Oncosiphon grandiflorum & $\mathrm{T}$ & (Thunb.)Källersjö & Malvaceae & & \\
\hline Oncosiphon suffruticosum & $\mathrm{T}$ & (L.)Källersjö & Malva parviflora & $\mathrm{T}$ & L.var. \\
\hline Othonna sedifolia & Cmes & DC. & Molluginaceae & & \\
\hline Pteronia ciliata & Cmes & Thunb. & Hypertelis salsoloides & Cnan & (Burch.) Adamson \\
\hline Limeum africanum & Cmic & R.Br. & Asparagaceae & & \\
\hline Pharnaceum croceum mini & $\mathrm{T}$ & E. Mey. ex Fenzl & Asparagus burchellii & Pnan & Baker \\
\hline Neuradaceae & & & Asparagus capensis & Cmes & L. \\
\hline Grielum humifusum & $\mathrm{H}$ & Thunb. & Asparagus multituberosus & $\mathrm{L}$ & R.A.Dyer \\
\hline Oxalidaceae & & & Asphodelaceae & & \\
\hline Oxalis ambigua & G & Jacq. & Trachyandra muricata & G & (L.f.) Kunth \\
\hline Oxalis Bõumchen & G & $\mathrm{L}$. & Trachyandra revoluta & G & (L.) Kunth \\
\hline Oxalis Fabaceae & G & L. & Colchicaceae & & \\
\hline Oxalis flach & G & L. & Androcymbium sp. & G & Willd. \\
\hline Oxalis gestielt Schirm & G & $\mathrm{L}$. & Ornithoglossum vulgare & G & B. Nord. \\
\hline Oxalis kurz gestielte Blüten & G & L. & Hyacinthaceae & & \\
\hline Oxalis pes-caprae & G & $\mathrm{L}$. & Albuca cooperi & G & Baker \\
\hline Oxalis sp. & G & L. & Albuca maxima & G & Burm. f. \\
\hline Oxalis zusammengef. Blätter & G & L. & Albuca verzweigt & G & L. \\
\hline Plantaginaceae & & & Lachenalia sp. & G & J.Jacq. ex Murray \\
\hline Plantago cafra & $\mathrm{T}$ & Decne. & Lachenalia framesii & G & W.F. Barker \\
\hline Polygonaceae & & & Ornithogalum Rinnenblatt & G & L. \\
\hline Emex australis & $\mathrm{T}$ & Steinh. & Ornithogalum polyphyllum & G & Jacq. \\
\hline Santalaceae & & & Ornithogalum suaveolens & G & Jacq. \\
\hline Thesium elatius & Cmes & Sond. & Ornithogalum xanthochlorum & G & Baker \\
\hline Scrophulariaceae & & & Iridaceae & & \\
\hline Hebenstretia parviflora & $\mathrm{T}$ & E.Mey. & Lapeirousia arenicola & G & Schltr. \\
\hline Lyperia tristis & $\mathrm{T}$ & (L.f.) Benth. & Poaceae & & \\
\hline Manulea corymbosa & $\mathrm{T}$ & L.f. & Bromus pectinatus & $\mathrm{T}$ & Thunb. \\
\hline Nemesia gr weiße Blüten & $\mathrm{T}$ & Vent. & Chaetobromus involucratus & $\mathrm{H}$ & (Schrad.) Nees \\
\hline Peliostomum virgatum & Cnan & E. Mey. Ex Benth. & Ehrharta flache & $\mathrm{T}$ & Thunb. \\
\hline Phyllopodium phyllopodioides & $\mathrm{T}$ & (Schltr.) Hilliard & Achse gewellter Rand & & \\
\hline Scrophulariaceae gekn. weiß & $\mathrm{T}$ & & Ehrharta pusilla & $\mathrm{T}$ & Ness ex Trin. \\
\hline Scrophulariacea kl. Blü wenig & $\mathrm{T}$ & & Fingerhuthia africana & $\mathrm{H}$ & Lehm. \\
\hline Selago divaricata & Pnan & L.f. & Pentaschistis patula & $\mathrm{T}$ & (Nees) Stapf \\
\hline Zaluzianskya affinis & $\mathrm{T}$ & Hilliard & Stipagrostis ciliata & $\mathrm{H}$ & (Desf.) De Winter \\
\hline Zaluzianskya benthamiana & $\mathrm{T}$ & Walp. & Stipagrostis obtusa & $\mathrm{H}$ & (Delile) Nees \\
\hline Solanaceae & & & Karroochloa schismoides & $\mathrm{T}$ & (Stapf ex Conert) \\
\hline Lycium sp. & Pnan & L. & & & Conert \& Türpe \\
\hline Lycium cinereum & Pnan & Thunb. & Stipa capensis & $\mathrm{T}$ & Thunb. \\
\hline Lycium ferocissimum & Pnan & Miers & Tribolium utriculosum & $\mathrm{T}$ & (Nees) Renvoize \\
\hline Lycium oxycarpum & Cmes & Dunal & Unknown family & & \\
\hline Solanum sp. & $\mathrm{H}$ & L. & Geophyt broad undulated & G & \\
\hline Sterculiaceae & & & Geophyt dunkle Blätter 1 & G & \\
\hline $\begin{array}{l}\text { Hermannia cuneifolia } \\
\text { var. glabrescens }\end{array}$ & Cmes & Jacq. (Harv.) I. Verd. & & & \\
\hline
\end{tabular}




\begin{tabular}{lll}
\hline Name & Life form & Author \\
\hline Hermannia trifurca & Cmes & L. \\
Zygophyllaceae & & \\
Tribulus zeyheri & T & Sond. \\
Zygophyllum morgsana & Pnan & L. \\
Zygophyllum retrofractum & Pnan & Thunb. \\
Monocotyledonae & & \\
Anthericaceae & & \\
Chlorophytum crassinerve & G & (Baker) Oberm. \\
& & \\
\hline
\end{tabular}

Appendix XV: Species names, family, life form and author of recorded species from Ratelgat. Life forms: $\mathrm{T}=$ therophyte; C: chamaephyt ; Cmac= 30-50 cm; Cmes= 15-30 cm, Cmic= 5-15cm, Cnan= $<5 \mathrm{~cm} ; \mathrm{G}=$ geophyte; $\mathrm{H}=$ hemicryptophyte; $\mathrm{L}=$ liane; $\mathrm{P}=$ phanerophyte; Pmes = 100-200cm; Pmic, Pnan= 50-100 cm. Nomenclature follows the annotated checklist "Plants of southern Africa" (Germishuizen \& Meyer 2003) besides the fact that the Mesembryanthemaceae are included in the Aizoaceae.

\begin{tabular}{|c|c|c|c|c|c|}
\hline Name & Life form & Author & Name & Life form & Author \\
\hline Dicotyledonae & & & Psilocaulon dinteri & Cmes & (Engl.) Schwantes \\
\hline Aizoaceae & & & Psilocaulon leptathron & Cmac & (A.Berger) N.E.Br. \\
\hline Antimima excedens & Cmes & (L.Bolus) Klak & Psilocaulon sp. & unknown & N.E.Br. \\
\hline Antimima hantamensis & Cmes & (Engl.) H.E.K. Hartmann \& Stüber & Ruschia burtoniae & Cmes & L.Bolus \\
\hline Antimima solida & Cmic & (L.Bolus) H.E.K. Hartmann & Ruschia burtoniae \& lasti K & Cmac & Schwantes \\
\hline Antimima watermeyeri & Cnan & (L.Bolus) H.E.K. Hartmann & Ruschia grün polster & Cmac & Schwantes \\
\hline Argyroderma crateriforme & Cnan & (L.Bolus) N.E.Br. & Ruschia bolusiae & $\mathrm{Cmac}$ & Schwantes \\
\hline Argyroderma delaetii & Cnan & C.A. Maas & Ruschia sp. Schmiedel 116834 & Cmac & Schwantes \\
\hline Argyroderma fissum & Cnan & (Haw.) L.Bolus & Ruschia spec. & Cmac & Schwantes \\
\hline Argyroderma Keimling cf & Cnan & & Ruschia spinosa & Cmes & (L.) Dehn \\
\hline Aridaria noctiflora & Cmes & (L.) Schwantes & Ruschia subsphaerica & Cmes & L.Bolus \\
\hline Aridaria serotina & Cmes & L.Bolus & spiny mesem & $\mathrm{Cmec}$ & \\
\hline Caulipsolon rapaceum & Cmic & (Jacq.) Klak & Strauch Succ Eiblätteer & unknown & \\
\hline Cephalophyllum framesii & Cnan & L.Bolus & Succ strauchig & unknown & \\
\hline Cephalophyllum spec. & Cnan & N.E.Br. & Tetragonia fruticosa & Cmes & L. \\
\hline \multirow[t]{2}{*}{ Cephalophyllum spissum } & Cnan & H.E.K. Hartmann & Tetragonia microptera & Cmic & Fenzl. \\
\hline & & & Tetragonia verrucosa & Cmes & Fenzl. \\
\hline Conophytum subfenestratum & Cnan & Schwantes & Asteraceae & & \\
\hline Drosanthemum roseatum & Cmes & (N.E.Br.) L.Bolus & Amellus microglossus & Tmes & DC. \\
\hline Drosanthemum deciduum & $\mathrm{Cmac}$ & H.E.K. Hartmann \& Bruckmann & Arctotis campanulata & Tmic & DC. \\
\hline Drosanthemum diversifolium & Cmic & L.Bolus & Arctotis sp. 17828_2005 & Tmic & L. \\
\hline Drosanthemum globosum & Cmac & L.Bolus & Arctotis sp. 17991_2005 & Tmic & L. \\
\hline Drosanthemum gross grün & $\mathrm{Cmac}$ & Schwantes & Asteraceae & $(\mathrm{T})$ & \\
\hline Drosanthemum hispidum & Cmic & (L.)Schwantes & Asteraceae gelb & $(\mathrm{T})$ & \\
\hline Drosanthemum pulverulentum & Cmes & (Haw.)Schwantes & Asteraceae sp. 17965_2005 & $(\mathrm{T})$ & \\
\hline Name & Life form & Author & Name & Life form & Author \\
\hline Drosanthemum schoenlandianum & Cnan & (Schltr.)L.Bolus & Asteraceae sp. 17991_2005 & $(\mathrm{T})$ & \\
\hline Drosanthemum sp. Schmiedel 116576 & Cmes & Schwantes & Berkheya fruticosa & Cmes & (L.)Ehrh. \\
\hline
\end{tabular}




\begin{tabular}{|c|c|c|c|c|c|}
\hline Name & Life form & Author & Name & Life form & Author \\
\hline Drosanthemum sp. Schmiedel 116844 & Cmac & Schwantes & Didelta carnosa & Cmes & (L.f.) Aiton \\
\hline Drosantheum deciduum & $\mathrm{Cmac}$ & H.E.K. Hartmann \& Bruckman & Eriocephalus namaquensis & Cmes & M.A.N. Müller \\
\hline Galenia africana & $\mathrm{Cmac}$ & L. & Foveolina dichotoma & $\mathrm{T}$ & (DC.) Källersjö \\
\hline Galenia fruticosa & Cmes & (L.f)Sond. & Gazania lichtensteinii & Tmic & Less. \\
\hline Galenia meziana & Cmes & K.Müll. & Helichrysum leontonyx & $\mathrm{T}$ & DC. \\
\hline Galenia pelzig & Cmes & L. & Helichrysum sp. & $\mathrm{T}$ & Mill. \\
\hline Galenia sarcophylla & Cmes & Fenzl & Hirpicium alienatum & Cmic & (Thunb.)Druce \\
\hline Lampranthus otzenianus & Cmac & (Dinter) Friedrich & Oncosiphon grandiflorum & Tmes & (Thunb.) Källersjö \\
\hline Leipoldtia schultzei & Cmes & (Schltr. \& Diels) Friedrich & Oncosiphon suffruticosum & Tmes & (L.) Källersjö \\
\hline Malephora purpureo-croccea & Cmic & (Haw.) Schwantes & Osteospermum grandiflorum & Cmes & DC. \\
\hline Mesembryanthemum nodiflorum & Tnan & L. & Osteospermum pinnatum & Tmes & (Thunb.) Norl. \\
\hline Mesembryanthemum guerichianum & Tmic & Pax & Osteospermum sp. & $\mathrm{T}$ & \\
\hline Mesembryanthemum hypertrophicum & Tmic & Dinter & Othonna protecta & Cmes & Dinter \\
\hline Monilaria moniliformis & Cmes & (Thunb.) Ihlenf. \& Jörg. & Pentzia incana & Cmac & (Thunb.) Kuntze \\
\hline Monilaria pisiformis & Cmic & (Haw.) Schwantes & Pteronia sp. & unknown & L. \\
\hline Phyllobolus abbreviatus & G & (L.Bolus) Gerbaulet & Rhynchopsidium pumilum & Tmic & (L.f.) DC. \\
\hline Phyllobolus nitidus & Cmes & (Haw.) Gerbaulet & Senecio aloides & $\mathrm{H}$ & DC \\
\hline Phyllobolus sp. & unknown & N.E.Br. & Senecio arenarius & Tmes & Thunb. \\
\hline Phyllobolus spinuliferus & Cmes & (Haw.) Gerbaulet & Tripteris amplectens & $\mathrm{T}$ & Harv. \\
\hline Phyllobolus trichotomus & Cmes & (Thunb.) Gerbaulet & Tripteris sinuata var. sinuata & Cmes & DC. \\
\hline Ursinia nana ssp. nana & Tnan & Gaertn. & Lycium oxycarpum & Pnan & Dunal \\
\hline Ursinia sp. 17503_2004 & Tnan & Gaertn. & Sterculiaceae & & \\
\hline Brassicaceae & & & Hermannia cuneifolia & Cmes & Jacq. \\
\hline Heliophila sp. & $\mathrm{T}$ & $\mathrm{L}$. & var. glabrescens & & \\
\hline Heliophila variabilis & Tmic & Burch. ex DC. & Zygophyllaceae & & \\
\hline Caryophyllaceae & & & Zygophyllum cordifolium & Cmic & L.f. \\
\hline Caryophyllaceae & unknown & & Zygophyllum retrofractum & Cmac & Thunb. \\
\hline Caryophyllaceae pelzig & unknown & & Monocotyledonae & & \\
\hline Spergularia media & Cmic & (L.) C. Presl ex Grieseb. & Asparagaceae & & \\
\hline Chenopodiaceae & & & Asparagus capensis & Cmac & L. \\
\hline Atriplex lindleyi ssp. inflata & Tmes & Moq. & Asphodelaceae & & \\
\hline Atriplex semibaccata & Tmes & R.Br. & Trachyandra tortilis & G & (Baker) Oberm. \\
\hline Chenopodium murale/album & Tmes & L. & Hyacinthaceae & & \\
\hline Chenopodium sp. & $\mathrm{T}$ & L. & Lachenalia sp. 17951_2005 & G & J.Jacq. ex Murray \\
\hline Manochlamys albicans & Cmac & (Aiton) Aellen & Lachenalia sp. 17986_2005 & G & J.Jacq. ex Murray \\
\hline Salsola blaugrau & Cmac & L. & Poaceae & & \\
\hline Salsola graugrün & Cmac & L. & Erharta sp.17979_2004 & Cmes & Thunb. \\
\hline Salsola sp. & Cmac & $\mathrm{L}$. & Gras & & \\
\hline Salsola sp. 123660 & Cmes & $\mathrm{L}$. & Gras breite Scheide, Rispe & unknown & \\
\hline Salsola sp. 123673 & Cmes & $\mathrm{L}$. & Gras lange Blätter & unknown & \\
\hline Salsola sp. Schmiedel 118975 & Cmac & $\mathrm{L}$. & Schismus barbatus & Tmic & (Loefl. ex. L.) Thell. \\
\hline Salsola zeyheri & Cmac & (Moq.)Bunge & Unknown family & & \\
\hline Sarcocornia xerophila & Cmic & (Tölken) A.J.Scott & Bäumchen Rosette & unknown & \\
\hline Crassulaceae & & & ausgefranster Blattrand & & \\
\hline Crassula barklyi & Cnan & N.E.Br & creeping mit Blasenzellen & unknown & \\
\hline Crassula sp. & unknown & L. & Geophyt sp. 17976_2005 & G & \\
\hline
\end{tabular}




\begin{tabular}{|c|c|c|c|c|c|}
\hline Name & Life form & Author & Name & Life form & Author \\
\hline Euphorbiaceae & & & Geophyt sp. 17981_2005 & G & \\
\hline Euphorbia sp. & Cmac & L. & Geophyt sp. 17984_2005_1 & G & \\
\hline Fabaceae & & & Geophyt sp. 17984_2005_2 & G & \\
\hline Crotalaria sp. 17990_2005 & $\mathrm{T}$ & L. & Hasenohr K & unknown & \\
\hline Geraniaceae & & & Hasenohr, gelbe Keimblätter & unknown & \\
\hline Geraniaceae sp. 17980_2005 & unknown & & Keimling blau & unknown & \\
\hline Sarcocaulon crassicaule & Cmes & Rehm & Keimling hoher Stengel blau & unknown & \\
\hline Pelargonium crithmifolium & Cmes & Sm. & Keimling lange Blätter, hart & unknown & \\
\hline Pelargonium echinatum & Cmes & Curtis & Kleeblatt & unknown & \\
\hline Molluginaceae & & & Succ Bäumchen & unknown & \\
\hline Hypertelis salsoloides & Cmes & (Burch.) Adamson & Succ Blasenzelle & unknown & \\
\hline var. salsoloides & & & Succ Rand \& Fenster K & unknown & \\
\hline \multicolumn{6}{|l|}{ Oxalidaceae } \\
\hline Oxalis 3blatt behaart & G & L. & & & \\
\hline Oxalis louisae & G & T.M. Salter & & & \\
\hline Oxalis pes-caprae & G & L. & & & \\
\hline Oxalis sp. & G & & & & \\
\hline Oxalis sp. 17955_2005 & G & L. & & & \\
\hline Oxalis sp. 17956_2005 & G & L. & & & \\
\hline \multicolumn{6}{|l|}{ Scrophulariaceae } \\
\hline Peliostomum virgatum & Cmac & E.Mey. ex Benth. & & & \\
\hline \multicolumn{6}{|l|}{ Solanaceae } \\
\hline Lycium cinereum & Pnan & Thunb. & & & \\
\hline Lycium ferocissimum & Pnan & Miers & & & \\
\hline
\end{tabular}




\section{Eidesstattliche Versicherung}

Ich versichere hiermit, dass ich die vorliegende Arbeit selbstständig ohne fremde Hilfe verfasst und keine anderen als die im Literaturverzeichnis angegebenen Quellen benutzt habe.

Stellen, die wörtlich oder sinngemäß aus veröffentlichten oder noch nicht veröffentlichten Quellen entnommen sind, sind als solche kenntlich gemacht.

Die Zeichnungen oder Abbildungen in dieser Arbeit sind von mir selbst erstellt worden oder mit einem entsprechenden Quellennachweis versehen.

Diese Arbeit ist in gleicher oder ähnlicher Form noch bei keiner anderen Prüfungsbehörde eingereicht worden.

26.08.09,

Datum, Unterschrift 